\title{
LA INVESTIGACIÓN SOBRE LAS \\ NECESIDADES DE INFORMACIÓN EN DIFERENTES COMUNIDADES
}

Memoria del III Seminario de Usuarios de la Información

\author{
COORDINADOR
}

Juan José Calva González

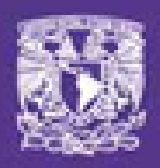


La presente obra está bajo una licencia de:

http://creativecommons.org/licenses/by-ncsa/3.0/deed.es MX

\section{(c) cointive}

Eres libre de:

(15)

copiar, distribuir y comunicar públicamente la obra

(D) hacer obras derivadas

Bajo las condiciones siguientes:

Atribución - Debes reconocer la autoría de la obra en los términos

especificados por el propio autor o licenciante.

No comercial - No puedes utilizar esta obra para fines comerciales.

Licenciamiento Reciproco - Si alteras, transformas o creas una obra a

partir de esta obra, solo podrás distribuir la obra resultante bajo una licencia igual a ésta.

Esto es un resumen fácilmente legible del: texto legal (de la licencia completa)

\section{En los casos que sea usada la presente obra, deben respetarse los términos especificados en esta licencia.}
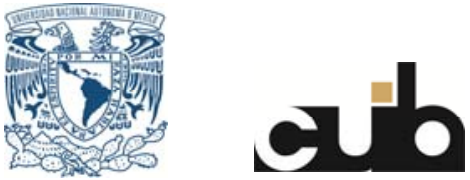
La investigación sobre las necesidades de información en diferentes comunidades 
La investigación sobre las necesidades de información en diferentes

\section{comunidades}

Memoria del III Seminario de

Usuarios de la Información

Coordinador

Juan José Calva González

Universidad Nacional Autónoma de México 2009 
S45158 Seminario de Usuarios de la Información (3 : 2008 : México, D.F.)

La investigación sobre las necesidades de información de diferentes comunidades: memoria del III Seminario de Usuarios de la Información / coordinador, Juan José Calva González. - México: UNAM, Centro Universitario de Investigaciones Bibliotecológicas, 2009.

308 p. (Cuadernos de Investigación ; 12)

ISBN: 978-607-02-0576-7

1.Necesidades de Información - Investigación 2. Necesidades de Información - Comunidades Académicas 3. Necesidades de Información - Comunidades Indígenas 4 .

Necesidades de Información - Comunidades Vitivinícolas I. Calva González, Juan José, ed. II. t. III. ser.

Diseño de portada: Mario Ocampo Chávez

Primera Edición, 2009

DR (C) UNIVERsidAd NACIONAL AUTÓNOMA DE MÉXICO

Ciudad Universitaria, 04510, México, D.F.

Impreso y hecho en México

ISBN: 978-607-02-0576-7 


\section{Contenido}

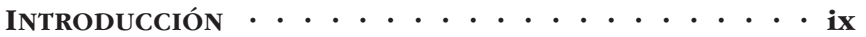

Juan José Calva González

\section{CONFERENCIA INAUGURAL}

Los estudios de usuarios publicados en España

en el siglo XXI . . . . . . . . . . . . . . . . • 3

Isabel Villaseñor Rodríguez

\section{COMUNIDADES DE INVESTIGADORES UNIVERSITARIOS}

La medición de la satisfacción del científico matemático en el uso de algunas fuentes de información y servicios bibliotecarios . . . . . 81 Angélica Guevara Villanueva

La recuperación de información a través de los Sistemas de Información Geográfica • . . . • • 109 Antonia Santos Rosas

\section{COMUNIDADES DE PROFESORES Y ESTUDIANTES UNIVERSITARIOS}

Comportamiento informativo de alumnos y profesores universitarios

Fabiola Martínez López

Comportamiento informativo de los tesistas de licenciatura en Bibliotecología de la ENBA, el Colegio de Bibliotecología de la UNAM y de la UAEM: causas que lo originan . . . . . . 141 Armando Sánchez Soto 
Nuevas alternativas de servicios de información con base en las necesidades de información de los estudiantes de preparatoria del ITESM • • • • 155 Laura Miranda Munguía

El comportamiento informativo de los usuarios basado en las TIC de las bibliotecas del Tecnológico de Monterrey. . . . . . . . . • 163 Juan C. Alba Leonel

El comportamiento informativo de los docentes en las áreas de Educación y Humanidades en la Universidad Autónoma del Estado de México . . . . . . . . . . . . . . 171 José Arturo Mejía López

\section{COMUNIDADES VITIVINÍCOLAS}

Desarrollo de la industria vitivinícola en México. Información para la producción de Vitis vinífera.

Proyecto PAPIIT IN404408-3 • . . . . . . . . . 189 Juan José Calva González

Los vitivinicultores de la región de Baja California: necesidades de información y comportamiento informativo . . . . . . . . 203 Fermín López Franco

Información y vitivinicultores en Aguascalientes, Zacatecas y Durango: el acercamiento inicial . . . . . . . . . . . . 229 José Tomás Palacios Medellín 
Recursos de información para el uso de los productores de la vid en el estado

de Guanajuato . . . . . . . . . . . . . . . 251

Ana Laura Peña Aguilar

El perfil de información de los

vitivinicultores de Vitis vinífera

en la región de Coahuila . . . . . . . . . 259

Enedina Salazar Méndez

El perfil informativo de los vitivinicultores

en el estado de Querétaro: el cultivo

de la vid . . . . . . . . . . . . . . . . . 273

José Mejía Ruiz

\section{COMUNIDADES INDÍGENAS}

La satisfacción de las necesidades de información como factor de cambio en la identidad indígena de la comunidad amuzga:

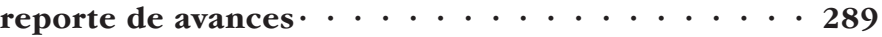

César Augusto Ramírez Velázquez

CONCLUSIONES. . . . . . . . . . . . 305 



\section{Introducción}

a realización de reuniones con investigadores y Lprofesores interesados en las necesidades de información de diversas comunidades es una labor que no debe abandonarse en ningún país, principalmente en los que se encuentran en vías de desarrollo. Lo anterior obedece a que los usuarios de la información, que a final de cuentas son los ciudadanos de cada país, al cubrir sus necesidades de información presentarán cambios que pueden redituar en la transformación y desarrollo de su nación.

Entonces, cuando se habla de diversas comunidades de usuarios se evidencian los perfiles informativos de cada una de ellas, es decir, las características que tienen como usuarios de la información. Debido a que la situación geográfica, social, económica, educativa, tecnológica, política, religiosa, ideológica, histórica y cognitiva es diferente entre todas ellas, cada una de las comunidades presentará diferencias con respecto a otras.

Desde este punto de vista parece muy compleja la investigación de dichas comunidades, ya que es preciso considerar todas las variables involucradas 
La investigación sobre las necesidades de información en...

en los estudios de usuarios; sin embargo, a pesar de esa complejidad aparente, los problemas pueden ser superados, solo es cuestión de dedicación, tiempo y serenidad para poder avanzar poco a poco en la elaboración de perfiles informativos que nos permitan describir la comunidad, predecir sus comportamientos en la búsqueda de información y, por lo tanto, tener datos valiosos que permitan el diseño de servicios bibliotecarios y de información que atiendan sus necesidades reales.

El presente documento incluye los avances de las investigaciones que los profesores y alumnos del Posgrado en Bibliotecología y Estudios de la Información llevan a cabo sobre esta temática. Los trabajos fueron presentados en la sesión abierta de la tercera reunión del Seminario de Investigación Permanente sobre Usuarios de la Información que se lleva a cabo en el Centro Universitario de Investigaciones Bibliotecológicas. Estas investigaciones permitirán nutrir a la disciplina bibliotecológica en México sobre la temática de las necesidades de información, los estudios de usuarios y su nexo con diversos sectores de la sociedad mexicana. El aporte al conocimiento de la disciplina y el seguimiento de sus líneas de investigación pueden ser de gran utilidad para otros investigadores nacionales o extranjeros, así como en los mismos posgrados en bibliote- 
cología que se imparten en las universidades mexicanas.

El trabajo con diversas comunidades, como lo son las académicas, será atendido por los profesionales de la información como ha sucedido siempre; una mirada más amplia debe dirigirse hacia otros sectores sociales que no han sido investigados como lo son las comunidades indígenas, las comunidades productoras y comerciantes por solo mencionar algunas de ellas.

Con esta publicación presentamos por primera vez el acercamiento, a través de varias investigaciones, a una comunidad social poco estudiada mundialmente por los profesionales de la información como lo es la comunidad de vitivinicultores mexicanos. Estos sujetos de investigación representan un sector complejo e interesante de ser estudiado, ya que es muy reciente su desarrollo como industria en México, a pesar de que sus inicios se remontan a la llegada de los españoles a América. Con los primeros evangelizadores llegó de Europa la vid o Vitis vinifera pero, por cuestiones comerciales y de competencia, la misma España impidió su desarrollo durante varios siglos no permitiendo su crecimiento, por lo que es hasta la segunda mitad del siglo XX cuando inicia su resurgimiento, a pesar de que ya existían los viñedos de la Hacienda de San Lorenzo en Parras, Coahuila. 
La investigación sobre las necesidades de información en...

De esta forma iniciamos la aventura de investigar otro tipo de usuarios que los que comúnmente había trabajado el bibliotecólogo; es decir, las comunidades de corte académico. En este rumbo, en el que se involucraran varios profesores y estudiantes de posgrado acompañados por un investigador, se escudriñarán las necesidades y comportamiento informativo de vitivinicultores y enólogos encargados de la producción de Vitis vinifera en las cinco regiones en donde es cultivada y en donde se produce el vino mexicano. Estas cinco regiones comprenden los estados de Baja California Norte, Coahuila, Aguascalientes, Zacatecas, Durango, Guanajuato y Querétaro.

Por otro lado, en este documento también se presenta otra investigación en una comunidad no académica, como lo es la indígena, que en este caso corresponde a la comunidad amuzga.

Con los trabajos aquí presentados y con las discusiones que se dieron a través de las presentaciones de cada uno de ellos es que esta publicación espera contribuir a los estudios de usuarios en México y a la aportación de diversas metodologías no solo cuantitativas sino también cualitativas para llevar a cabo las investigaciones respectivas.

\section{Juan José Calva González}


Conferencia Inaugural 


\title{
Los estudios de usuarios publicados en España en el siglo XXI
}

\author{
ISABEL VILLASEÑOR RODRÍGUEZ \\ Facultad de Ciencias de la Documentación \\ Universidad Complutense de Madrid
}

\section{Introducción}

Oon el presente trabajo queremos mostrar al-
gunos avances de la investigación que esta-
mos llevando a cabo y que se basa en el análisis de
los estudios de usuarios publicados en España en el
siglo XXI. Con ella queremos conocer, por un lado,
el grado de difusión de los trabajos dedicados a estu-
diar a los usuarios de información y, por otro, as-
pectos relacionados con ellos tales como autoría,
fuentes, objetivos, metodología, etcétera. En defi-
nitiva, queremos saber si, en nuestro país y en los
últimos 8 años, se dan a conocer, de alguna manera,
trabajos que tengan como objetivo fundamental es-
tudiar a un grupo de usuarios de información y
también dónde, quiénes, cómo y por qué se hacen
visibles. Todo con la finalidad de saber el interés
que despiertan este tipo de investigaciones, porque
consideramos necesario e imprescindible que los
resultados de una investigación se hagan públicos


La investigación sobre las necesidades de información en...

(pueden ser de utilidad para otros profesionales de la información) y porque creemos que, desgraciadamente, esto no es lo habitual. Para completar lo dicho, consideraremos también si en ese tiempo se han publicado estudios que afronten el tema desde un plano teórico.

Para empezar, creemos conveniente hacer algunas aclaraciones. Hemos partido de un concepto amplio del término "estudios de usuarios" en el sentido de considerar como tal todos aquellos trabajos que se llevan a cabo para conocer no sólo necesidades de información y/o formación (surgimiento de la necesidad) sino también demandas y hábitos de información (manifestación, comportamiento) así como el grado de satisfacción con respecto a un producto, un servicio o un centro de información determinados de un grupo concreto de usuarios. Nos hemos centrado en los publicados, esto es, en los que se han querido mostrar de forma pública con la finalidad de darles difusión, y, sobre todo, de forma tradicional (impresos). Y, además, hemos limitado geográfica y cronológicamente nuestra investigación por motivos puramente prácticos en el sentido de que queremos conocer nuestra realidad más cercana en el tiempo y en el espacio.

La muestra que se ofrece es sólo una parte de la investigación que está en proceso y que se completará ampliando el estudio a un mayor número de 
ejemplos de las fuentes que aquí se presentan y de otras posibles (tesis doctorales) así como a trabajos de carácter bibliométrico y valorando los métodos empleados en todos los estudios con el fin de determinar el carácter científico de los mismos y la calidad de la información metodológica que aportan. Además, se analizarán los trabajos de carácter teórico que hayan sido publicados durante este tiempo y en cualquier fuente.

\section{Estado de la cuestión}

Se puede afirmar que, al menos en España, no existen trabajos de idénticas características a éste. Contamos con dos referentes que tratan asuntos parciales relacionados con el que nos ocupa y de fechas anteriores a las estudiadas. Por una parte está el de Carina Rey, "La aplicación de los estudios de satisfacción de usuarios en la biblioteca universitaria: el caso de las universidades catalanas", ${ }^{1}$ donde la autora estudia, utilizando la técnica de la encuesta, con un cuestionario dirigido a distintas bibliotecas universitarias catalanas, si se realizan estudios de usuarios en las mismas y con qué fin y metodología. Por

1 En BiD, vol.3, desembre, 1999. Disponible en: (http://www2. ub.es/bid/consulta_articulos.php?fichero $=03$ rey. htm) [Consulta: 08-06-2008] 
La investigación sobre las necesidades de información en...

otra, el trabajo de Emilio Delgado López-Cózar que lleva por título "La investigación por encuesta en la biblioteconomía y documentación española: análisis de las encuestas publicadas en revistas y congresos de la especialidad entre 1976 y 1997", donde el autor se centra en el análisis de trabajos de investigación que emplean como método la encuesta, entre los que se cuentan algunos estudios de usuarios de información. El trabajo que nos ocupa está más en la línea del desarrollado por $\mathrm{Calva}^{3}$ sobre la difusión de estudios de usuarios, en el sentido de que el autor se propone analizar el grado de difusión que en esa fuente tienen los estudios de usuarios de información.

\section{Metodología}

El asunto mencionado se ha abordado utilizando un método de investigación bibliotecológica posible: el que Rodríguez Gallardo denomina de "investigación documental", ${ }^{4}$ que se basa en fuentes escritas (publicadas o no) y sirve, gracias a la información recabada con él, para conocer mejor un aspecto con-

2 En Metodología de investigación en Información y Documentación. Salamanca: Universidad, 2002, pp. 71-135.

3 "Las necesidades de información: la difusión de estudios en las Jornadas Mexicanas de Biblioteconomía”, en Forinf@, n ${ }^{\circ}$, 2002, pp. 9-22. 
creto. El primer paso dado ha sido el de identificar y seleccionar las fuentes escritas y publicadas que servirán para obtener la información. Una vez hecho esto, se ha procedido a la identificación de los trabajos que reúnen las características mencionadas y pueden considerarse como estudios de usuarios o como trabajos teóricos sobre el tema. Tras la detenida lectura de los mismos y el análisis de contenido de los materiales seleccionados, se ha procedido a la valoración de los datos aportados. En esta ocasión presentamos parte del trabajo realizado, ofreciendo a la consideración de los presentes un trabajo de carácter meramente descriptivo y cuantitativo, que será ampliado posteriormente con un estudio cualitativo de la información obtenida donde se valorarán aspectos tales como la idoneidad de los métodos y técnicas empleados, su correcta descripción y elaboración, la adecuación de la muestra respecto a la población, el uso de una terminología apropiada, el concepto que de "estudios de usuarios" se aporta, etcétera. Con el presente trabajo se ha pretendido cuantificar, ofreciéndose información sobre el nú-

4 "De la práctica a la investigación", en La investigación bibliotecológica en la era de la información. Memoria del XXI Coloquio de Investigación Bibliotecológica y de la información. 24-26 de septiembre de 2003. Compiladores Filiberto Felipe Martínez Arellano, Juan José Calva González. México: UNAM, 2004, pp.3-21. 
La investigación sobre las necesidades de información en...

mero de estudios de usuarios publicados, las fuentes donde aparecen y sobre otros datos de interés relacionados con los estudios de usuarios identificados. Para la obtención de estos datos se ha utilizado una plantilla que se ha aplicado a cada uno de los trabajos analizados y que se compone de los siguientes ítems:

- autoría (quién)

- objetivo/s (para qué)

- método/os, técnica/as e instrumento/s(cómo)

- usuarios estudiados (qué)

En cuanto a la autoría, se identifica la filiación institucional de los autores y su pertenencia al mundo profesional o académico; también se destaca si se trata de un autor individual o colectivo. Estos datos nos permitirán conocer no sólo de dónde procede la investigación en este campo sino también si se trabaja en equipo o individualmente. El conocer los objetivos perseguidos nos permitirá saber para qué se hacen estudios de usuarios de información en España. Esta información se completará con la conseguida en relación con los métodos, técnicas e instrumentos empleados para la obtención de información y con los usuarios estudiados, de forma que se pueda conocer qué variedades de unos y otras son los más utilizados y qué usuarios son los que merecen mayor atención por parte de los autores de estos estudios. En cuanto a los métodos, hemos empleado la clasificación que distingue entre directos e indirec- 
tos, teniendo en cuenta si se tiene (directos) o no (indirectos) una interrelación con el usuario durante la investigación, al margen de cómo se analicen los resultados. En un estudio posterior se considerarán teniendo en cuenta cómo se analicen los resultados, distinguiendo entre métodos cuantitativos (sin tener en cuenta la subjetividad del individuo estudiado) y métodos cualitativos (desde el punto de vista del individuo estudiado).

Los datos obtenidos se presentan en primer lugar por fuentes consultadas (jornadas, revistas) y, como conclusión, en su conjunto, utilizando gráficos que permitan su lectura de una forma más cómoda.

\section{Fuentes}

Las fuentes utilizadas para la identificación de nuestro objeto de estudio han sido las actas de congresos o jornadas ${ }^{5}$ de profesionales de la información y las revistas especializadas en Biblioteconomía y Documentación por considerar que tanto unas como otras constituyen un canal de comunicación esencial no sólo para la puesta en común de experiencias pro-

5 Nos referimos a eventos de carácter periódico "en que los miembros de una asociación, cuerpo, organismo, profesión, etc. se reúnen para debatir cuestiones previamente fijadas" (definición dada por la Real Academia Española en la $21^{\text {a }}$ edición de su Diccionario de la lengua española-1992- de "Congreso"). 
La investigación sobre las necesidades de información en...

fesionales sino también para la presentación de líneas de investigación, además de ofrecer información de actualidad. Para los trabajos de carácter teórico, además de las fuentes mencionadas se ha considerado también la publicación de monografías. En cuanto a los criterios empleados para la selección de la muestra sobre la que se ha trabajado cabe decir que han sido fundamentalmente los de prestigio y continuidad así como el que se encontraran publicados, esencialmente de forma convencional (papel), o en dos soportes (informático, en línea).

En el caso de los congresos se ha partido, para la identificación de los existentes, del registro realizado por Rodríguez Yunta y Tejada Artigas, ${ }^{6}$ que da cuenta de 83 reuniones científicas, congresos, jornadas, simposios y seminarios que se celebran en España desde el año 2000 y que se han convocado de forma periódica desde esa fecha o han nacido recientemente con previsión de continuidad. De todos estos eventos hemos seleccionado para esta ocasión los 6 que tienen más resonancia, tanto en el ámbito profesional como en el académico, por la calidad de sus organizadores y que representan una

6 "Recursos de Internet sobre desarrollo profesional en Documentación: 4. Reuniones científicas, congresos, jornadas, simposios y seminarios en España" en Revista Española de Documentación Científica, 29, 1, 2006, pp.153-173 
variedad basada en 3 criterios: encuentros de carácter general y ámbito nacional (1 y 2), encuentros de carácter general pero de ámbito autonómico (3 y 4) y encuentros referidos a un tipo de centros de información como son las bibliotecas y de ámbito autonómico (5 y 6). Estos son:

- Jornadas Españolas de Documentación.

- Jornadas sobre Gestión de la Información y del Conocimiento.

- Jornadas Andaluzas de Documentación.

- Jornades Catalanes d'Informació I Documentació.

- Jornadas Bibliotecarias de Andalucía.

- Jornadas Bibliotecarias de la Comunidad de Madrid.

Todas, salvo las últimas, son jornadas organizadas por asociaciones profesionales: FESABID (Federación Española de Sociedades de Archivística, Biblioteconomía, Documentación y Museística), SEDIC (Sociedad Española de Documentación e Información Científica), AAD (Asociación Andaluza de Documentalistas), COBDC (Col.legi Oficial de Bibliotecaris-Documentalistes de Catalunya) y AAB (Asociación Andaluza de Bibliotecarios), en el mismo orden, dándose el caso de que la FESABID, representa a un amplio y variado conjunto de asociaciones profesionales. Las Jornadas Bibliotecarias de la Comunidad de Madrid son responsabilidad de un organismo público (la Subdirección 
La investigación sobre las necesidades de información en...

General de Bibliotecas de la Comunidad de Madrid) y las únicas que restringen la participación a los profesionales de las bibliotecas dependientes de ese organismo. El resto, aunque algunas lleven en su denominación algún rasgo determinante (ya sea geográfico, ya de tipo de institución informativa) son abiertas en su participación y en su temática. El haber seleccionado las Jornadas bibliotecarias de la Comunidad de Madrid se debe al importante papel que han jugado en la consolidación del sistema bibliotecario de esa Comunidad Autónoma por establecer criterios comunes consensuados para todas las bibliotecas dependientes de ese sistema bibliotecario (determinante para el resto del país).

Para la identificación de las revistas españolas especializadas en Biblioteconomía y Documentación se ha consultado DICE (Difusión y Calidad Editorial de las Revistas Españolas de Humanidades y Ciencias Sociales y Jurídicas), base de datos fruto de un convenio de colaboración entre el Consejo Superior de Investigaciones Científicas (CSIC) y la Agencia Nacional de Evaluación de la Calidad y Acreditación (ANECA) $)^{7}$ y que tiene el objetivo de

7 Entidad que financia su mantenimiento y ha sido creada por el Grupo de Investigación "Evaluación de publicaciones científicas en Ciencias Sociales y Humanas" del Centro de Información y Documentación Científica (CINDOC), CSIC. ANECA utiliza DICE como referencia de calidad de las publicaciones españolas, en sus procesos de evaluación de profesorado. 
facilitar el conocimiento y la consulta de algunas de las características editoriales de las revistas españolas de Humanidades y Ciencias Sociales más estrechamente ligadas a la calidad, relativas a aspectos tan cualitativos como los mecanismos de evaluación de originales para publicar, la apertura de los órganos de gestión y dirección, la presencia de diversas instituciones no vinculadas a la entidad editora entre las contribuciones publicadas, la difusión de las revistas en bases de datos multidisciplinares y especializadas de prestigio internacional o el tipo de presencia en Internet. La consulta de este recurso se ha contratado con la de RESH (Revistas españolas de Ciencias Sociales y Humanas: Valoración integrada e índice de citas), ${ }^{8}$ que aporta, especialmente, datos relativos al uso e influencia de las revistas, a partir de la elaboración de índices de

8 "Aporta los resultados del análisis de las Revistas Españolas de Ciencias Sociales y Humanas desde el punto de vista de su calidad. Presenta en primer lugar los Índices de Citas correspondientes a los años 1999, 2000, 2001, 2002 y 2003 a través de los cuales puede valorarse el uso y la influencia de cada una de las revistas que aparecen citadas. A partir de las revistas citadas, con un simple clic, se puede acceder a los datos bibliográficos básicos de las revistas así como a los niveles de cumplimiento de otros parámetros fundamentales de calidad, tanto editorial como de visibilidad internacional, facilitando así una visión de conjunto sobre los diferentes aspectos de la calidad de cada revista, base de una valoración integrada". 
La investigación sobre las necesidades de información en...

citas que permiten calcular el impacto de cada una en el entorno disciplinar mas próximo. El hecho de que DICE aporte información sobre los criterios LATINDEX (Sistema Regional de Información en Línea para Revistas Científicas de América Latina, el Caribe, España y Portugal) cumplidos por las revistas que describe, nos ha hecho considerar fundamentalmente este recurso para seleccionar las revistas especializadas en Biblioteconomía y Documentación mejor valoradas y objeto de nuestra investigación. En esta ocasión nos centraremos en el estudio de 6 de ellas, por guardar la proporción respecto a las Jornadas estudiadas. Todas ellas se encuentran incluidas en las principales base de datos nacionales e internacionales de la especialidad. Las revistas seleccionadas, de entre las 22 que analiza DICE y las 17 que recoge RESH, son:

1. Revista Española de Documentación Científica.

2. Revista General de Información y Documentación.

3. Ítem. Revista de biblioteconomía i documentació.

4. Documentación de las Ciencias de la Información.

5. Bid. Textos universitaris de biblioteconomia i documentació.

6. Forinf@ Revista Iberoamericana sobre Usuarios de Información 
Las 6 representan tres sectores de la actividad desarrollada en Biblioteconomía y Documentación: el académico, el de la investigación y el profesional. La primera de ellas es responsabilidad de un centro de investigación especializado en la materia, la tercera de un colegio profesional y el resto, de centros universitarios que imparten docencia en la misma. Hemos de decir que la número 6 se ha incluido aun no respetando algunos de los criterios establecidos para la selección de las fuentes: se trata de una revista electrónica (no impresa) y está por debajo de otras en cuanto a criterios LATINDEX cumplidos; pero también es la única revista en lengua española dedicada exclusivamente a temas relacionados con los usuarios de la información. Todas ellas acogen colaboraciones procedentes tanto del mundo académico como del profesional.

\section{Presentación y tratamiento de los datos obtenidos}

A partir de la consulta de las fuentes, se han analizado un total de 339 comunicaciones a congresos contenidas en 13 actas de las jornadas elegidas así como de 669 artículos incluidos en 107 volúmenes o números de las revistas seleccionadas, lo cual hace un total de 1008 trabajos examinados, todos ellos publicados en el período comprendido entre enero de 2001 y junio de 2008. De todos ellos, se han po- 
La investigación sobre las necesidades de información en...

dido identificar 36 trabajos $^{9}$ que pueden considerarse estudios de usuarios. A continuación presentamos la información obtenida, distinguiendo entre jornadas y revistas especializadas.

\section{Jornadas}

\section{Las Jornadas Españolas de Documentación}

Se celebran cada 2 años y de ellas contamos con las actas impresas correspondientes a las ediciones $8^{\mathrm{a}}$ (2003), $9^{\mathrm{a}}(2005)$ y $10^{\mathrm{a}}$ (2007). No hemos considerado la $7^{\text {a }}$ edición porque se celebró en el año 2000. De un total de 115 ponencias $^{10}, 5$ son las identificadas como estudios de usuarios, de las cuales, 2 se presentaron en la $9^{\mathrm{a}}$ edición y 3 en la $10^{\mathrm{a}}$, dándose el hecho de que en la $8^{a}$ edición no se ha identificado ninguna. Las ponencias son:

9 En Anexo se incluye una relación de los títulos de los trabajos identificados como estudios de usuarios de información.

10 Vamos a utilizar este término para referirnos tanto a comunicaciones ("escrito sobre un tema determinado que el autor presenta a un congreso o reunión de especialistas para su conocimiento y discusión") como a ponencias ("comunicación o propuesta sobre un tema concreto que se somete al examen y resolución de una asamblea") sin tener en cuenta cómo se denominan en las Jornadas estudiadas. Definiciones de RAE: Diccionario de la lengua española, $21^{\text {a }}$ ed. Madrid: RAE, 1992. 
- "Diseño de un plan de formación de usuarios como estrategia de difusión de recursos electrónicos. Propuesta metodológica basada en un estudio de caso" (IX Jornadas, 2005)

- "El impacto de los archivos de e-prints en la comunicación científica entre los investigadores españoles: aceptación y uso" (IX Jornadas, 2005)

- "Los usuarios de información en las organizaciones empresariales: Un estudio de caso" (X Jornadas, 2007)

- "El usuario en PoliBuscador. Un nuevo modelo de evaluación en la Biblioteca Digital" (X Jornadas, 2007)

- "Midiendo la satisfacción de usuarios para mejorar la calidad en las bibliotecas universitarias" (X Jornadas, 2007)

En cuanto a la primera de las ponencias, ${ }^{11}$ se trata de un estudio de usuarios realizado por dos autoras procedentes del mundo académico aunque de distintos campos; una de ellas es docente universitaria

11 En IX Jornadas españolas de Documentación. FESABID 2005. Infogestión. Madrid: FESABID, 2005, pp. 137-149. Las autoras son Margarita Pérez Pulido (profesora de la Facultad de Biblioteconomía y Documentación de la Universidad de Extremadura) y María Terrón Torrado (becaria predoctoral del Instituto de Arqueología del Consejo Superior de Investigaciones Científicas en Mérida). 
La investigación sobre las necesidades de información en...

de Biblioteconomía y Documentación y la otra, becaria predoctoral de un instituto de investigación especializado en Arqueología. El estudio se hace con la finalidad de identificar distintas categorías de usuarios y sus necesidades específicas así como para evaluar los factores que influyen en la adopción de recursos electrónicos por parte de los mismos. Todo ello como paso previo a la planificación de la formación de usuarios. Se utiliza un método directo basado en la técnica de la encuesta con el envío de un cuestionario a una muestra de usuarios potenciales pertenecientes al grupo de docentes e investigadores de las áreas Biosanitaria, Científico-Tecnológica y Ciencias Sociales.

La segunda ponencia ${ }^{12}$ es obra de una profesional de la información (documentalista) y se trata de un estudio de usuarios de información con independencia del centro de información que puedan utilizar. La autora estudia la significación de los archivos de e-prints entre los científicos del Consejo Superior de Investigaciones Científicas, esto es, el uso que de un tipo de fuente de información concreta hace un grupo de usuarios. El objetivo del tra-

12 En IX Jornadas españolas de Documentación. FESABID 2005. Infogestión. Madrid: FESABID, 2005, pp. 443-462. La autora es Isabel Fernández Morales, documentalista del CINDOC, dependiente del Consejo Superior de Investigaciones Científicas. 
bajo es el de obtener datos que sirvan para poder analizar el uso, la aceptación y el impacto del movimiento e-prints entre un grupo de investigadores de las áreas de Ciencias de la Vida y Ciencias Sociales y Humanidades. El método empleado es directo, basado en la técnica de la encuesta aplicada a través de un cuestionario (en anexo) enviado por correo electrónico a la totalidad de la población objeto de estudio.

La tercera ponencia ${ }^{13}$ ofrece un estudio de usuarios dirigido a analizar las necesidades y usos de la información de los miembros de una organización privada y de carácter empresarial con el fin de, posteriormente, poder evaluar su sistema de información. Para alcanzar el objetivo propuesto el autor, documentalista del centro, utiliza la combinación de dos métodos: el estudio de usuarios y la audito-

13 En X Jornadas españolas de Documentación. E-información: integración y rentabilidad en un entorno digital. Madrid: FESABID, 2007, pp. 241-249. El autor es Miguel Ángel del Prado Martínez, documentalista responsable del Servicio de Documentación y Archivos de la Confederación de la Pequeña y Mediana Empresa Aragonesa (CEPYME Aragón). 
ría de la información. ${ }^{14}$ En cuanto al estudio de usuarios, empleando un método directo y basándose en las técnicas de la encuesta y la entrevista, utiliza como instrumento dos cuestionarios dirigidos a todos los miembros de la organización (una sobre necesidades de información y otra sobre las fuentes de información utilizadas) y un guión para la entrevista mantenida con una muestra representativa.

14 Auditoría de los recursos de la información: enfoque más global, centrado en los requisitos de la organización (no tanto de las personas), y que parte de la consideración de la información como un recurso corporativo que debe ser adecuadamente gestionado. Se parte del conocimiento de la organización, de su cultura corporativa, de su negocio y de sus actividades, de los elementos integrantes relacionados con la gestión de la información. Pretende diagnosticar su uso dentro de la organización, identificar e inventariar los recursos de información que dispone, descubrir qué información es esencial, por qué y para quién, analizar como se usa y se comparte y establecer su coste y valor. Técnicas: mapas de información, hojas de trabajo, análisis de flujo, análisis de procesos de negocio, inventarios de recursos...(Esteban Navarro, M.A.: "La auditoría de los recursos de información: naturaleza, fin y método", en Gestión y auditoría de los recursos de información en las organizaciones. Curso extraordinario de verano de la Universidad de Zaragoza. Zaragoza: Universidad, 2005. Soy Aumatell, C.: Auditoría de la información: análisis de la información generada en la empresa. Barcelona: UOC, 2003) 
La cuarta ponencia ${ }^{15}$ corre a cargo de dos autoras procedentes del ámbito profesional bibliotecario (universitario) y del académico (del área de la Biblioteconomía y la Documentación). Se trata de un trabajo que pretende conocer el nivel de corrección y de éxito de las búsquedas realizadas por el usuario en un portal de acceso a la biblioteca digital de una universidad y comprobar la evolución que pueda haberse dado durante el tiempo que lleva funcionando el servicio. No se trata de medir la satisfacción de usuario sino de evaluar el uso y la usabilidad del portal. Para conseguir el fin perseguido utilizan la combinación de dos metodologías: la de los estudios de usuarios y la de los estudios de minería de datos. ${ }^{16}$ La primera la basan en la selección de una pequeña muestra de usuarios para estudiar en profundidad su conducta. El método empleado es el indirecto y la técnica la que podríamos llamar de "análisis de las transacciones entre el usuario y el sistema”. El instrumento empleado es el conjunto de informes del módu-

15 En X Jornadas españolas de Documentación. E-información: integración y rentabilidad en un entorno digital. Madrid: FESABID, 2007, pp. 251-263. Las autoras son Inmaculada Ribes Llopes, subdirectora de la Biblioteca de la Universidad Politécnica de Valencia, y Gloria Colomina Fons, del Área de Documentación Científica de la misma Universidad.

16 Análisis de los ficheros de logs. 
La investigación sobre las necesidades de información en...

lo de administración Metalib Search Queries, que muestran todas las consultas realizadas por una institución en un rango de fechas dado y por un grupo determinado de usuarios que, en este caso, lo constituye la comunidad universitaria objeto de estudio.

Por último, la quinta ponencia ${ }^{17}$ identificada es obra de un equipo de investigación constituido por especialistas de distintas materias: informáticos, bibliotecarios universitarios y docentes de Biblioteconomía y Documentación que ha llevado a cabo un estudio de satisfacción de usuarios a petición de la Biblioteca universitaria. Aunque el trabajo no especifica el grupo de usuarios al que va dirigido ni el número de la muestra, por la información que aporta de los datos obtenidos podemos decir que el estudio es sobre parte de la comunidad universitaria: estudiantes de grado, de postgrado, personal docente e investigador, de servicios y bibliotecario. El método empleado es el directo, la técnica, la de la encuesta y el instrumento, un cuestionario. Se pretende cono-

17 Ibídem. Los autores constituyen el grupo de investigación SECABA y son Enrique Herrera Viedma y Sergio Alonso, del Departamento de Computación e I.A.; Francisco Herranz Navarra y Antonio Fernández Porcel, de la Biblioteca Universitaria de Granada, y Javier López Gijón y Josefina Vílchez Pardo, de la Facultad de Documentación de esa Universidad. 
cer el nivel de satisfacción de los usuarios con los servicios de la biblioteca.

\section{Jornadas sobre Gestión de la Información y del} Conocimiento

Se celebran anualmente pero sólo hemos identificado las actas impresas de 2 ediciones: la $8^{\mathrm{a}}$ (2006) y la $9^{a}$ (2007). De un total de 31 ponencias, tan sólo 2 pueden considerarse como estudios de usuarios y se encuentran en la $8^{a}$ edición. Estas ponencias son:

- "Evaluación heurística y pruebas con usuarios: aplicación a interfaces de bases de datos terminológicas"

- "Blogs y usabilidad: el caso del blog de SEDIC"

La primera ponencia ${ }^{18}$ es obra de un grupo de investigadores de la Universidad Pompeu Fabra relacionados con el mundo de la Lingüística. El estudio se ha hecho utilizando una metodología que com-

18 En VIII Jornadas de Gestión de la Información. Nuevas interfaces centradas en el usuario: tendencias en la organización de contenidos, documentos y bibliotecas. Madrid: SEDIC, 2006, pp. 63-73. Los autores son Bartolomé Mesa Lao, Mari Carmen Marcos, Albert Morales Moreno y Agustí Mayor Lloret. 
La investigación sobre las necesidades de información en...

bina la evaluación heurística ${ }^{19}$ con pruebas realizadas con usuarios utilizando tests, cuestionarios y entrevistas. Aunque las técnicas e instrumentos sean diversos, el método empleado es el directo porque se da interrelación con el usuario durante la investigación. La finalidad no es otra que la de analizar la calidad de determinadas bases de datos terminológicas (se toma una muestra de 10) tomando como criterio la usabilidad y analizar el grado de efectividad, eficacia y satisfacción de un grupo de usuarios. Los usuarios que han intervenido en el estudio son traductores, redactores técnicos y asesores lingüísticos con conocimientos avanzados de Internet. Para la evaluación heurística se contó con 5 evaluadores expertos y para las demás pruebas con un grupo de 30 usuarios. El test se utilizó para que los observadores pudieran tomar nota de las dificultades encontradas por los usuarios al realizar 4 tareas determinadas; el cuestionario, para medir la eficacia, y la entrevista, para conocer el grado de satisfacción.

19 Método de análisis según el cual un conjunto de expertos en usabilidad evalúan individualmente un sistema y describen los problemas que detectan a partir de una serie de principios de usabilidad reconocidos y siguiendo una guía elaborada para posteriormente poner en común los resultados obtenidos. 
La segunda ponencia ${ }^{20}$ presenta un estudio dirigido a los miembros de una asociación profesional (SEDIC) con el fin de evaluar el grado de usabilidad de su blog. El trabajo corre a cargo de 2 documentalistas que, aun de centros de información diferentes, tienen en común ser socias de la asociación. Utilizan como metodología la combinación de la evaluación heurística (3 evaluadores) con el test de usuarios (6 usuarios avanzados de Internet. Como en el caso anterior, el estudio se centra en un método directo basado en dos técnicas diferentes. Los usuarios tienen en común el ser socios de SEDIC.

\section{Jornadas Andaluzas de Documentación}

De éstas contamos con las actas publicadas de su $3^{\text {a }}$ edición (2003) y de un total de 38 ponencias identificamos una que tiene relación con un estudio de usuarios pero que no puede considerarse como tal ya que lo que hacen las autoras es describir pormenorizadamente la metodología empleada en un estudio que han realizado.

20 En VIII Jornadas de Gestión de la Información. Nuevas interfaces centradas en el usuario: tendencias en la organización de contenidos, documentos y bibliotecas. Madrid: SEDIC, 2006, pp. 75-83. Las autores son María Jesús Butera y Nuria Escudero Galán. 
La investigación sobre las necesidades de información en...

Jornades Catalanes d'Informació $i$ Documentació

De celebración bianual, nos ofrecen 3 ediciones en el marco cronológico propuesto: la $8^{\mathrm{a}}$ (2001 y con el nombre de Jornades Catalanes de Documentació), la $9^{\mathrm{a}}(2004)$ y la $10^{\mathrm{a}}$ (2006). De un total de 80 ponencias, pueden identificarse como estudios de usuarios 3 , que pertenecen a la $9^{a}$ edición y que son:

- "Experiències i perspectives dels professionals de la informació respecte als recursos electrònics: els resultats d'una enquesta"

- "PaB24x7: una experiencia del Servei d'Informació i Referencia Virtual a la Biblioteca de la Universitat de Barcelona”

- "La base de dades de sumaris del CBUC: anàlisi global del seu ús i de la relació entre la utilització del seu servei de subscripcions per correu electrònic i el consum d'articles i sumaris d'un paquet de revistes electròniques"

La primera de las ponencias ${ }^{21}$ presenta un estudio ejecutado por un grupo de profesionales procedentes de distintas instituciones y especialidades. Se

21 En 9es. Jornades d'Informació i Documentació. Barcelona: Col.legi oficial de Bibliotecaris-Documentalistes de Catalunya, 2004, pp. 221-234. Los autores son, según se ha hecho referencia a ellos en el texto, Elea Jiménez, Alice Keefer, Carlos Tejada, Concha Álvaro, Tomàs Baiget, Dirk Lens y Juan Carlos Martín. 
trata de un trabajo realizado por 7 autores entre los cuales encontramos 3 docentes universitarios de Biblioteconomía y Documentación representantes de distintas universidades españolas (de Navarra, de Barcelona y Complutense de Madrid), 2 documentalistas (del CINDOC y del Institut d'Estadística de Catalunya) y dos profesionales de una empresa privada dedicada al mundo de la información (Swets Information Services) que son quienes dirigen y coordinan. El responsable principal de este estudio es la empresa privada de suscripciones de recursos de información, que ha contado con la colaboración de una asociación profesional (SEDIC) y de una revista especializada en Biblioteconomía y Documentación (El profesional de la información) para poder llevar a cabo el trabajo. La finalidad del estudio es la de conocer el estado de los recursos electrónicos en las bibliotecas españolas así como las experiencias y expectativas de los profesionales de la información respecto a estos. En esta ocasión se ofrecen los datos referidos a España pero el estudio se quiere aplicar a otros 3 países (Bélgica, Francia y Suiza) para poder comparar los resultados. En cuanto al que se describe, el método empleado ha sido el directo a través de la técnica de la encuesta basada en un cuestionario (en anexo) que se ha hecho llegar a una muestra elegida de entre los socios de la asociación que colabora, los 
La investigación sobre las necesidades de información en...

clientes de la empresa responsable del estudio y mediante las listas de distribución Iwtel y Fidel. En esta ocasión, los usuarios estudiados han sido los profesionales de la información.

La segunda de las ponencias ${ }^{22}$ presenta un estudio realizado sobre un servicio: el de Información y Referencia virtual de las bibliotecas de la Universidad de Barcelona (Pregunteu al bibliotecari). La autoría corresponde al grupo de trabajo $\mathrm{PaB} 24 \mathrm{x} 7$, dependiente de la Unidad de Proyectos del CRAI-Biblioteca de la Universidad de Barcelona y compuesto por 9 bibliotecarios. La finalidad del trabajo es la de conocer el funcionamiento de ese servicio a lo largo de 10 meses obteniendo información sobre el número de consultas, el tipo de usuarios que lo utilizan (externos o internos), la tipología de las preguntas, los formularios de solicitud más utilizados, las horas de uso y el tiempo de respuesta de los profesionales. Se utiliza el método indirecto de recogida de datos basado en la técnica que hemos llamado "análisis de las transacciones entre el usuario y el sistema”. El estudio no informa sobre la herramienta utilizada pero cabe suponer que sea el registro de las consultas hechas al servicio. En cuanto a los usuarios estudiados,

22 Ibidem, pp. 235-258. 
son todos aquellos que han usado el servicio, sean de la Universidad o no.

Por último, la tercera de las ponencias identificadas ${ }^{23}$ es obra de 4 autores de los cuales 3 tienen en común ser docentes universitarios en Biblioteconomía y Documentación de la Universidad de Barcelona mientras que el cuarto es bibliotecario del Consorci de Biblioteques Universitàries de Catalunya. El estudio se hace para conocer el uso de una base de datos: la de sumarios de revistas del Consorcio, centrándose en el análisis de las consultas, las suscripciones al servicio de recepción de sumarios por correo electrónico y la posible existencia de una relación entre el uso del servicio de suscripciones y el consumo en línea de artículos y sumarios de un número determinado de revistas electrónicas. El método utilizado para el estudio es indirecto y la técnica, la del "análisis de las transacciones entre el usuario y el sistema”, empleando como herramienta los registros (inventarios) de usuarios y suscripciones y los ficheros de logs (minería de datos) durante un período de tiempo determinado (18 meses). Los usuarios estudiados son los suscriptores al servicio mencionado, quizá universitarios.

23 Ibídem, pp. 15-23. Los autores son Ángel Borrego, Cristóbal Urbano, Ramón Ros y Miquel Térmens. 
La investigación sobre las necesidades de información en...

\section{Jornadas Bibliotecarias de Andalucía}

Se celebran cada dos años. De las ediciones $12^{\mathrm{a}}$ (2002) y $13^{\mathrm{a}}$ (2004), de un total de 50 ponencias, tan sólo 2 son estudios de usuarios y corresponden a las jornadas de 2002. Se da el caso de que las actas de la $14^{a}$ edición (celebrada en 2007) no se han publicado. Los estudios de usuarios identificados son:

- "Encuesta de uso y valoración de la biblioteca universitaria de Almería"

- "Metodología evaluativa del servicio de préstamo de la biblioteca pública infantil Jorge Juan de Novelda (Alicante)"

La primera de ellas ${ }^{24}$ es obra de un grupo compuesto por 5 bibliotecarios universitarios pertenecientes al centro objeto de estudio. Presenta las principales conclusiones, resultados y la metodología de investigación seguida en el estudio recogidos en un informe más extenso. El método es el directo, aplicado a través de la técnica de la encuesta (el cuestionario se ofrece en un anexo). El objetivo del

24 En XII Jornadas Bibliotecarias de Andalucía. Los nuevos retos de los servicios bibliotecarios. Málaga: Asociación Andaluza de Bibliotecarios, 2002, pp. 385-397. Los autores son José Juan Moreno Martínez, $\mathrm{M}^{\mathrm{a}}$ del Mar López Castro, Eugenio Pérez Jover, Belén Prieto Rodríguez y $\mathrm{M}^{\mathrm{a}}$ Louise Romera Bautista, de la Biblioteca Universitaria de Almería. 
estudio es doble: por una parte, conocer la tipología y características de los usuarios que acuden a la biblioteca (usuarios reales) y el uso que hacen de ella, y por otra, recoger su opinión sobre el centro después de haber puesto a su disposición un nuevo edificio y nuevos servicios. En cuanto a los usuarios estudiados, se trata del colectivo de los alumnos de la Universidad.

La segunda ponencia ${ }^{25}$ expone un estudio de usuarios realizado por una autora relacionada con una universidad pero no se especifica si es profesional de la información o docente. El objetivo explícito del estudio es el de conocer la razón por la que el servicio de préstamo de una biblioteca infantil no tiene la aceptación que se espera pero, a través del análisis de los datos aportados podría decirse que la finalidad real del estudio es la de conocer la opinión de un grupo de usuarios reales sobre los servicios que presta el centro. El método empleado es directo y las técnicas, la encuesta y la entrevista, aplicadas a través de dos instrumentos: el cuestio-

25 En XII Jornadas Bibliotecarias de Andalucía. Los nuevos retos de los servicios bibliotecarios. Málaga: Asociación Andaluza de Bibliotecarios, 2002, pp. 433-451. La autora es Manuela Rodríguez Luna, de la Universidad Politécnica de Valencia. De ella sabemos que en la actualidad es la directora de una biblioteca municipal de la provincia de Alicante. 
La investigación sobre las necesidades de información en...

nario y un guión para la entrevista. Los usuarios estudiados responden a edades de entre 2 y 14 años.

Jornadas Bibliotecarias de la Comunidad de Madrid

Han publicado tan sólo las actas de la $3^{\text {a }}$ (2002) y $4^{\text {a }}$ edición (2004). De un total de 25 ponencias, identificamos 2 estudios de usuarios, 1 en las de 2002 y 1 en las de 2004. En la edición de 2002 encontramos un trabajo ${ }^{26}$ que, aunque relacionado con los estudios de usuarios, no puede considerarse como tal porque lo que ofrece es una propuesta metodológica para aplicar. Las ponencias que pueden considerarse como estudios son:

- "Los Opac y la formación de usuarios" (Terceras Jornadas, 2002)

- "Las demandas de usuarios en las Bibliotecas Públicas de la Comunidad de Madrid" (Cuartas Jornadas, 2004)

La primera ponencia ${ }^{27}$ presentada en la $3^{a}$ edición de estas Jornadas es de autoría individual; co-

26 "Evaluación y calidad de los servicios", en Actas de las Terceras Jornadas Bibliotecarias de la Comunidad de Madrid. Madrid; Las Rozas: Consejería de las Artes: Concejalía de Cultura, 2002, pp. 99- 149. Los autores son 10 bibliotecarios de distintas bibliotecas municipales de la Comunidad de Madrid.

27 Ibídem, pp. 203-209. El autor es Pedro Valverde Ogallar, bibliotecario de la biblioteca del distrito de Vallecas. 
rresponde a un bibliotecario que expone una experiencia llevada a cabo en su propia biblioteca y por iniciativa propia con el fin de demostrar la falsedad de algunas ideas preconcebidas en torno a la formación de usuarios y a los conocimientos que estos tienen de las nuevas tecnologías (sobre todo los más jóvenes). El método empleado es el directo y la técnica, la de la encuesta (ofrece el cuestionario en un anexo) y los usuarios estudiados son usuarios reales con edades comprendidas entre 8 y 14 años que deben responder sobre las preguntas que se les formula en torno a su experiencia en el uso de ordenadores y en la búsqueda de información en la biblioteca. Se trata de un estudio de usuarios hecho con la intención de confirmar la creencia del autor de que es necesario llevar a cabo una política coherente y continuada de formación de usuarios.

La ponencia presentada a la $4^{\mathrm{a}}$ edición $^{28}$ es obra de un nutrido grupo de bibliotecarios que son responsables de algunas de las bibliotecas que constituyen la mencionada red. Se trata de un estudio de usuarios de información que utiliza un método directo a partir del uso de dos cuestionarios (una para

28 En Actas de las Cuartas Jornadas Bibliotecarias de la Comunidad de Madrid. Madrid: Consejería de Cultura y Deportes, 2004, pp. 129-202. Los autores son 11 bibliotecarios de distintas bibliotecas municipales de la Comunidad de Madrid. 
La investigación sobre las necesidades de información en...

\begin{tabular}{|c|c|c|c|}
\hline \multicolumn{4}{|c|}{$\begin{array}{l}\text { Figura } 1 \\
\text { Relación entre ediciones, número de ponencias y } \\
\text { estudios de usuarios publicados }\end{array}$} \\
\hline Jornada & Eds. & Pon. & E.de U. \\
\hline $\begin{array}{l}\text { Jornadas Españolas de } \\
\text { Documentación }\end{array}$ & $\begin{array}{l}8^{a}(2003) \\
9^{a}(2005) \\
10^{a}(2007)\end{array}$ & 115 & $\begin{array}{l}0 \\
2 \\
3\end{array}$ \\
\hline $\begin{array}{l}\text { Jornadas sobre Gestión de la } \\
\text { Información y del Conocimiento }\end{array}$ & $\begin{array}{l}8^{a}(2006) \\
9^{a}(2007)\end{array}$ & 31 & $\begin{array}{l}2 \\
0\end{array}$ \\
\hline $\begin{array}{l}\text { Jornadas Andaluzas de } \\
\text { Documentación }\end{array}$ & $3^{a}(2003)$ & 38 & 0 \\
\hline $\begin{array}{l}\text { Jornades Catalanes d’Informació i } \\
\text { Documentació }\end{array}$ & $\begin{array}{l}8^{a}(2001) \\
9^{a}(2004) \\
10^{a}(2006)\end{array}$ & 80 & $\begin{array}{l}0 \\
3 \\
0\end{array}$ \\
\hline $\begin{array}{l}\text { Jornadas Bibliotecarias de } \\
\text { Andalucía }\end{array}$ & $\begin{array}{l}12^{\mathrm{a}}(2002) \\
13^{\mathrm{a}}(2004)\end{array}$ & 50 & $\begin{array}{l}2 \\
0\end{array}$ \\
\hline $\begin{array}{l}\text { Jornadas Bibliotecarias de la } \\
\text { Comunidad de Madrid }\end{array}$ & $\begin{array}{l}3^{a}(2002) \\
4^{a}(2004)\end{array}$ & 25 & $\begin{array}{l}1 \\
1\end{array}$ \\
\hline TOTAL & 13 & 339 & 14 \\
\hline $\begin{array}{l}\text { Eds: Ediciones } \\
\text { Pon: Ponencias } \\
\text { E. de U.: Estudios de Usuarios }\end{array}$ & & & \\
\hline
\end{tabular}


usuarios y otra para bibliotecarios) con el fin de conocer la realidad de las bibliotecas de la Comunidad Autónoma de Madrid respecto a las demandas ${ }^{29}$ de los estudiantes, sobre las colecciones, los servicios y las tecnologías de la información. Los usuarios estudiados son reales y responden a todas las categorías propias de la biblioteca pública.

Según podemos ver en la Figura 1, en las 13 ediciones de las distintas Jornadas analizadas, encontramos un total de 14 trabajos que podrían considerarse como estudios de usuarios de información y, de entre todos los encuentros, son las Jornadas Españolas de Documentación las que ofrecen un mayor número de los mismos (5). Por otra parte, no parece que exista relación entre el número de estudios publicados y el año en que se celebra cada uno de los eventos. El primero no aumenta necesariamente con el paso del tiempo, ni siquiera considerando todas las Jornadas en su conjunto, como puede verse gráficamente a continuación:

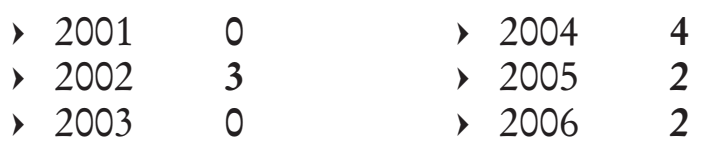

29 Término empleado en el estudio. 
La investigación sobre las necesidades de información en...

En cuanto a los ítems marcados para estudiar en cada uno de los trabajos, podemos decir, como se puede ver en los cuadros que siguen, que en los estudios dados a conocer en las ponencias presentadas en las Jornadas analizadas es más frecuente la autoría colectiva (10) y que se da por igual la actuación de un grupo de profesionales de la información (4) que la de equipos formados por profesionales y docentes universitarios del área de Biblioteconomía y Documentación (4). En cuanto a los objetivos propuestos en los estudios, vemos que prima el interés por conocer el uso (conducta) que se hace tanto de fuentes de información (3) como de servicios que ofrecen las unidades de información (3). El método más empleado es el directo (11), la técnica la de la encuesta (9) y el instrumento, el cuestionario (10). En cuanto a los usuarios que han contado con mayor interés por parte de los estudios analizados, debemos decir que son los miembros de la comunidad universitaria (alumnos y profesores), con 5 trabajos dedicados a conocerlos. 


\begin{tabular}{||l|c|c|c|c|c|c||}
\hline \multicolumn{7}{|c||}{ La Autoría } \\
\hline Modalidad & A & B & C & D & E & Total \\
\hline Individual & 3 & 1 & & & & 4 \\
\hline Colectiva & 4 & & 1 & 1 & 4 & 10 \\
\hline A: Profesional B y D \\
B: Académico B y D \\
C. Académico Otras Disciplinas \\
D: Académico B y D + Otras Disciplinas \\
E. Profesional +Académico B Y D \\
\hline
\end{tabular}

\begin{tabular}{||l|l||}
\hline \multicolumn{2}{|c|}{ Los Objetivos } \\
\hline Identificación de hábitos y necesidades para FU & 2 \\
\hline Uso de fuentes de información & 3 \\
\hline Uso de un servicio & 3 \\
\hline Necesidades, uso y evaluación del centro & 2 \\
\hline Satisfacción respecto a un centro & 1 \\
\hline Satisfacción respecto a fuentes de información & 1 \\
\hline Satisfacción respecto a un servicio & 1 \\
\hline Evaluación de un centro & 1 \\
\hline
\end{tabular}

\begin{tabular}{||l|c|}
\hline \multicolumn{2}{|c|}{ Métodos } \\
\hline Directo & 11 \\
\hline Indirecto & 3 \\
\hline
\end{tabular}


La investigación sobre las necesidades de información en...

\begin{tabular}{||l|l||}
\hline \multicolumn{2}{|c|}{ Técnicas } \\
\hline Encuesta & 9 \\
\hline Encuesta, entrevista & 1 \\
\hline Encuesta, entrevista, observación & 1 \\
\hline Análisis transacciones usuario/sistema & 3 \\
\hline
\end{tabular}

\begin{tabular}{||l|c|}
\hline \multicolumn{2}{|c|}{$\begin{array}{c}\text { Instrumento } \\
\text { (algunos, combinados) }\end{array}$} \\
\hline Cuestionario & 10 \\
\hline Registro/inventario & 3 \\
\hline Guión entrevista & 2 \\
\hline Guión para observación (test) & 2 \\
\hline \hline
\end{tabular}

\begin{tabular}{||l|l||}
\hline \multicolumn{2}{|c||}{ Usuarios Estudiados } \\
\hline $\begin{array}{l}\text { Docentes, } \\
\text { investigadores }\end{array}$ & $\begin{array}{l}\text { 2 (Áreas Biosanitaria, Científico-tecno- } \\
\text { lógica, C. Sociales) (Áreas de C. de la } \\
\text { Vida, C. Sociales y Humanidades) }\end{array}$ \\
\hline Comunidad universitaria & 4 (totalidad) 1 (estudiantes) \\
\hline $\begin{array}{l}\text { Profesionales de la } \\
\text { información }\end{array}$ & $\begin{array}{l}2 \text { (socios de CEDIC) (socios y clientes } \\
\text { de una empresa de información) }\end{array}$ \\
\hline $\begin{array}{l}\text { Profesionales de otros } \\
\text { campos }\end{array}$ & $\begin{array}{l}2 \text { (empresarios) (traductores, redacto- } \\
\text { res técnicos y asesores lingüísticos) }\end{array}$ \\
\hline Público en general & 1 \\
\hline Público infantil, juvenil & 2 \\
\hline
\end{tabular}




\section{Revistas especializadas}

\section{Revista Española de Documentación Científica} (REDC)

La edita el Centro deInformación y Documentación Científica (CINDOC), del Consejo Superior de Investigaciones Científicas (CSIC). Se publica desde 1977 y su periodicidad es trimestral. Cumple con 33 criterios LATINDEX, constituyéndose en la mejor valorada. Para nuestro estudio hemos analizado 8 volúmenes (desde el 24-2001- hasta el $31-2008$ ) y un total de 30 números ya que los números 3 y 4 del volumen 31 aún no han salido ${ }^{30}$. Se han tenido en cuenta tan sólo los estudios y no otras secciones de la revista tales como notas o reseñas. Teniendo en cuenta que cada número cuenta con 4 estudios, salvo el número 2 del volumen 31 que recoge 5, hemos analizado un total de 121 estudios. De todos ellos analizaremos los que hemos identificado como estudios de usuarios de información (8) volumen a volumen.

30 En el transcurso de la redacción de este trabajo hemos encontrado información sobre el número 3 del volumen 31. En él aparece el artículo que lleva por título "Estudio de los hábitos de uso de los estudiantes en la biblioteca de la Universidad Complutense de Madrid" (Alicia Arias y José Simón) pero que no analizamos por estar fuera de los límites cronológicos que nos hemos propuesto. 
La investigación sobre las necesidades de información en...

En el volumen 24 (2001), encontramos los siguientes:

- "Análisis de uso de las bases de datos de la biblioteca de la Universidad Carlos III de Madrid" ( ${ }^{\circ}{ }^{1}$ )

- "Demanda de información de actualidad en un servicio de referencia periodística. Análisis descriptivo de 4.160 solicitudes" ( $\mathrm{n}^{\circ} 1$ )

- "Evaluación de la base de datos ISOC a través de un estudio de usuarios. Homenaje a José María Sánchez Nistal" ( $\left.\mathrm{n}^{\circ} 3\right)$

El primer artículo ${ }^{31}$ es de autoría múltiple, interdisciplinar e internacional. Se trata de un grupo compuesto por dos docentes y dos profesionales de la información. El objetivo del estudio es el de caracterizar el uso que hace de las bases de datos la comunidad de usuarios de la Universidad Carlos III de Madrid a través del servicio de bases de datos de su biblioteca. A partir de un método indirecto basado en la técnica del "análisis de las transacciones entre el usuario y el sistema" y utilizando como instrumento los registros de accesos realizados duran-

31 En pp. 23-35. Los autores son Carlos Suárez Balseiro (Fac. Comunicación, Universidad de La Habana), Elías Sanz Casado (Departamento de Biblioteconomía y Documentación, Universidad Carlos III de Madrid), Pilar Vergara González (Servicio de bases de datos de la biblioteca de la Universidad Carlos III de Madrid) y Gilberto Sotolongo Aguilar (Instituto Finlay, Centro de Investigación de Vacunas y Sueros de La Habana). 
te el período de 1995 a 1998 a una selección de bases de datos, se obtiene información sobre el comportamiento de la totalidad de la comunidad universitaria, esto es, estudiantes, profesorado, personal de la biblioteca y de administración respecto a un servicio que presta la biblioteca.

El segundo artículo ${ }^{32}$ es obra de los profesionales del centro en el que se basa elestudio. En este caso se trata de un estudio cuantitativo de las demandas planteadas por los usuarios en el servicio de referencia de la unidad de Documentación escrita de un medio de comunicación con el fin de obtener una serie de datos (tema y objeto de la solicitud y tipo de información solicitada) que permitan apoyar las decisiones de diseño de un nuevo sistema a implantar. El método empleado es el indirecto basado en la técnica del "análisis de las transacciones entre el usuario y el sistema" que emplea como instrumento el registro, elaborado al efecto, de la formulación literal de la petición, la identidad del peticionario, su actividad y la fecha de cada solicitud. Los usuarios estudiados son los empleados del medio de comunicación que han formulado alguna solicitud de información.

32 En pp. 36-50. Los autores son Lourdes Castillo Blasco, Soledad Doménech Vidal, Concha Soler Monreal y Carlos Benito Amat, documentalistas de Radiotelevisión Valenciana. 
La investigación sobre las necesidades de información en...

El último artículo ${ }^{33}$ identificado en este volumen es obra de un grupo de documentalistas-investigadores del CINDOC (CSIC) que estudian el uso y valoración de una base de datos creada por esa institución: la base de datos bibliográfica ISOC. ${ }^{34}$ Se trata de un ejemplo de evaluación realizada por el productor y distribuidor de un producto como un recurso para la gestión y mejora continua de sus productos y servicios. El método empleado es el directo a través de la técnica de la encuesta y con el uso de dos cuestionarios diferentes como instrumentos utilizados para la recogida de datos. Cada uno de ellos dirigido a dos categorías de usuarios: profesionales responsables de los servicios de referencia de bibliotecas universitarias o de centros de investigación (referencistas) y usuarios finales que utilizan directamente la base de datos para realizar búsquedas bibliográficas (investigadores, docentes universitarios y estudiantes). El diseño de los cuestionarios corrió a cargo de un equipo de trabajo formado por productores o analistas que elaboran la base de datos y bibliotecarios referencistas. No

33 En pp. 275-288. Los autores son $\mathrm{M}^{\mathrm{a}}$ Dolores Alcain, Piedad Baranda, Luis Rodríguez Yunta, Adelaida Román y Ángel Villagrá.

34 Desde 1975 recoge artículos publicados en revistas científicas españolas, informes técnicos, comunicaciones a congresos, etc. de Ciencias Sociales y Humanas. 
hay muestra concreta sino que se informa de que los cuestionarios se enviaron (por correo postal o electrónico) a "todos los colectivos e instituciones reconocidos como potenciales usuarios". ${ }^{35}$

En el volumen 25 (2002) encontramos:

- "La biblioteca de la Universidad da Coruña. Estudio con los alumnos" ( $\left.\mathrm{n}^{\mathrm{o}} 1\right)^{36}$

Se trata de un trabajo obra de un autor que nada tiene que ver con el mundo de la Biblioteconomía y Documentación. Se encuadra dentro de un proyecto de investigación orientado a evaluar la calidad en los servicios de bibliotecas universitarias. La finalidad es la de analizar la actividad de una biblioteca universitaria a partir de la obtención de datos de la relación que ésta mantiene con sus usuarios, sus comportamientos y necesidades de información. En definitiva, de estudiar el uso y valorar el servicio (grado de satisfacción). El estudio se ha hecho con una muestra escogida de entre la población de estudiantes y utilizando el método directo basado en la técnica de la encuesta a través del reparto "in situ" (en distintas bibliotecas de Facultad de distintos

35 p. 279.

36 pp. 29-48. El autor es Gustavo Perea Vega, del Departamento de Métodos de Investigación y Diagnóstico en Educación de la Universidade da Coruña. 
La investigación sobre las necesidades de información en...

ámbitos científicos) de un cuestionario (se incluye en anexo), por lo que los usuarios estudiados son reales. do:

El volumen 27 (2004) contiene el estudio titula-

- "Productores de información interesantes para las empresas. Resultados de una encuesta sobre consumo de información a empresas de la Comunidad de Madrid" ( $\left.{ }^{\circ} 1\right)$.

Se trata de un trabajo ${ }^{37}$ producto de la colaboración de dos profesionales procedentes de distintos ámbitos: el docente y el de la investigación en Biblioteconomía y documentación. El objetivo es el de conocer las necesidades y los hábitos de información (tipos de información más demandados, productores de información de mayor interés, los tipos de documentos y canales de información más utilizados) de un grupo de empresas de la Comunidad de Madrid seleccionadas de entre todas las que pertenecen a los 7 sectores más productivos (Construcción, Química, Farmacia, Electrónica, Tecnología de los alimentos, Mecánica y Telecomunicaciones). El método empleado es el directo a través

37 pp. 73-92. Las autoras son Elea Jiménez Toledo, de la Universidad de Navarra (no se ofrecen datos de su dedicación) y Adelaida Román Román, profesional del CINDOC. 
de la técnica de la encuesta basada en un cuestionario (se incluye en anexo).

El volumen 28 (2005) cuenta con el estudio:

- "Estudio sobre la satisfacción de los usuarios de la biblioteca del Hospital Universitario Puerta de Hierro" ( $\left.\mathrm{n}^{\circ} 3\right)$.

Este artículo ${ }^{38}$ se debe a un grupo de autores pertenecientes a distintas unidades del hospital, entre ellas la biblioteca. El objetivo fundamental es el de conocer la opinión y grado de satisfacción de los usuarios sobre la calidad de los servicios de la biblioteca. El método empleado es el directo basado en la técnica de la encuesta que se desarrolló con la distribución de un cuestionario entre usuarios reales y potenciales de la biblioteca. Los usuarios estudiados pertenecen a distintos sectores relacionados con la institución: médicos, estudiantes, residentes, profesionales de enfermería.

El volumen 29 (2006) presenta el estudio titulado:

- "Presente y futuro de los servicios de las bibliotecas médicas. Revisión de la literatura y estudio realizado en un hospital de más de 1.400 camas" $\left(n^{\circ} 3\right)$.

38 pp. 349-358. Los autores son Montserrat Solís Muñoz, Cristina Escudero Gómez, Fernando García López y Margarita Alonso Durán. 
La investigación sobre las necesidades de información en...

Se trata de un trabajo ${ }^{39}$ obra de un grupo de profesionales de la información (bibliotecarios) relacionados con la institución que es objeto de estudio. El objetivo fundamental es el de conocer los hábitos y las necesidades reales de información de los médicos de un hospital. El método empleado es el directo a través de la técnica de la encuesta con el uso de un cuestionario elaborado al efecto para recoger los datos que se precisan y distribuido al azar. Los usuarios estudiados responden a una muestra seleccionada de entre toda la población, luego son usuarios potenciales.

El volumen 30 (2007) ofrece un estudio:

- "La herramienta "BiQual» como instrumento para el estudio de la calidad del servicio en bibliotecas universitarias españolas de ciencia y tecnología" (no 4).

El trabajo ${ }^{40}$ es obra de 3 docentes universitarias, una de ellas identificada como del área de Bibliote-

39 pp. 364-381. Los autores son M. Rodríguez del Castillo Martín, M.M. Rodríguez del Águila, C. Herrera Espiñeira, A. Quero Rufián, C. Martínez Cirre, F. Lechuga Rodríguez del Castillo (Grupo Aldebarán. Biblioteca general del Hospital Universitario Virgen de las Nieves).

40 pp. 465-491. Las autoras son María Pinto (Facultad de Biblioteconomía, Universidad de Granada), Viviana Fernández Marcial (Universidad CEU-San Pablo. Madrid), Carmen Gómez-Camarero (Universidad de Málaga). 
conomía y Documentación. Forma parte de los resultados de un proyecto de investigación y se propone evaluar y estudiar la calidad del servicio de bibliotecas universitarias de Ciencia y Tecnología (excepto Medicina) a través de una herramienta que se propone y basándose en los comportamientos de una muestra de usuarios del sector académico (investigadores, profesores y estudiantes) procedentes de 19 universidades seleccionadas según unos criterios. El interés del artículo reside en la herramienta utilizada (BiQual) ${ }^{41}$ para conocer la calidad de servicio desde el punto de vista de la percepción del usuario/cliente. El método es el directo, la técnica la de la encuesta y la herramienta un cuestionario que se envió por correo electrónico a usuarios potenciales de bibliotecas especializadas en las materias seleccionadas. El estudio se llevó a cabo en dos etapas; en la primera se utilizaron como técnicas el focus group y entrevistas mantenidas con egresados, pro-

41 Se basa en la experiencia del proyecto LibQUAL + (cuestionario con 23 preguntas agrupadas en cinco dimensiones y que recoge estos tres aspectos: el valor del servicio mínimo esperado por los usuarios antes de recibir el servicio, el valor del servicio recibido por el usuario, y el nivel del servicio mínimo percibido de la biblioteca, independientemente de los servicios recibidos. Hay una pregunta de carácter abierto para recoger cualquier comentario del usuario. Trabaja con las percepciones de los usuarios/clientes para conocer los niveles de calidad de los servicios de biblioteca y con la mejora de las deficiencias detectadas). 
La investigación sobre las necesidades de información en...

fesores e investigadores y cuestionarios aplicados a estudiantes universitarios de los distintos ciclos académicos con la finalidad de diseñar la herramienta BiQual. En la segunda etapa se utilizó la mencionada herramienta (se incluye en el texto) pero excluyendo a los estudiantes.

\section{Revista General de Información y Documentación}

La publica la que fue Escuela Universitaria de Biblioteconomía y Documentación y ahora es Facultad de Ciencias de la Documentación de la Universidad Complutense de Madrid. Se creó en 1992 y su periodicidad es semestral. Recoge fundamentalmente los trabajos generados por la investigación propia y ajena a la institución, así como los aspectos de toda índole relacionados con el ámbito académico de la misma. Cumple 32 criterios LATINDEX. Los volúmenes analizados han sido 7 (del 11-2001- al 17-2007) ${ }^{42} y$, teniendo en cuenta la publicación de 2 números por volumen, los números examinados han sido 14. Sólo se han considerado los artículos que aparecen como estudios y los que

42 A la hora de redactar estas líneas se está cerrando el número 1 del volumen 18 donde nos consta que aparece al menos un artículo que podemos identificar como un estudio de usuarios pero que no vamos a considerar teniendo en cuenta que aún no se ha dado a la luz. 
constituyen las ponencias de algunas de las Jornadas Académicas celebradas por la Facultad de Ciencias de la Documentación (las XV y XVI). ${ }^{43}$ Se han analizado un total de 131 trabajos, de entre los cuales se han identificado 7 estudios de usuarios de información que se describirán volumen a volumen. Así, en el volumen 13 encontramos el trabajo titulado:

- "Las necesidades de información de los investigadores del área de Humanidades y Ciencias Sociales" ( $\left.\mathrm{n}^{\circ} 2\right)$.

El artículo ${ }^{44}$ es obra de un investigador-docente universitario. Tiene como objetivo determinar las necesidades de información de los investigadores en el área de Humanidades y Ciencias Sociales así como estudiar la relación entre la etapa y tipo de investigación y categoría profesional y esas necesidades de información. Se emplea el método directo basado en la técnica de la encuesta y utilizando

43 XV Jornadas de la Escuela Universitaria de Biblioteconomía y Documentación: Políticas de información y discapacidad, nuevos retos para la integración (vol. 16, $\mathrm{n}^{\mathrm{a}}$ 1) y XVI Jornadas EUBD/FADOC: Los estudios de usuarios de información (vol. 17, $\mathrm{n}^{\circ} 2$ ). En este último caso se dio la circunstancia de que la sesión académica se celebró conjuntamente con el IV Seminario bispano-mexicano de investigación en Bibliotecología y Documentación.

44 pp. 155-180. El autor es Juan José Calva González, del Centro Universitario de Investigaciones Bibliotecológicas de la UNAM. 
La investigación sobre las necesidades de información en...

como instrumento un cuestionario que se distribuyó al azar a una muestra estratificada seleccionada de entre investigadores que trabajan en los institutos de investigación del área mencionada de la Universidad Nacional Autónoma de México.

En el volumen 14 se nos ofrece el trabajo que lleva por título:

- "Evaluación de hemerotecas electrónicas: resultados de un estudio de usuarios realizado en la Hemeroteca Electrónica de la Facultad de Ciencias de la Información de la Universidad Complutense" ( $\left.{ }^{\circ} 1\right)$.

En esta ocasión encontramos un artículo que constituye el complemento a otras publicaciones de las autoras, ${ }^{45}$ que proceden de dos ámbitos diferentes como son el profesional bibliotecario (universitario) y el académico, ya que se trata de una bibliotecaria y una profesora universitaria (del área de Biblioteconomía

45 Véase "Diseño y planteamiento de un estudio de usuarios en una hemeroteca electrónica: el servicio de prensa electrónica de la biblioteca de la Facultad de Ciencias de la Información de la Universidad Complutense", en III Jornadas Andaluzas de Documentación. JADOC 03. Organizaciones electrónicas. Situación actual y perspectivas de la e-documentación. Pp. 205-217. Las autoras son $\mathrm{M}^{\mathrm{a}}$ Luisa García-Ochoa Roldán, directora de la Biblioteca de la Facultad de Ciencias de la Información de la Universidad Complutense de Madrid y Rosario Arquero Avilés, profesora de la Facultad de Ciencias de la Documentación de la misma Universidad. 
y Documentación). El trabajo presenta parte del estudio de usuarios que han llevado a cabo. En esta ocasión se ofrecen los resultados del estudio. El objetivo del estudio es el de analizar las necesidades de información, el grado de utilización y satisfacción del servicio de prensa electrónica de la biblioteca de la Facultad de Ciencias de la Información de la Universidad Complutense por parte de un segmento (usuarios reales) de la comunidad de usuarios del centro (estudiantes, personal docente e investigador y de Administración y Servicios). Se pretende que las conclusiones sean tenidas en cuenta como punto de partida para la planificación estratégica del servicio. El método empleado es el directo, la técnica la de la encuesta y el instrumento de recogida de datos un cuestionario que se ofrece en anexo, como en la publicación mencionada. En el volumen 16 se presenta el trabajo:

- "Los archivos históricos provinciales: estudio de usuarios aplicado en Jaén". ${ }^{4}$

46 En pp. 155-167. La autora es Rita Dolores Santaella Ruiz y trabaja en el Servicio de Información Ciudadana y Comunicación Social de la Diputación Provincial de Jaén. Cabe decir con respecto a esta profesional que, además de ser la única autora que ha publicado en este tiempo sobre usuarios de archivos, es coautora del único libro publicado en nuestro país dedicado a un estudio de usuarios: Estudio de usuarios de información aplicado al archivo: la ciudad de Jaén (con A. A. Ruiz Rodríguez. Publicado por la Universidad de Jaén en 2007). 
La investigación sobre las necesidades de información en...

Se trata de un artículo publicado por una profesional de la información. Se propone conocer las características de los usuarios de los archivos históricos provinciales a partir del estudio llevado a cabo con los del archivo de Jaén (ciudad andaluza). El método empleado es el indirecto, utilizando como técnica el recuento y análisis de las consultas realizadas en este archivo durante dos décadas (1976-1996) y como instrumento el registro de consultas del centro. Los usuarios estudiados son básicamente investigadores, ya que es este colectivo el que realiza un mayor número de consultas.

El número 2 del volumen 17 representa un caso excepcional al ofrecernos 4 estudios de usuarios diferentes; esto se debe a que publica las ponencias presentadas a las XVI Jornadas EUBD/FADOC dedicadas a "Los estudios de usuarios de información". De todas ellas se han seleccionado las que ofrecen estudios de usuarios de información prácticos, dejando para otro momento el análisis de las que se dedicaron a tratar el tema desde un plano teórico. Los artículos a analizar son:

- "Estudio de satisfacción de usuarios en la red de bibliotecas del Instituto Cervantes".

- "Nuevas técnicas de estudios de usuarios aplicadas a bibliotecas".

- "Estudio sobre la satisfacción de los usuarios de una biblioteca hospitalaria". 
- "Usuarios de información pública de la ciudad de Jaén (1976-1996)”.

El primero de los artículos ${ }^{47}$ es obra de una profesional de la información. Recoge el estudio llevado a cabo en una red de bibliotecas ${ }^{48}$ (la del Instituto Cervantes) durante el mes de julio de 2006 y con el objetivo de medir el grado de satisfacción de sus usuarios obteniendo datos que, junto con los que se cuenta de las estadísticas anuales de funcionamiento, puedan utilizarse para la elaboración del Plan Director de la Red de Bibliotecas del Instituto Cervantes. El método empleado es el directo, la técnica la de la encuesta y el instrumento un cuestionario repartido en 37 bibliotecas de 25 países (se presenta en anexo). Los usuarios estudiados forman parte de las distintas categorías de usuarios reales de estas bibliotecas: alumnos y profesores de cada centro, personal, investigadores, público en general, etc., todos ellos interesados por "lo español".

El segundo artículo ${ }^{49}$ es obra de un gestor responsable de una red nacional de bibliotecas: la de Caja

47 En pp.9-30. La autora es Irene Martín-Montalvo, responsable del Departamento de Bibliotecas y Documentación del Instituto Cervantes.

48 Aunque algunas bibliotecas de la red realizan periódicamente estudios de usuarios, ésta es la primera vez que se realiza uno sobre el conjunto de todas ellas.

49 En pp. 45-61. La autora es Maribel Riaza Chaparro. 
La investigación sobre las necesidades de información en...

Madrid, entidad privada, bancaria, que cuenta con este servicio desde los años 70. El trabajo informa de un estudio de usuarios que está llevándose a cabo desde 2005. Se trata de un programa que abarca hasta 2008 y que tiene como finalidad conocer el grado de satisfacción de los usuarios para adaptar los servicios a sus necesidades. Los socios estudiados son tanto los internos (deben contar con una cuenta bancaria en la entidad y tienen derechos que no poseen los externos) y los externos. La variedad tipológica responde a la propia de las bibliotecas públicas. En cuanto a los métodos empleados en el estudio, se utilizan tanto el directo como el indirecto. Las técnicas empleadas son, para el método directo la encuesta (basada en un cuestionario y realizada telefónicamente a una muestra aleatoria de socios) y para el indirecto, la gestión de sugerencias y reclamaciones (a partir de los registros semanales que se hacen de éstas a través del portal de Internet de la entidad y en cada uno de los centros) y el cliente oculto ${ }^{50}$ (a través de distintos instrumentos: un registro de valoraciones numéricas, una lista de chequeo, un parte de incidencias y un informe subjetivo que conforman el "informe de auditoria”).

50 “mystery shopping, silent shopping”. 
El siguiente artículo ${ }^{51}$ se debe a un grupo de profesionales pertenecientes a la unidad de Biblioteca del hospital. El objetivo fundamental es el de conocer la opinión y grado de satisfacción de los usuarios sobre la calidad de los servicios de la biblioteca. El método empleado es el directo basado en la técnica de la encuesta que se desarrolló con la distribución de un cuestionario (se incluye en anexo) entre usuarios reales y potenciales artículo recoge la misma información expuesta en el volumen 28 (2005) de la Revista Española de Documentación Científica.

El cuarto artículo ${ }^{52}$ completa el trabajo presentado por la misma autora en el volumen $16\left(\mathrm{n}^{\circ} 2\right)$ de esta revista. En esta ocasión se informa del estudio realizado no sólo en el Archivo Histórico Provincial de Jaén sino también en el Archivo Municipal de esa ciudad y en el Archivo de la Diputación Provincial. El método empleado es el indirecto, utilizando como técnica el recuento y análisis de las consultas realizadas en estos del centro. Los usuarios estudiados son básicamente investigadores y

51 En pp. 63-76. Los autores son Montserrat Solís Muñoz, Cristina Escudero Gómez y Margarita Alonso Durán.

52 En pp. 77-94. La autora es Rita Dolores Santaella Ruiz y trabaja en el Servicio de Información Ciudadana y Comunicación Social de la Diputación Provincial de Jaén. 
La investigación sobre las necesidades de información en...

Administración, ya que son estos colectivos los que realizan un mayor número de consultas.

\section{Ítem. Revista de biblioteconomía i documentació}

La publica el Col.legi Oficial de Bibliotecaris-Documentalistes de Catalunya desde 1987. Cumple con 32 criterios LATINDEX y es de periodicidad cuatrimestral. En los 21 volúmenes analizados (del 28 , que corresponde al año 2001, al 48, que es el primero del año 2008) y en los 145 trabajos estudiados no hemos encontrado ninguno que podamos identificar como un estudio de usuarios.

\section{Documentación de las Ciencias de la Información}

La revista es responsabilidad del Departamento de Biblioteconomía y Documentación de la Facultad de Ciencias de la Información de la Universidad Complutense de Madrid. Se publica desde 1976 y su periodicidad es anual. Cumple con 31 criterios LATINDEX. Para el presente trabajo cabe decir que hemos analizado 7 volúmenes, los que van del 24 (2001) al $30(2007)^{53}$. En cuanto al número total de artículos estudiados es de 115, de entre los cuales

53 Nos consta que en el volumen 31 (2008) aparece un trabajo referido al tema que nos ocupa: "Propuesta metodológica para un estudio de usuarios de documentación filosófico-jurídica” (Isabel Villaseñor Rodríguez). 
encontramos únicamente un trabajo que se refiere a los estudios de usuarios pero que no consideraremos por tratarse de una reflexión en torno a las necesidades de información de un colectivo y no de un estudio propiamente dicho. ${ }^{54}$

BiD. Textos universitaris de biblioteconomia i documentació es obra

Revista de la Facultat de Biblioteconomia i Documentació de la Universitat de Barcelona. Se publica desde 1998 y es de periodicidad semestral. Cumple con 30 criterios LATINDEX. Para nuestro estudio hemos tenido en cuenta sólo las secciones de Articles y de Experiéncies, que contienen un total de 134 trabajos incluidos en los 14 números analizados (del n ${ }^{\circ} 7$, de 2001, al n' o 20, de 2008). De todos ellos, 3 pueden identificarse como estudios de usuarios y son:

- "El web de la Biblioteca de la Universitat Pompeu Fabra: un disseny orientat a l'usuari” (2003, $\left.\mathrm{n}^{\mathrm{o}} 10\right)$.

54 Juan José Calva González: "Las necesidades y comportamiento de los investigadores como usuarios de las bibliotecas de las instituciones de educación superior en América Latina”, en Documentación de las Ciencias de la Información, 2004, vol. 27, pp. 97-116. 
La investigación sobre las necesidades de información en...

- "Avaluació de la satisfacció dels usuaris de les biblioteques publiques" (2002, $\mathrm{n}^{\circ}$ 9).

- "L'ús i la satisfacció dels usuaris de les biblioteques públiques en municipis de més de 30.000 habitants" (2005, no 14).

El primero ${ }^{55}$ de ellos es obra de 3 profesionales de la información de la biblioteca donde se desarrolla el estudio. El trabajo tiene como fin conocer el grado de usabilidad de la web de una biblioteca universitaria. A través de un cuestionario (método directo, técnica de encuesta) distribuido a una muestra de usuarios (estudiantes, docentes y personal de administración y servicios) se obtienen datos necesarios para evaluar un servicio. La información obtenida se complementa con la conseguida mediante un test de usabilidad (una prueba de uso del servicio) realizada a un grupo reducido de usuarios mientras son observados por alguno de los miembros del equipo responsable del estudio. Se incluyen los modelos de instrumentos utilizados.

Los otros dos artículos forman parte de un mismo estudio realizado por el Servei de Biblioteques

55 En http://www2.ub.es/bid/consulta_articulos.php?fichero= 10cantos.htm [Consulta: 08-06-2008]. Las autoras son CarmeCantos Puig, Gemma García, Marina Losada y Mercé Martínez, de la Biblioteca de la Universidad Pompeu Fabra y responsables de la web que es objeto de evaluación. 
y l'Oficina d'Avaluació de Serveis i Qualitat de la Diputación de Barcelona. Los dos son obra de un organismo oficial (el Servicio de bibliotecas de la Diputación de Barcelona) y forman parte de una serie de trabajos promovidos por tal organismo con el fin de conocer la opinión que tienen los usuarios reales de las bibliotecas pertenecientes a la provincia de Barcelona y de los servicios que prestan. Se trata de un estudio de satisfacción. El primero ${ }^{56} \mathrm{de}$ los dos lo firman dos responsables de la gestión bibliotecaria del mencionado organismo y el segundo, ${ }^{57}$ uno de los autores anteriores más un gestor de calidad de servicios. El primero estudia las bibliotecas y bibliobuses públicos de la provincia de Barcelona y el segundo, las bibliotecas de municipios de más de 30.000 habitantes. El método empleado para los dos es el directo y la técnica la de la entrevista telefónica realizada a una muestra de usuarios

56 En http://www.ub.es/biblio/bid/09feliu.htm [Consulta: 0806-2008]. Los autores del artículo son Toni Feliu, de la Unitat d'Estadístiques del Servei de Biblioteques de la Diputació de Barcelona y Jordi Permanyer i Bastardas, Jefe de la Secció de Planificació i Programació del Servei de Biblioteques de la Diputació de Barcelona.

57 En http://www2.ub.es/bid/consulta_articulos.php?fichero= 14arbos.htm [Consulta: 8-07-2008]. Los autores del artículo son Toni Feliu, de la Unitat d'Estadístiques del Servei de Biblioteques de la Diputació de Barcelona y Ramon Arbós de la Oficina d'Avaluació de Serveis i Qualitat de la Diputació de Barcelona. 
La investigación sobre las necesidades de información en...

reales a partir de un cuestionario que incluyen en anexo.

\section{Forinf@Revista Iberoamericana sobre Usuariosde Información,}

Es la revista electrónica del Foro Internacional de Trabajo con Usuarios (FITCU). Se publica desde 1998 y es responsabilidad del Laboratorio de Estudios Métricos de Información del Departamento de Biblioteconomía y Documentación de la Universidad Carlos III. Su periodicidad es trimestral y cumple con 28 criterios LATINDEX. Teniendo en cuenta las limitaciones cronológicas de nuestro trabajo hemos analizado 21 volúmenes, desde el volumen número 11 (2001) al volumen 33 (2006), teniendo en cuenta que los volúmenes 20 y 23 no existen y que la revista no se publica desde el año 2006. Se han tenido en cuenta tan sólo los artículos y no se han considerado otras secciones tales como "editorial" o "comunicaciones". De los 23 artículos analizados, contamos con 4 estudios de usuarios. Cabe decir que existen dos artículos de gran interés pero que no se han considerado como estudios. Ambos son obra de Calva y se refieren, el uno ${ }^{58}$ a

58 "Las necesidades de información: la difusión de estudios en las Jornadas Mexicanas de Biblioteconomía”, en Forinf@, n 15, 2002, pp. 9-22. 
los estudios de usuarios difundidos en las actas de unas jornadas mexicanas y el otro ${ }^{59}$, a los asuntos que se deben tener en cuenta a la hora de estudiar un colectivo de usuarios como es el juvenil. Los estudios de usuarios son:

- "Hábitos y necesidades de información de los investigadores españoles en Ciencias de la Vida: Un estudio de las peticiones realizadas al Centro de Información y Documentación Científica" (2001, no 12)

- "La entrevista personal: método para el estudio de usuarios de información" (2001, no 14)

- "Bibliotecas hospitalarias: ¿satisfacción de usuarios remotos?" (año 2002, no 16)

- "Análisis de la percepción de una biblioteca de prisión por parte de la comunidad reclusa: propuesta metodológica basada en un estudio de caso" $\left(2002, \mathrm{n}^{\circ} 18\right)$

El primer artículo ${ }^{60}$ es obra de una docente universitaria del área de Biblioteconomía y Documentación. Se trata de un estudio que pretende conocer

59 "El usuario de la información y la biblioteca escolar", en Forinf@, no 21, 2003,pp.6-11.

60 En pp. 8-27. La autora es Carmen Martín Moreno, profesora del Departamento de Biblioteconomía y Documentación de la Universidad Carlos III de Madrid. 
La investigación sobre las necesidades de información en...

las características, hábitos y necesidades de información de la comunidad de científicos españoles que trabajan en el área de las Ciencias de la Vida. El método empleado es el indirecto y la técnica el análisis de más de 43.000 peticiones de información formuladas (durante 10 años) al Servicio de Fotodocumentación (préstamo interbibliotecario) del CINDOC por usuarios de esas ciencias. El instrumento, el registro de peticiones elaborado por los profesionales del centro.

El segundo artículo ${ }^{61}$ tiene en común con el anterior el ser obra de otra docente universitaria del área de Biblioteconomía y Documentación. También este estudio pretende conocer las necesidades y hábitos de información de una comunidad de usuarios, la de las empresas farmacéuticas (laboratorios) ubicadas en la Comunidad Autónoma de Madrid y durante un año. El método aplicado es el directo y la técnica la entrevista personal utilizando como instrumento un formulario semiestructurado en 3 modelos diferentes: el empleado con responsables de los servicios de información, el de los directivos y el de los investigadores. Los usuarios estudiados (reales y potenciales de centros de infor-

61 En pp. 6-23. La autora es María José Ordóñez Vergara, profesora de Biblioteconomía y Documentación de la Universidad de la Coruña. 
mación) son una muestra representativa de la población total.

El tercer artículo ${ }^{62}$ es obra de un autor colectivo e interdisciplinar ya que participan en su elaboración un docente, un profesional de la información y un profesional (sin determinar actividad) del sector hospitalario. Se plantea como objetivos conocer los hábitos de información (consumo) y el grado de satisfacción respecto a los servicios a distancia que las bibliotecas hospitalarias ofrecen de los usuarios remotos (los que utilizan los servicios de la biblioteca en línea, no presencial). Se hace a través de dos centros hospitalarios que imparten docencia. La población está constituida por el personal (médicos, farmacéuticos, residentes, personal de enfermería, personal de gestión y dirección) que tiene acceso a correo electrónico y la muestra, por aquellos usuarios que respondieron a la invitación de los autores del estudio. El método de recogida de datos es el directo, la técnica la de la encuesta y el instrumento un cuestionario (incluido en Anexo).

62 En pp. 7-29. Las autora son Isabel Martínez Hervás, de la Unidad de Docencia e Investigación del Hospital Severo Ochoa (Leganés, Madrid), Belén Martínez Mondejar, de la Unidad de Medicina Preventiva del mismo hospital, y Rosa Trueba Gómez, de la Unidad de Biblioteca del Hospital Universitario Príncipe de Asturias (Alcalá de Henares, Madrid). 
La investigación sobre las necesidades de información en...

El cuarto ${ }^{63}$ y último artículo tiene en común con los dos primeros el ser obra de una docente universitaria del área de Biblioteconomía y Documentación y tener como objetivo el conocer las necesidades, hábitos y conducta de una comunidad de usuarios. En este caso los usuarios estudiados (reales y potenciales de centros de información) son reclusos del centro penitenciario de Badajoz (Extremadura). La autora combina el método directo y el indirecto así como técnicas propias del primero (encuesta, entrevista personal) y del segundo (observación), utilizando como instrumentos un cuestionario, un guión para la entrevista y un registro de conductas que se aplicaron a una muestra de usuarios.

Según podemos ver en la Figura 2, de los 107 artículos analizados, encontramos un total de 22 trabajos que podrían considerarse como estudios de usuarios de información y, de entre todas las revistas, es la Revista Española de Documentación Cientifi$c a$ (con 8 estudios) la que difunde con más frecuencia este tipo de trabajos. Es cierto que la Revista General de Información y Documentación ofrece también un número considerable de estudios (7), aunque hay que tener en cuenta que en gran parte se debe a

63 En pp. 6-34. La autora es Margarita Pérez Pulido, profesora de la Facultad de Biblioteconomía y Documentación de la Universidad de Extremadura. 


\section{Conferencia inaugural}

\begin{tabular}{|c|c|c|c|}
\hline \multicolumn{4}{|c|}{$\begin{array}{c}\text { Figura } 2 \\
\text { Relación de revistas, volúmenes, números } \\
\text { y estudios de usuarios }\end{array}$} \\
\hline Revistas & Volúmenes & Núms. & $\begin{array}{c}\text { Estudios de } \\
\text { usuarios }\end{array}$ \\
\hline A & $\begin{array}{l}24(2001) \\
25(2002) \\
26(2003) \\
27(2004) \\
28(2005) \\
29(2006) \\
30(2007) \\
31(2008)\end{array}$ & $\begin{array}{c}1,2,3,4 \\
1,2,3,4 \\
1,2,3,4 \\
1,2,3,4 \\
1,2,3,4 \\
1,2,3,4 \\
1,2,3,4 \\
1,2 \\
\end{array}$ & $\begin{array}{c}3\left(n^{0} 1 \text { y } 3\right) \\
1\left(n^{0} 1\right) \\
0 \\
1\left(n^{0} 1\right) \\
1\left(n^{0} 3\right) \\
1\left(n^{0} 3\right) \\
1\left(n^{0} 4\right) \\
0 \\
\end{array}$ \\
\hline B & $\begin{array}{l}11(2001) \\
12(2002) \\
13(2003) \\
14(2004) \\
15(2005) \\
16(2006) \\
17(2007)\end{array}$ & $\begin{array}{l}1,2 \\
1,2 \\
1,2 \\
1,2 \\
1,2 \\
1,2 \\
1,2 \\
\end{array}$ & $\begin{array}{c}0 \\
0 \\
1\left(n^{0} 2\right) \\
1\left(n^{0} 1\right) \\
0 \\
1\left(n^{0} 2\right) \\
4\left(n^{0} 2\right) \\
\end{array}$ \\
\hline C & $\begin{array}{l}\text { año } 2001 \\
\text { año } 2002 \\
\text { año } 2003 \\
\text { año } 2004 \\
\text { año } 2005 \\
\text { año } 2006 \\
\text { año } 2007 \\
\text { año } 2008\end{array}$ & $\begin{array}{c}28,29 \\
30,31,32 \\
33,34,35 \\
36,37,38 \\
39,40,41 \\
42,43,44 \\
45,46,47 \\
48\end{array}$ & $\begin{array}{l}0 \\
0 \\
0 \\
0 \\
0 \\
0 \\
0 \\
0\end{array}$ \\
\hline TOTAL & 40 & 107 & 22 \\
\hline \multicolumn{4}{|c|}{$\begin{array}{l}\text { A: Revista Española de Documentación Cientifica (33 criterios) } \\
\text { B: Revista General de Información y Documentación (32 criterios) } \\
\text { C: İtem. Revista de biblioteconomía i documentació ( } 32 \text { criterios) } \\
\text { D: Documentación de las Ciencias de la Información ( } 31 \text { criterios) } \\
\text { E: BiD:Textos universitaris de biblioteconomia i documentació } \\
\text { ( } 30 \text { criterios) } \\
\text { F: Forinf@. Revista Iberoamericana sobre Usuarios de Información } \\
\text { (28 criterios) }\end{array}$} \\
\hline
\end{tabular}


La investigación sobre las necesidades de información en...

\begin{tabular}{|c|c|c|c|}
\hline \multicolumn{4}{|c|}{$\begin{array}{c}\text { Figura } 2 \\
\text { Relación de revistas, volúmenes, números } \\
\text { y estudios de usuarios } \\
\text { (Cont.) }\end{array}$} \\
\hline Revistas & Volúmenes & Núms. & $\begin{array}{c}\text { Estudios de } \\
\text { usuarios }\end{array}$ \\
\hline D & $\begin{array}{l}24(2001) \\
25(2002) \\
26(2003) \\
27(2004) \\
28(2005) \\
29(2006) \\
30(2007)\end{array}$ & $\begin{array}{l}1 \\
1 \\
1 \\
1 \\
1 \\
1 \\
1 \\
1\end{array}$ & $\begin{array}{l}0 \\
0 \\
0 \\
0 \\
0 \\
0 \\
0\end{array}$ \\
\hline$E$ & $\begin{array}{l}\text { año } 2001 \\
\text { año } 2002 \\
\text { año } 2003 \\
\text { año } 2004 \\
\text { año } 2005 \\
\text { año } 2006 \\
\text { año } 2007 \\
\text { año } 2008\end{array}$ & $\begin{array}{c}7 \\
8,9 \\
10,11 \\
12,13 \\
14,15 \\
16,17 \\
18,19 \\
20\end{array}$ & $\begin{array}{c}0 \\
1\left(n^{0} 9\right) \\
1\left(n^{0} 10\right) \\
0 \\
0 \\
1\left(n^{0} 14\right) \\
0 \\
0\end{array}$ \\
\hline $\mathrm{F}$ & $\begin{array}{l}\text { año } 2001 \\
\text { año } 2002 \\
\text { año } 2003 \\
\text { año } 2004 \\
\text { año } 2005 \\
\text { año } 2006\end{array}$ & $\begin{array}{c}11,12,13,14 \\
15,16,17,18 \\
19,21,22 \\
24,25,26 \\
27,28,29,30 \\
31,32,33 \\
\end{array}$ & $\begin{array}{l}2 \\
2 \\
0 \\
0 \\
0 \\
0\end{array}$ \\
\hline TOTAL & 40 & 107 & 22 \\
\hline \multicolumn{4}{|c|}{$\begin{array}{l}\text { A: Revista Española de Documentación Científica ( } 33 \text { criterios) } \\
\text { B: Revista General de Información y Documentación ( } 32 \text { criterios) } \\
\text { C: İtem. Revista de biblioteconomía i documentació ( } 32 \text { criterios) } \\
\text { D: Documentación de las Ciencias de la Información ( } 31 \text { criterios) } \\
\text { E: BiD:Textos universitaris de biblioteconomia i documentació } \\
\text { (30 criterios) } \\
\text { F: Forinf@. Revista Iberoamericana sobre Usuarios de Información } \\
\text { (28 criterios) }\end{array}$} \\
\hline
\end{tabular}


la circunstancia de que se publicaran en ella las ponencias presentadas en unas Jornadas dedicadas al tema. Por otra parte, no parece que exista relación entre el número de estudios publicados y el año en que se publican los distintos volúmenes analizados. El primero no aumenta necesariamente con el paso del tiempo, ni siquiera considerando todas las revistas en su conjunto, como puede verse gráficamente a continuación.

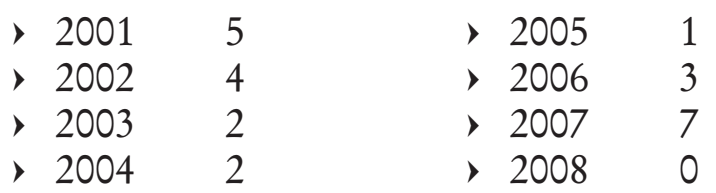

En cuanto a los ítems marcados para estudiar en cada uno de los trabajos, podemos decir, como se puede ver en los cuadros que siguen, que en los estudios dados a conocer en las ponencias presentadas en las Jornadas analizadas es más frecuente la autoría colectiva (13) y que predomina la actuación de un grupo de profesionales de la información (5). En cuanto a los objetivos propuestos en los estudios, vemos que prima el interés por conocer los hábitos y necesidades de información (surgimiento de la necesidad) de los usuarios estudiados (9). El método más empleado es el directo (14), la técnica 
La investigación sobre las necesidades de información en...

la de la encuesta (13) y el instrumento, el cuestionario (13). Cabe decir que es en los artículos de revistas especializadas donde encontramos el uso de la combinación de dos tipos de métodos (directo e indirecto). En cuanto a los usuarios que han contado con mayor interés por parte de los estudios analizados, debemos decir que son los miembros de comunidades de profesionales de otros campos distintos a los habitualmente estudiados, con 7 trabajos dedicados a conocerles.

\begin{tabular}{|c|c|c|c|c|c|c|}
\hline \multicolumn{7}{|c|}{ La Autoría } \\
\hline A & B & C & D & E & $\mathbf{F}$ & G \\
\hline 3 & 4 & 1 & & & & 1 \\
\hline 5 & 1 & & 1 & 2 & 2 & 2 \\
\hline \multicolumn{7}{|c|}{ A: Profesional B y D } \\
\hline \multicolumn{7}{|c|}{ B: Académico B y D } \\
\hline \multicolumn{7}{|c|}{ C. Académico Otras Disciplinas } \\
\hline \multicolumn{7}{|c|}{ D: Académico B y D + Otras Disciplinas } \\
\hline \multicolumn{7}{|c|}{ E. Profesional +Académico B Y D } \\
\hline \multicolumn{7}{|c|}{ F.: Profesional +Académico de Otras Disciplinas. } \\
\hline \multicolumn{7}{|c|}{ G: Gestores } \\
\hline \multicolumn{5}{|c|}{ Número total autor individual } & \multicolumn{2}{|c|}{9} \\
\hline \multicolumn{5}{|c|}{ Número total autor colectivo } & \multicolumn{2}{|c|}{13} \\
\hline
\end{tabular}


Conferencia inaugural

Los objetivos

- Identificación de hábitos y necesidades 9

- Uso de un servicio 2

- Satisfacción respecto a un centro 7

- Satisfacción respecto a fuentes de información 1

- Satisfacción respecto a un servicio 3

\begin{tabular}{||l|c|}
\hline \multicolumn{2}{|c|}{ Métodos } \\
\hline Directo & 14 \\
\hline Indirecto & 5 \\
\hline Directo e indirecto & 3 \\
\hline
\end{tabular}

\begin{tabular}{||l|c||}
\hline \multicolumn{2}{|c|}{ Técnicas } \\
\hline Encuesta & 13 \\
\hline Análisis transacciones usuario/sistema & 5 \\
\hline Entrevista & 1 \\
\hline Encuesta, entrevista, observación & 1 \\
\hline $\begin{array}{l}\text { Encuesta, gestión de sugerencias y reclamaciones, } \\
\text { cliente oculto }\end{array}$ & 1 \\
\hline Encuesta, observación & 1 \\
\hline
\end{tabular}


La investigación sobre las necesidades de información en...

\begin{tabular}{|l|c|}
\hline \multicolumn{2}{|c|}{$\begin{array}{c}\text { Instrumentos } \\
\text { (Algunos, Combinados) }\end{array}$} \\
\hline Cuestionario & 13 \\
\hline Registro/inventario & 5 \\
\hline Guión entrevista & 1 \\
\hline Cuestionario, registro, informe de auditoria & 1 \\
\hline Cuestionario, guión para observación & 1 \\
\hline $\begin{array}{l}\text { Cuestionario, guión entrevista, guión para ob- } \\
\text { servación }\end{array}$ & 1 \\
\hline
\end{tabular}

\begin{tabular}{||l|l||}
\hline \multicolumn{2}{|c||}{ Usuarios Estudiados } \\
\hline Docentes, investigadores & $\begin{array}{l}5 \text { (Usuarios base de datos ISOC), } \\
\text { (Áreas de Humanidades y Cien- } \\
\text { cias Sociales), (2 de investigado- } \\
\text { res de archivos), (Área Ciencias } \\
\text { de la Vida) }\end{array}$ \\
\hline Estudiantes universitarios & 1 \\
\hline Comunidad universitaria & 4 \\
\hline Profesionales de otros & $\begin{array}{l}7 \text { (Periodistas de T.V.), (Distintas } \\
\text { empresas), (Personal de hospital } \\
\text { 3), (Médicos), (Empresa farma- } \\
\text { céutica) }\end{array}$ \\
\hline Público en general & $\begin{array}{l}5 \text { (Instituto Cervantes, Caja Ma- } \\
\text { drid, prisiones, 2 de bibliotecas } \\
\text { públicas) }\end{array}$ \\
\hline
\end{tabular}




\section{Algunas conclusiones en cifras}

Tras el análisis que se ha llevado a cabo de 1008 trabajos de entre 339 comunicaciones a congresos contenidas en 13 actas y 669 artículos incluidos en 107 volúmenes o números de revistas especializadas, se puede decir que son tan sólo 36 los que identificamos como estudios de usuarios de información, esto es, el 3,57\%. Considerándolos en su totalidad, podemos afirmar que la proporción de estudios publicados es superior en Jornadas que en Revistas especializadas, aunque en una proporción poco significativa ya que las ponencias-estudio suponen el 4,12\% (14 de 339 comunicaciones) y los artículos-estudio el 3,28\% (22 de 669 artículos de revistas) del total analizado en cada fuente. En cuanto a la autoría, predominan los trabajos de autoría colectiva (23 frente a 13 ; el 63,88\%) y obra de profesionales de la información ( 15 a solas y 8 en colaboración con docentes universitarios). Por otra parte, aunque analizados por fuentes advertimos que el interés de los estudios se centra bien en el conocimiento del uso (conducta) bien en el de hábitos y necesidades de información de los usuarios (surgimiento), según sean ponencias o artículos respectivamente, al considerar los 36 estudios globalmente advertimos que la mayoría de ellos (15; esto es, el $41,66 \%)$ se realizan para medir la satisfacción del 
La investigación sobre las necesidades de información en...

usuario respecto a un centro, un servicio o una fuente de información. Se trata de trabajos de naturaleza aplicada. Queda claro que el método que más se utiliza es el directo ( 25 trabajos; esto es, el $69,44 \%$; que la técnica más empleada es la de la encuesta (22; esto es, el 61,11\%) y que el instrumento (o herramienta) más manejado es el cuestionario (23; esto es, el 63,88\%). Por último, podemos decir que la comunidad de usuarios más estudiada es la universitaria (10; esto es, el 27,77\%), seguida de la de profesionales de otros ámbitos distintos a los estudiados anteriormente (9; esto es, el 25\%), docentes e investigadores (7; esto es, el 19,44\%), público en general (6; esto es, el 16,66\%), profesionales de la información (2; esto es, el 5,55\%) y público infantil-juvenil (2; esto es, el 5,55\%).

\section{Referencias bibliográficas}

XII Jornadas Bibliotecarias de Andalucía. Los nuevos retos de los servicios bibliotecarios. Málaga: Asociación Andaluza de Bibliotecarios, 2002.

VIII Jornadas de Gestión de la Información. Nuevas interfaces centradas en el usuario: tendencias en la organización de contenidos, documentos y bibliotecas. Madrid: SEDIC, 2006.

IX Jornadas españolas de Documentación. FESABID 2005. Infogestión. Madrid: FESABID, 2005. 
X Jornadas españolas de Documentación. E-información: integración y rentabilidad en un entorno digital. Madrid: FESABID, 2007.

9es. Jornades d'Informació i Documentació. Barcelona: Col.legi oficial de Bibliotecaris-Documentalistes de Catalunya, 2004.

Calva González, J.J.: "Las necesidades de información: la difusión de estudios en las Jornadas Mexicanas de Biblioteconomía”, en Forinf@, no 15, 2002, pp. 9-22

Cuartas Jornadas Bibliotecarias de la Comunidad de Madrid. Madrid: Consejería de Cultura y Deportes, 2004.

Delgado López Cózar, E.: "Los métodos de investigación empleados en la literatura científica producida en Biblioteconomía y Documentación”, en Primer congreso universitario de Ciencias de la Documentación. Madrid: UCM, 2000, pp. 625-641.

Delgado López Cózar, E.: La investigación en Biblioteconomía y Documentación. Gijón: Trea, 2002.

Delgado López Cózar, E.: “La investigación por encuesta en la biblioteconomía y documentación española: análisis de las encuestas publicadas en revistas y congresos de la especialidad entre 1976 y 1997", en Metodología de investigación en Información y Documentación. Salamanca: Universidad, 2002, pp. 71-135. 
La investigación sobre las necesidades de información en...

DICE. Difusión y Calidad Editorial de las Revistas Españolas de Humanidades y Ciencias Sociales y Jurídicas (http://dice.cindoc.csic.es) [Consulta: 20-05-2008].

RESH. Revistas españolas de Ciencias Sociales y Humanas. (http://resh.cindoc.csic.es/index.php) [Consulta: 20-05-2008].

Rey, C.: "La aplicación de los estudios de satisfacción de usuarios en la biblioteca universitaria: el caso de las universidades catalanas”, en BiD, vol.3, desembre, 1999. (http://www2.ub.es/bid/consulta_articulos. php?fichero=03rey.htm) [Consulta: 08-06-2008].

Rodríguez Gallardo, Adolfo: "De la práctica a la investigación”, en La investigación bibliotecológica en la era de la información. Memoria del XXI Coloquio de Investigación Bibliotecológica y de la información. 24-26 de septiembre de 2003. Compiladores Filiberto Felipe Martínez Arellano, Juan José Calva González. México: UNAM, 2004, pp. 3-21.

Rodríguez Yunta, J.; Tejada Artigas, C.: "Recursos de Internet sobre desarrollo profesional en Documentación: 4. Reuniones científicas, congresos, jornadas, simposios y seminarios en España" en Revista Española de Documentación Científica, 29, 1, 2006, pp.153-173.

Terceras Jornadas Bibliotecarias de la Comunidad de Madrid. Madrid; Las Rozas: Consejería de las Artes: Concejalía de Cultura. 


\section{Anexo \\ Títulos de los trabajos identificados como estudios de usuarios de información}

\section{Ponencias en Jornadas}

1. "Diseño de un plan de formación de usuarios como estrategia de difusión de recursos electrónicos. Propuesta metodológica basada en un estudio de caso".

2. "El impacto de los archivos de e-prints en la comunicación científica entre los investigadores españoles: aceptación y uso".

3. "Los usuarios de información en las organizaciones empresariales: Un estudio de caso".

4. "El usuario en PoliBuscador. Un nuevo modelo de evaluación en la Biblioteca Digital”.

5. "Midiendo la satisfacción de usuarios para mejorar la calidad en las bibliotecas universitarias".

6. "Evaluación heurística y pruebas con usuarios: aplicación a interfaces de bases de datos terminológicas".

7. "Blogs y usabilidad: el caso del blog de SEDIC".

8. "Experiències i perspectives dels professionals de la informació respecte als recursos electrònics: els resultats d'una enquesta” . 
La investigación sobre las necesidades de información en...

9. “PaB24x7: una experiencia del Servei d'Informació i Referencia Virtual a la Biblioteca de la Universitat de Barcelona”.

10. "La base de dades de sumaris del CBUC: anàlisi global del seu ús i de la relació entre la utilització del seu servei de subscripcions per correu electrònic i el consum d'articles i sumaris d'un paquet de revistes electròniques".

11. "Encuesta de uso y valoración de la biblioteca universitaria de Almería".

12. "Metodología evaluativa del servicio de préstamo de la biblioteca pública infantil Jorge Juan de Novelda (Alicante)".

13. "Los Opac y la formación de usuarios".

14. "Las demandas de usuarios en las Bibliotecas Públicas de la Comunidad de Madrid".

\section{Artículos en revistas especializadas}

1. "Análisis de uso de las bases de datos de la biblioteca de la Universidad Carlos III de Madrid".

2. "Demanda de información de actualidad en un servicio de referencia periodística. Análisis descriptivo de 4.160 solicitudes".

3. "Evaluación de la base de datos ISOC a través de un estudio de usuarios. Homenaje a José María Sánchez Nistal”. 
4. "La biblioteca de la Universidade da Coruña. Estudio con los alumnos".

5. "Productores de información interesantes para las empresas. Resultados de una encuesta sobre consumo de información a empresas de la Comunidad de Madrid".

6. "Estudio sobre la satisfacción de los usuarios de la biblioteca del Hospital Universitario Puerta de Hierro".

7. "Presente y futuro de los servicios de las bibliotecas médicas. Revisión de la literatura y estudio realizado en un hospital de más de 1.400 camas".

8. "La herramienta «BiQual» como instrumento para el estudio de la calidad del servicio en bibliotecas universitarias españolas de ciencia y tecnología”.

9. "Las necesidades de información de los investigadores del área de Humanidades y Ciencias Sociales".

10. "Evaluación de hemerotecas electrónicas: resultados de un estudio de usuarios realizado en la Hemeroteca Electrónica de la Facultad de Ciencias de la Información de la Universidad Complutense".

11. "Los archivos históricos provinciales: estudio de usuarios aplicado en Jaén".

12. "Estudio de satisfacción de usuarios en la red de bibliotecas del Instituto Cervantes”. 
La investigación sobre las necesidades de información en...

13. "Nuevas técnicas de estudios de usuarios aplicadas a bibliotecas".

14. "Estudio sobre la satisfacción de los usuarios de una biblioteca hospitalaria".

15. "Usuarios de información pública de la ciudad de Jaén (1976-1996)".

16. "El web de la Biblioteca de la Universitat Pompeu Fabra: un disseny orientat a l'usuari".

17. "Avaluació de la satisfacció dels usuaris de les biblioteques publiques".

18. "L'ús i la satisfacció dels usuaris de les biblioteques públiques en municipis de més de 30.000 habitants".

19. "Hábitos y necesidades de información de los investigadores españoles en Ciencias de la Vida: Un estudio de las peticiones realizadas al Centro de Información y Documentación Científica".

20. "La entrevista personal: método para el estudio de usuarios de información".

21. "Bibliotecas hospitalarias: ¿satisfacción de usuarios remotos?".

22. "Análisis de la percepción de una biblioteca de prisión por parte de la comunidad reclusa: propuesta metodológica basada en un estudio de caso". 
Comunidades de investigadores universitarios 


\title{
La medición de la satisfacción del científico matemático en el uso de algunas fuentes de información y servicios bibliotecarios
}

\author{
ANGÉlica GueVARA VillanUeVA \\ Colegio de Bibliotecología \\ Universidad Nacional Autónoma de México
}

\section{Introducción}

T a razón de ser de la presente investigación es el $\mathcal{L}$ dar cobertura al vacío de estudios sobre el tópico relacionado con la satisfacción en el uso de algunas fuentes de información y servicios bibliotecarios de la comunidad de investigadores-profesores del área de las matemáticas. De esta forma, el trabajo no sólo pretende dar un resultado en sí mismo, sino que intenta vincular la atención en dos campos específicos como es la bibliotecología y el área matemática, para que a partir de la información que se desprenda existan elementos para el diseño de futuras unidades de información del área en cuestión y se ofrezcan novedosos y acordes servicios bibliotecarios y de información a los investigadores que están relacionados con las matemáticas. 
La investigación sobre las necesidades de información en...

\section{Antecedentes}

A manera de antecedente sobre las investigaciones que se han realizado a nivel internacional como nacional, se puede destacar que, en la línea de la satisfacción referente a la comunidad matemática, éstas han sido escasas, sin embargo, existen algunos trabajos como el de Kirsch, 1979; Brown, 1999; Hernández, 2001; Bérard, 2002; Vigeannel, 2002; Fowler, 2004 y Macías, 2006 que estudian algunos aspectos relacionados con las necesidades de información y el comportamiento informativo de estos investigadores.

Por lo que la especificidad de un estudio sobre la satisfacción dirigido en nuestro país en el área de las matemáticas, es hasta el momento una línea fresca y poco abordada en investigaciones de fondo.

Con base en estos argumentos y debido a la escasa literatura en nuestro país, es preciso subrayar que el estudio derivó del siguiente cuestionamiento: ¿En qué medida las fuentes de información y los servicios bibliotecarios utilizados por la comunidad de científicos del área matemática han permitido cubrir satisfactoriamente sus necesidades de información? 


\section{Objetivos}

De esta manera, al desarrollar la investigación, se pretendió como objetivo general determinar el grado en que las fuentes de información y los servicios bibliotecarios satisfacen las necesidades de información de los investigadores- profesores en el área de las matemáticas.

\section{Hipótesis}

Tomando en consideración que la comunidad matemática utiliza información para el desarrollo de sus investigaciones, y que de ésta depende el éxito o fracaso para la conclusión de sus proyectos, encontramos que la satisfacción de las necesidades de información esta determinada por el tipo de fuente de información que utiliza el investigador-profesor para satisfacer sus necesidades.

\section{Marco de Referencia}

Para la realización de la investigación se contempló, como objeto de estudio, a la población total de los investigadores-profesores matemáticos que comprende a 513 sujetos que se distribuyen en 24 departamentos, escuelas e institutos educativos (Catálogo, 2000 y Atlas, 2008) localizados en el Distrito Federal como en el interior de la república (ver Anexo 1). 
La investigación sobre las necesidades de información en...

Ahora bien, dentro de las características esenciales que distinguió a la población objeto de estudio, fueron las siguientes:

1. Profesores de tiempo completo e investigadores de tiempo completo.

2. Poseer el grado académico de nivel maestría y/o doctorado. ${ }^{1}$

3. Impartir al menos cuatro horas de docencia.

4. Que estén ejerciendo actualmente sus actividades profesionales.

5. Que pertenezcan a instituciones públicas.

6. Con género indistinto.

7. Con nacionalidad indistinta pero que estén trabajando actualmente en el momento de la investigación en alguna de las instituciones o centros referidos.

\section{Muestra}

Por el número de éstos, no se tomó una muestra de la población de investigadores, sino que se optó por abordar a la población en su conjunto de acuerdo a las características que se han señalado, debido a que se pretendió obtener el mayor número de respues-

1 Para este estudio se decidió seleccionar ambos grados - maestría y doctorado-, puesto que su formación académica profesional brinda los conocimientos requeridos para contribuir a la producción del conocimiento universal. 
tas posibles, y con ello fortalecer la información que se deseó recuperar para fines de la investigación. Esto se decidió porque en experiencias anteriores se identificó que los investigadores disponen de un tiempo limitado que les hace casi imposible atender las interrogantes correspondientes.

\section{Metodología}

A partir del reconocimiento de la población total, se seleccionó el método de estudios de usuarios, y adicionalmente el método cuantitativo y descriptivo que orientó la recuperación de información de los sujetos como unidades de análisis; conforme a los cuáles se identificó: el nivel de satisfacción en sus necesidades de información.

Por las características de nuestro objeto de estudio y como medio que garantiza el acopio, procesamiento y análisis de la información, se retomó como técnica de investigación el censo; mediante el cual se intentó obtener el mayor número de respuestas por parte de los investigadores en el área matemática. A su vez, se determinó establecer como instrumento de investigación el cuestionario, (ver Anexo 2) puesto que se consideró como un medio confiable, útil y eficaz para recoger información en un tiempo relativamente breve y con la posibilidad de abarcar un área geográfica extensa. Para con ello, obtener mediciones de las características de la población que res- 
La investigación sobre las necesidades de información en...

pondan a un objetivo y a la validación de la hipótesis, y así, tener los elementos necesarios que contribuyan al desarrollo del estudio.

Por lo cual, el cuestionario se diseñó y se puso a prueba con 30 investigadores del Instituto de Matemáticas de la Universidad Nacional Autónoma de México. Para evitar contratiempos en las futuras respuestas y asegurar que todas las variables pertinentes fueran incluidas, después de hacer algunas modificaciones mínimas, el cuestionario fue enviado, como primera alternativa, vía correo electrónico a cada investigador, y como segunda, a través del correo ordinario. Para ello, se determinó establecer un período en la devolución de los cuestionarios, el cual contempló 15 días hábiles, pero previendo que la devolución por correo electrónico no se diera en este plazo, se procedió a reenviarlo, vía correo ordinario, a aquellos investigadores que no proporcionaron las respuestas por correo electrónico, y para lo cual, se estableció el mismo plazo de tiempo.

Una vez que se devolvieron los cuestionarios, por parte de los investigadores, se procedió al análisis y evaluación correspondiente de las respuestas proporcionadas. 


\section{Resultados}

De 513 cuestionarios enviados, sólo fueron devueltos 317 debidamente llenados por los sujetos de investigación, lo que representó el $61.7 \%$ del total que conformaban las características señaladas de la población a estudiar. Para realizar el análisis de las respuestas, los cuestionarios fueron codificados y capturados en una base de datos que se realizó para tal fin.

\section{Análisis de los resultados}

Los resultados que se obtuvieron al analizar cada uno de los cuestionarios, fueron los que a continuación se expresan.

Entre las características que mayor saltan a la vista para la satisfacción a sus necesidades de información, los investigadores destacan que la disponibili$\operatorname{dad}^{2}(30 \%)$, la accesibilidad (23\%) y la actualidad $(13 \%)$ son rasgos esenciales para dar cobertura a la satisfacción de sus necesidades; (Ver Tabla 1) es de-

2 Disponibilidad (que esté listo por sí se necesita); Accesibilidad (que esté en el lugar adecuado); Actualidad (que sea lo último que ha aparecido); Oportunidad (que esté listo en el momento que se necesita); Pertinencia (Que trate sobre el asunto que se investiga); Relevancia (que sea importante para la actividad que se realiza) y Calidad (que contenga un formato, tamaño, presentación, etcétera). 
La investigación sobre las necesidades de información en...

cir, que los documentos deben de estar listos en el momento que se necesitan, que se encuentren en su lugar y que sean actuales. Esta respuesta resulta normal si se comprende que los investigadores generalmente disponen de un tiempo limitado, ya que su trabajo exige demasiadas horas dedicadas a su trabajo que lo agobian, $y$, por lo tanto, plantean la necesidad de que el documento al cual acuden tenga las características anteriormente señaladas.

\begin{tabular}{|l|c|c|c|c|c|c|c|c|c||}
\hline \multicolumn{10}{|c|}{ Tabla 1 } \\
Orden de importancia de las características que \\
debe poseer el documento para la satisfacción \\
de las necesidades de información \\
de los investigadores
\end{tabular}


En cuanto a la satisfacción de sus necesidades de información a través del uso de dos bases de datos especializadas, se encuentra que el MathSciNet cubre parcialmente un $64 \%$ de su satisfacción, el $18 \%$ considera que la satisfacción es cubierta totalmente, y el 14\% satisfecha escasamente su necesidad con el uso de la base de datos (ver Tabla 2).

\begin{tabular}{||l|c|c|}
\hline \multicolumn{3}{|c|}{$\begin{array}{c}\text { Tabla } 2 \\
\text { Medida en que las bases de datos especializadas } \\
\text { satisfacen sus necesidades de información: } \\
\text { MathSciNet }\end{array}$} \\
\hline $\begin{array}{c}\text { MathSciNet } \\
\text { Medida }\end{array}$ & $\begin{array}{c}\text { Número de } \\
\text { investigadores }\end{array}$ & $\%$ \\
\hline Totalmente & 57 & 18 \\
\hline Parcialmente & 204 & 64 \\
\hline Escasamente & 44 & 14 \\
\hline Nunca & 12 & 4 \\
\hline Total & 317 & 100 \\
\hline \hline
\end{tabular}

Con relación al empleo del Zentralblatt MATH los resultados arrojados muestran que el $73 \%$ de los investigadores se encuentran parcialmente satisfechos al hacer uso de ésta, 19\% totalmente se encuentra satisfecho y sólo el $6 \%$ escasamente satisface sus necesidades de información (Ver Tabla 3). 
La investigación sobre las necesidades de información en...

\begin{tabular}{|c|c|c|}
\hline \multicolumn{3}{|c|}{$\begin{array}{c}\text { Tabla } 3 \\
\text { Medida en que las bases de datos especializadas } \\
\text { satisfacen sus necesidades de información: } \\
\text { Zentralblatt MATH }\end{array}$} \\
\hline $\begin{array}{c}\text { Zentralblatt MATH } \\
\text { Medida }\end{array}$ & $\begin{array}{c}\text { Número de } \\
\text { investigadores }\end{array}$ & $\%$ \\
\hline Totalmente & 62 & 19 \\
\hline Parcialmente & 230 & 73 \\
\hline Escasamente & 18 & 6 \\
\hline Nunca & 7 & 2 \\
\hline Total & 317 & 100 \\
\hline
\end{tabular}

Por lo datos obtenidos, se podría pensar, como una posibilidad, que la presencia de otros medios alternativos -colegas, Internet, publicaciones periódicas, etcétera- suplen el vacío de información al cual no logran dar cobertura las bases de datos especializadas en matemáticas, por lo que se sugiere tomar en consideración el llevar a cabo estudios de usuarios de las necesidades reales de información de los investigadores a los que ofrecen sus productos, y de esta forma, redefinir, si es necesario, su diseño, contenido, estrategias de búsquedas, etcétera. Aunque también no hay que olvidar que existen factores internos (Calva González, 2004. p. 114) que influyen sobre el grado de satisfacción que puede tener una persona con respecto al uso de éstas fuentes de información. Pudiendo ser algunos de estos factores, tales como: habilidades o capacidad para 
usar las herramientas informativas, la experiencia del sujeto en la búsqueda de información, conocimientos sobre el tema e idiomas que maneja.

De acuerdo a la pregunta que se les formuló a esta comunidad de investigadores sobre el diseño, presentación y contenido de los catálogos automatizados de las bibliotecas (UNAM; CINVESTAV; CIMAT; etcétera), de los 317 censados, el 41\% de éstos reportó que los catálogos automatizados para buscar y localizar información satisfacen sus necesidades de información de una manera aceptable; $28 \%$ de forma excelente y $17 \%$ de modo regular (Ver Tabla 4).

\begin{tabular}{||l|c|c|}
\hline \multicolumn{3}{|c|}{$\begin{array}{c}\text { Tabla } 4 \\
\text { Porcentaje en que el diseño y contenido de los ca- } \\
\text { tálogos automatizados de las bibliotecas satisfa- } \\
\text { cen sus necesidades de información }\end{array}$} \\
\hline \multicolumn{1}{|c|}{ Porcentaje } & $\begin{array}{c}\text { Número de } \\
\text { investigadores }\end{array}$ & $\%$ \\
\hline $0 \%$ (nulo) & 3 & 1 \\
\hline $25 \%$ (deficiente) & 41 & 13 \\
\hline $50 \%$ (regular) & 53 & 17 \\
\hline $75 \%$ (aceptable) & 131 & 41 \\
\hline $100 \%$ (excelente) & 89 & 28 \\
\hline Total & 317 & 100 \\
\hline \hline
\end{tabular}


La investigación sobre las necesidades de información en...

Por esta tendencia se puede advertir que el diseño, presentación y el contenido de los catálogos automatizados, resultan favorables para el desarrollo de las investigaciones u otras actividades de los investigadores de matemáticas, logrando de esta manera obtener un grado de satisfacción hacia la búsqueda de la información

De los servicios de información y bibliográficos podemos mencionar que suelen ofrecer las bibliotecas para la satisfacción de las necesidades de información de los investigadores, éstos señalaron su amplia preferencia $(48 \%)$ por el acceso directo a revistas electrónicas, en un número menor $(20 \%)$ señalaron que la exhibición de nuevas adquisiciones se ubica en un segundo lugar y que el libro a vistas $(14 \%)$ también mantiene un nivel de preferencia entre ellos (Ver Tabla 5).

Por los datos de la Tabla 5 se puede detectar que los servicios de información que proporciona la biblioteca en colaboración con los proveedores no pasan inadvertidos y más bien favorecen la satisfacción de necesidades de información al permitir que los investigadores puedan obtener el artículo en el momento que lo necesitan, sin tener que trasladarse de un lugar a otro, esperar ser atendidos en su necesidad y perder tiempo para obtener las fotocopias del artículo. 
Comunidades de investigadores universitarios

\begin{tabular}{|l|c|c||}
\hline \multicolumn{1}{|c|}{ Tabla 5} \\
\multicolumn{1}{|c|}{$\begin{array}{c}\text { Servicios de información y bibliográficos que satisfacen sus } \\
\text { necesidades de información }\end{array}$} \\
\hline $\begin{array}{c}\text { Número de } \\
\text { investigadores }\end{array}$ & $\%$ \\
\hline Exhibición de nuevas adquisiciones & 65 & 20 \\
\hline $\begin{array}{l}\text { Accesibilidad directa a artículos en } \\
\text { revistas electrónicas }\end{array}$ & 151 & 48 \\
\hline Libros a vistas & 43 & 14 \\
\hline Catálogos impresos & 8 & 2 \\
\hline Servicio de alerta bibliográfica & 21 & 7 \\
\hline Boletines & 19 & 6 \\
\hline Búsquedas en índices y/o abstracts & 2 & 1 \\
\hline Otro & 0 & 0 \\
\hline No contestó & 8 & 2 \\
\hline Total & 317 & 100 \\
\hline
\end{tabular}

Finalmente, al preguntar a los investigadores sobre el nivel de satisfacción que tienen al hacer uso de algunas fuentes informativas, esto fue lo que se obtuvo (ver Tabla 6). 
La investigación sobre las necesidades de información en...

\begin{tabular}{|c|c|c|c|}
\hline \multicolumn{4}{|c|}{$\begin{array}{c}\text { Tabla } 6 \\
\text { Nivel de satisfacción al hacer uso de algunas } \\
\text { fuentes informativas }\end{array}$} \\
\hline Fuente informativa & \multicolumn{2}{|c|}{$\begin{array}{c}\text { Nivel de satisfacción } \\
(\%)\end{array}$} & $\begin{array}{c}\text { Número de } \\
\text { investigadores }\end{array}$ \\
\hline \multirow{4}{*}{ Monografías } & Totalmente & $17 \%$ & 55 \\
\hline & Parcialmente & $71 \%$ & 226 \\
\hline & Escasamente & $12 \%$ & 36 \\
\hline & Nunca & $0 \%$ & 0 \\
\hline \multirow{4}{*}{ Publicaciones periódicas } & Totalmente & $94 \%$ & 298 \\
\hline & Parcialmente & $4 \%$ & 14 \\
\hline & Escasamente & $2 \%$ & 5 \\
\hline & Nunca & $0 \%$ & 0 \\
\hline \multirow{4}{*}{ Obras de consulta } & Totalmente & $1 \%$ & 2 \\
\hline & Parcialmente & $2 \%$ & 6 \\
\hline & Escasamente & $80 \%$ & 254 \\
\hline & Nunca & $17 \%$ & 55 \\
\hline \multirow{4}{*}{ Fuentes referenciales } & Totalmente & $4 \%$ & 13 \\
\hline & Parcialmente & $94 \%$ & 298 \\
\hline & Escasamente & $2 \%$ & 6 \\
\hline & Nunca & $0 \%$ & 0 \\
\hline \multirow{4}{*}{ Materiales audiovisuales } & Totalmente & $0 \%$ & 0 \\
\hline & Parcialmente & $0 \%$ & 0 \\
\hline & Escasamente & $1 \%$ & 4 \\
\hline & Nunca & $99 \%$ & 313 \\
\hline
\end{tabular}


- En cuanto a las monografías, el 71\% de la comunidad contestó que se siente parcialmente satisfecho al utilizar éstos materiales, el 17\% respondió que totalmente se encuentra satisfecho y sólo el $12 \%$ se encuentra escasamente satisfecho.

- Con el empleo de las publicaciones periódicas se tiene que el $94 \%$ de los investigadores se encuentra totalmente satisfecho con el empleo de esta fuente informativa, $4 \%$ parcialmente y el $2 \%$ escasamente.

- Sobre las obras de consulta los resultados arrojados fueron que el $80 \%$ de los matemáticos, escasamente logran satisfacer sus necesidades de información al utilizar las obras, $17 \%$ menciona que nunca ha quedad satisfecho al emplear éstos materiales y sólo $2 \%$ parcialmente esta satisfecho.

- En la práctica de utilizar las fuentes referenciales los resultados obtenidos fueron, $94 \%$ de los científicos parcialmente determinaron que se encuentran satisfechos, el $4 \%$ totalmente satisfechos y el $2 \%$ escasamente satisfechos.

- Por último, se encuentra los materiales audiovisuales, los datos obtenidos con este respecto fueron que el $99 \%$ no se siente satisfecho con el uso de esta fuente de información y sólo el 1\% escasamente lo esta. 
La investigación sobre las necesidades de información en...

A decir de los datos presentados en la Tabla 6, se podría creer, que la tradición científica de comunicar los resultados a través de los artículos científicos puede influir de alguna manera, sobre la preferencia hacia el uso de éstos materiales, por lo que, el nivel de satisfacción, evidentemente resulta mayor. En cuanto a las monografías, quizás una de las razones esté en función de los tiempos de publicación, porque a diferencia de las revistas éstas tardan un tiempo relativamente mayor en su edición. Con relación a las fuentes referenciales, se puede suponer, que por ser herramientas secundarias que en general compilan los datos de las fuentes primarias, éstas siempre tendrán un nivel de satisfacción parcial. Finalmente, el uso de las obras de consulta y los materiales audiovisuales se hará presente cuando se trate de resolver dudas específicas o de apoyo en la enseñanza de las matemáticas por lo que el nivel de satisfacción obviamente resulta en un nivel sumamente bajo.

\section{Discusión}

En la satisfacción de las necesidades de información, los investigadores en matemáticas parecen concordar con investigadores de otras disciplinas; de esto, Bichteler y Dederich (1989, p. 170) son certeros al subrayar estas características como ineludible en cualquier comunidad de investigadores. Así, 
la disponibilidad y la accesibilidad son rasgos esenciales y preferentes entre los investigadores matemáticos para calificar la satisfacción de sus necesidades de información.

De igual trascendencia resulta que un alto porcentaje de investigadores, indicaron que las bases de datos especializadas sólo satisfacen parcialmente sus necesidades de información. De esta manera, algunos estudios como el de Vigeannel-Larive (2002, p. 54) y Brown (1999, p. 931), establecen que el uso de las bases de datos no siempre figura en los niveles de preferencia de los investigadores en matemáticas, y esto, debido a varios factores, entre ellos: la actualización de las bases de datos especializadas que pareciera no ir al mismo ritmo que presenta la dinámica de producción del conocimiento en esta comunidad y, otra, a causa de no poder acceder de manera directa a los artículos científicos debido a que se tiene que tener una suscripción vigente.

Paralelamente a esto, el porcentaje de satisfacción de necesidades de información, a través del diseño, presentación y contenido de los catálogos automatizados, no logró alcanzar la excelencia. Así, estudios similares realizados por Brown (1999, p. 931) y Vigeannel-Larive (2002, p. 54) han ratificado que la preferencia por los catálogos de bibliotecas ocupan un segundo puesto de interés en la búsqueda de información de esta comunidad; esto puede 
La investigación sobre las necesidades de información en...

ser consecuencia de un desconocimiento, por parte de los diseñadores de estos programas -y de su escasa comunicación con los profesionales de la bibliotecología-, quienes, posiblemente, retoman las necesidades para la elaboración de los catálogos, de otras comunidades científicas distintas a la de los matemáticos, y dan por hecho que, a partir del estudio de algunos usuarios, las necesidades son generales para todo tipo de comunidades; lo cual en la práctica no siempre resulta objetivo, ya que si esto fuera así, no existiría indiferencia hacia la utilización de los programas de cómputo para satisfacer sus necesidades de información;

Con relación a los servicios de información y bibliográficos, la accesibilidad directa al artículo en revistas fue ponderada con un porcentaje considerable dentro de esta comunidad de matemáticos. Con esto se confirma que la tendencia en la satisfacción con artículos científicos cada vez se incrementará, como lo advierte Brown (1999, p. 931).

Finalmente, los niveles de satisfacción obtenidos por el empleo de las fuentes informativas destacan un porcentaje elevado hacia el uso de las publicaciones periódicas, enunciado que permite creer que, por el tipo de investigación que realizan, ésta, suele ser una excelente fuente que le permite llegar a la terminación de las investigaciones que realizan. 


\section{Conclusiones}

A decir de los datos presentados se puede determinar que, para la comunidad matemática nacional, la disponibilidad, la accesibilidad y la actualidad son características esenciales que debe poseer el documento para dar cobertura a la satisfacción de sus necesidades de información.

Referente a la hipótesis se logró comprobar que: la satisfacción de necesidades de información ciertamente está determinada por el tipo de fuente informativa que utiliza el investigador para satisfacer sus necesidades. Esto fue ratificado al observar que su tendencia favoreció, de manera total, la utilización de las publicaciones periódicas como fuente informativa que satisface las necesidades en la búsqueda de información, por lo cual es comprensible, que de la amplia gama de servicios de información y bibliográficos, exista una mayor respuesta hacia la accesibilidad directa a los artículos de revistas científicas electrónicas.

Entre esta comunidad, asimismo, se pudo apreciar que las bases de datos especializadas y las fuentes referenciales en el mayor número de los casos, satisfacen de manera parcial las necesidades de información, lo que hace suponer que, por la naturaleza de éstas, difícilmente la comunidad podrá satisfacer totalmente sus necesidades. 
La investigación sobre las necesidades de información en...

\section{Obras consultadas}

Atlas de la ciencia mexicana. Academia Mexicana de Ciencias. México: La Academia, 2008. [en línea]. Disponibilidad: http://www.amc.unam.mx/atlas.htm Fecha de consulta: 24, julio, 2008.

Bérard, Pierre. "Documentation issues for mathematics in the digital age." Inspel. Vol. 36, no. 3, 2002. p. $147-167$.

Bichteler, J. y Dederich, W. "Information-seeking behavior of geoscientists”. Special Libraries. Vol. 80, no. 3, winter, 1989. p. 170.

Brown, Cecelia. "Information seeking behavior of scientists in the electronic information age: astronomers, chemists, mathematicians, and physicists". Journal of the American Society for Information Sciences. Vol. 59, no. 10, 1999. p. 929-943.

Calva Gonzalez, Juan José. Las necesidades de información: fundamentos teóricos y métodos. México: UNAM, CUIB, 2004. 284 p.

Catálogo 1997-1999 de programas y recursos bumanos en matemáticas de instituciones académicas nacionales. México: Sociedad Matemática Mexicana, 2000.157 p. 
Hernández Salazar, Patricia. "La producción del conocimiento científico como base para determinar perfiles de usuarios". Investigación bibliotecológica. Vol. 15, No. 30, 2001. pp. 29-64.

Kirsch Schaefer, Barbara. Using the mathematical literature: a practical guide. New York: Marcel Dekker, 1979. $141 \mathrm{p}$.

Macías Virgos, Enrique. La importancia de las bases de datos en matemáticas. [en línea]. Disponibilidad: http://oro1.usc.es/ xtquique/ESLM_actas_v5.pdf Fecha de consulta: 24 de julio, 2008.

Vigeannel-Larive, Odile. "La bibliotheque, laboratoire du mathématicien." Bulletin des Bibliotheques de France. Vol. 47, no. 6, 2002. p. 50-54.

Using the mathematics literature. Fowler, Kristine K. (ed). New York: Marcel Dekker, 2004. 381 p. 
La investigación sobre las necesidades de información en...

\section{Anexo 1}

\begin{tabular}{|c|c|c|}
\hline Institución & $\begin{array}{l}\text { Centro, Departamento, } \\
\text { Escuela o Instituto }\end{array}$ & Planta académica \\
\hline $\begin{array}{l}\text { Universidad Autónoma de } \\
\text { Coahuila (UAdeC) }\end{array}$ & $\begin{array}{l}\text { Centro de Investigación en Matemá- } \\
\text { ticas Aplicadas (CIMA) }\end{array}$ & 7 investigadores \\
\hline $\begin{array}{l}\text { Instituto Politécnico Nacional } \\
\text { (IPN) }\end{array}$ & $\begin{array}{l}\text { Escuela Superior de Física y } \\
\text { Matemáticas }\end{array}$ & 9 profesores \\
\hline \multirow[b]{2}{*}{$\begin{array}{l}\text { Centro de Investigación y Estu- } \\
\text { dios Avanzados (CINVESTAV) }\end{array}$} & Departamento de matemáticas & 21 investigadores \\
\hline & $\begin{array}{l}\text { Departamento de Matemática } \\
\text { Educativa }\end{array}$ & 28 investigadores \\
\hline $\begin{array}{l}\text { Universidad Autónoma Metropoli- } \\
\text { tana Iztapalapa (UAM-I) }\end{array}$ & Departamento de Matemáticas & $\begin{array}{l}21 \text { profesores-investiga- } \\
\text { dores }\end{array}$ \\
\hline \multirow{5}{*}{$\begin{array}{l}\text { Universidad Nacional Autónoma } \\
\text { de México (UNAM) }\end{array}$} & $\begin{array}{l}\text { Facultad de Ciencias. } \\
\text { Departamento de Matemáticas }\end{array}$ & 44 profesores \\
\hline & $\begin{array}{l}\text { Instituto de Matemáticas. } \\
\text { Unidad Ciudad Universitaria }\end{array}$ & 56 investigadores \\
\hline & $\begin{array}{l}\text { Instituto de Matemáticas. } \\
\text { Unidad Morelia, Michoacán }\end{array}$ & 21 investigadores \\
\hline & $\begin{array}{l}\text { Instituto de Matemáticas. } \\
\text { Unidad Cuernavaca, Morelos }\end{array}$ & 24 investigadores \\
\hline & $\begin{array}{l}\text { Instituto de Investigaciones en } \\
\text { Matemáticas Aplicadas y en } \\
\text { Sistemas (IIMAS) }\end{array}$ & 51 investigadores \\
\hline $\begin{array}{l}\text { Colegio de Postgrados, Estado } \\
\text { de México (COLPOS) }\end{array}$ & $\begin{array}{l}\text { Instituto de Socioeconomía, Esta- } \\
\text { dística e Informática. Maestría y } \\
\text { Doctorado en Estadística }\end{array}$ & $\begin{array}{l}17 \text { profesores-investiga- } \\
\text { dores }\end{array}$ \\
\hline
\end{tabular}




\section{Comunidades de investigadores universitarios}

\begin{tabular}{|c|c|c|}
\hline Institución & $\begin{array}{l}\text { Centro, Departamento, } \\
\text { Escuela o Instituto }\end{array}$ & Planta académica \\
\hline $\begin{array}{l}\text { Universidad de Guanajuato } \\
\text { (UG) }\end{array}$ & Facultad de Matemáticas & $\begin{array}{l}\text { La planta académica es integrada } \\
\text { por los investigadores que laboran } \\
\text { en el área de probabilidad y esta- } \\
\text { dística del CIMAT }\end{array}$ \\
\hline $\begin{array}{l}\text { Centro de Investigación en } \\
\text { Matemáticas (CIMAT) } \\
\text { Guanajuato }\end{array}$ & & 68 investigadores \\
\hline $\begin{array}{l}\text { rinOUniversidad Autónoma de } \\
\text { Guerrero (UAGRO) }\end{array}$ & Facultad de Matemáticas & $\begin{array}{l}\text { La planta académica es integrada } \\
\text { por los profesores-investigadores } \\
\text { que laboran en el CIMATE }\end{array}$ \\
\hline $\begin{array}{l}\text { Centro de Investigación en } \\
\text { Matemática Educativa } \\
\text { (CIMATE) de la UAGRO }\end{array}$ & & 6 profesores-investigadores \\
\hline \multirow[t]{2}{*}{$\begin{array}{l}\text { Universidad Autónoma del } \\
\text { Estado de Hidalgo (UAEH) }\end{array}$} & Facultad de Matemáticas. & $\begin{array}{l}\text { La planta académica es integrada } \\
\text { por los investigadores que laboran } \\
\text { en el CIMA }\end{array}$ \\
\hline & $\begin{array}{l}\text { Centro de Investigación en } \\
\text { Matemáticas (CIMA) de la } \\
\text { UAEH }\end{array}$ & 19 investigadores \\
\hline $\begin{array}{l}\text { Universidad de Guadalajara } \\
\text { (UdeG) }\end{array}$ & $\begin{array}{l}\text { Departamento de } \\
\text { Matemáticas }\end{array}$ & 29 profesores-investigadores \\
\hline $\begin{array}{l}\text { Universidad Michoacana de } \\
\text { San Nicolás de Hidalgo } \\
\text { (UMSNH) }\end{array}$ & $\begin{array}{l}\text { Departamento de Física y } \\
\text { Matemáticas }\end{array}$ & 7 profesores \\
\hline
\end{tabular}


La investigación sobre las necesidades de información en...

\begin{tabular}{||l|l|l||}
\hline \multicolumn{1}{|c|}{ Institución } & \multicolumn{1}{|c||}{$\begin{array}{c}\text { Centro, Departamento, } \\
\text { Escuela o Instituto }\end{array}$} & \multicolumn{1}{c||}{ Planta académica } \\
\hline $\begin{array}{l}\text { Benemérita Universidad Autó- } \\
\text { noma de Puebla (BUAP) }\end{array}$ & $\begin{array}{l}\text { Facultad de Ciencias Físico } \\
\text { Matemáticas }\end{array}$ & 22 profesores \\
\hline $\begin{array}{l}\text { Universidad de Sonora } \\
\text { (UNISON) }\end{array}$ & $\begin{array}{l}\text { Departamento de } \\
\text { Matemáticas }\end{array}$ & 13 profesores \\
\hline $\begin{array}{l}\text { Universidad Juárez Autónoma } \\
\text { de Tabasco (UJAT) }\end{array}$ & $\begin{array}{l}\text { División Académica de } \\
\text { Ciencias Básicas }\end{array}$ & 16 profesores-investigadores \\
\hline $\begin{array}{l}\text { Universidad Autónoma de Yu- } \\
\text { catán (UAdY) }\end{array}$ & Facultad de Matemáticas & 21 profesores \\
\hline $\begin{array}{l}\text { Universidad Autónoma de Za- } \\
\text { catecas (UAZ) }\end{array}$ & $\begin{array}{l}\text { Unidad Académica de } \\
\text { Matemáticas }\end{array}$ & 13 profesores-investigadores \\
\hline
\end{tabular}

\section{Anexo 2}

\section{Cuestionario}

Estimado (a) profesor (a) y/o investigador (a), con el objeto de identificar la satisfacción de sus necesidades de información, le solicitó de la manera más atenta indique las respuestas que considere adecuadas desde su particular punto de vista.

Instrucciones:

Marque con una "x" los datos que se le piden a continuación.

1. De las características siguientes. ¿Cuáles son las que Ud. considera importantes que debe de poseer el documento para satisfacer sus necesidades de información? (Señale por orden progresivo y de importancia del 1 al 8) 

a) disponibilidad (que esté listo por sí se necesita)
b) accesibilidad (que esté en el lugar adecuado)
c) actualidad (que sea lo último que ha aparecido)
d) oportunidad (que esté listo justo en el momento que se necesita)
e) pertinencia (que trate sobre el asunto que se investiga)
f) relevancia (que sea importante para la actividad que se realiza)
g) precio
h) calidad (que contenga un formato, tamaño, presentación, etc.)
i) Otra (especifique)

2. En que medida las bases de datos especializadas en el área matemática (MathSciNet y Zentralblatt Math) satisfacen sus necesidades de información.

\section{MathSciNet}
a) totalmente
b) parcialmente
c) escasamente
d) nunca

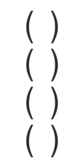

\section{Zentralblatt MATH}
a) totalmente
b) parcialmente
c) escasamente
d) nunca
()
()
()
() 
La investigación sobre las necesidades de información en...

3. En qué porcentaje considera que el diseño, presentación y contenido de los catálogos automatizados de las bibliotecas (Por ejemplo: IMATE, CINVESTAV, CIMAT, etc.) cubre sus necesidades de información en la búsqueda, localización y recuperación de datos vinculados a su investigación. (Marque sólo una respuesta)
a) $0 \%$ (nulo)
b) $25 \%$ (deficiente)
c) $50 \%$ (regular)
d) $75 \%$ (aceptable)
e) $100 \%$ (excelente)
( )

4. De los servicios de información y bibliográficos que se ofrecen por parte de las bibliotecas y proveedores. Señale cual de los siguientes satisfacen su necesidad de información. (Marque sólo una respuesta)
a) exhibición de nuevas adquisiciones
b) accesibilidad directa a artículos en revistas electrónicas
c) libros a vistas
d) catálogos impresos
e) servicio de alerta bibliográfica
f) boletines
g) búsqueda en índices 0 abstracts otro (especifique)

otro (especifique)


5. De las siguientes fuentes informativas (monografías, revistas, etc.) que utiliza regularmente, indique su nivel de satisfacción al hacer uso de ellas.

Monografías (libros, tesis, etc.)
a) totalmente
b) parcialmente
c) escasamente
d) nunca

Publicaciones periódicas (revistas, anuarios, etc.)
a) totalmente
b) parcialmente
c) escasamente
d) nunca
()

Obras de consulta (diccionarios, enciclopedias, etc.)
a) totalmente
b) parcialmente
c) escasamente
d) nunca

()

Fuentes referenciales (índices, abstracts, bibliografías, etc.)
a) totalmente
b) parcialmente
c) escasamente
d) nunca
()
()

Materiales audiovisuales (videos, cassets, cd, etc.)
a) totalmente
b) parcialmente
c) escasamente
d) nunca

()
()
() 


\title{
La recuperación de información a través de los Sistemas de Información Geográfica
}

\author{
ANTONIA SANTOS ROSAS \\ Colegio de Bibliotecología, Instituto de Geografía \\ Universidad Nacional Autónoma de México
}

\section{Introducción}

G1 ser humano a lo largo de su vida necesita y ge- nera información, la cual debe ser procesada, almacenada y difundida para ser usada por otras personas. Esta actividad humana de conservar, organizar y acceder a la información generada, lo ha llevado a establecer diversas unidades de información que respondan a ella, así como a generar sistemas de información utilizando las tecnologías de la información y la comunicación.

Una de estas tecnologías que utilizan no solo los geógrafos sino otros profesionales o investigadores del área son los Sistemas de Información Geográfica o SIG, los cuales permiten estudiar el espacio geográfico para planear o hacer predicciones, además de que versan sobre diferentes temáticas y contienen información muy diversa en presentaciones distintas como estadísticas, fotos, mapas, planos, texto, etcétera. 
La investigación sobre las necesidades de información en...

Por otro lado, los Sistemas de Información Geográfica o SIG persiguen la recuperación de información especializada por los usuarios, ya que permiten ver a detalle las características del terreno, lo que se torna importante para resolver problemas que enfrenta la sociedad actual como la salud, la educación, el transporte, los terremotos, el cambio climático, la biodiversidad, entre otros, desde la visión de diversos sectores sociales públicos y privados, como los gubernamentales.

Entonces, es preciso investigar la recuperación de la información que alcanzan los usuarios de los SIG, en términos del análisis espacial y de contenido, con la finalidad de aumentar su eficacia en el almacenamiento, organización y acceso a la información. Por lo anterior, esta investigación sobre la recuperación de la información por parte de los usuarios a través del uso de los Sistemas de Información Geográfica es importante para varios sectores sociales, no solo en México, sino en el mundo, ya que dichos sistemas son herramientas fundamentales en términos de análisis geográfico en diversos países tanto desarrollados como en vías de desarrollo

\section{Justificación y definición del problema}

A través de la construcción y el desarrollo de las tecnologías que permiten la recopilación, organización, almacenamiento y consulta de información 
sobre algún tópico en particular, entre ellas los Sistemas de Información Geográfica (SIG) que "en los últimos veinte años el número de usuarios, tanto en el sector público como en el privado, se han visto beneficiados con las facilidades y ventajas que proporciona el uso de un SIG. Tales organizaciones que han sido las receptoras de sus ventajas están relacionadas con la prestación de servicios, trabajos de agricultura, minería, geología, arqueología, conservación de recursos naturales, impacto y protección ambiental, climatología, cartografía, procesamiento digital de imágenes, fotointerpretación y fotogrametría, ingeniería civil, catastro, planificación del uso de suelo, planeación urbana y regional, manejo de redes de energía eléctrica, estudios de mercado entre otros". ${ }^{1}$

Por lo antes expuesto, se puede observar que esta herramienta es ampliamente usada por profesionales de diferentes disciplinas, por lo que es importante analizar la recuperación de la información que tienen los usuarios con respecto a la utilización de los SIG. Lo anterior también permitirá la determinación de las variables que intervienen en dicha re-

1 Dargermond citado por Laura Luna González. Los sistemas de información geográfica.: una alternativa para el análisis socioespacial de los accidentes de transito en carretera. Propuesta metodológica. México: LLG, 1997. Tesis Maestría en Geografía, p. 40. 
La investigación sobre las necesidades de información en...

cuperación de la información desde un aspecto teórico y llevándolo a la prueba en comunidades de usuarios específicas. Asimismo, los resultados pueden servir de base a los profesionales que mantienen o desarrollan algún SIG.

Por otro lado, hay que considerar que no existen investigaciones que aborden la recuperación de la información en los SIG por lo cual se torna importante investigar, ya que estos sistemas son ampliamente usados por varios sectores sociales tanto públicos como privados.

Por lo anterior, el problema de esta investigación parte de las siguientes interrogantes:

- ¿Cuáles son las variables que conforman la satisfacción informativa?

- ¿Cuáles son las variables que intervienen en el proceso de la satisfacción informativa de los usuarios de diferentes comunidades al utilizar los Sistemas de Información Geográfica?

- ¿Cuál es el perfil de los usuarios que utilizan los diferentes Sistemas de Información Geográfica?

- ¿Existe una relación entre la satisfacción de las necesidades de información de las diversas comunidades de usuarios que utilizan diferentes Sistemas de Información Geográfica? 


\section{Diseño de la Investigación}

\section{Objetivo General}

Analizar el proceso de satisfacción informativa que se lleva a cabo en los usuarios de la información, los que utilizan los Sistemas de Información Geográfica con el fin de encontrar las variables involucradas en dicho proceso.

\section{Objetivos Específicos}

A partir del planteamiento del problema y del objetivo general antes planteado se pueden precisar los objetivos específicos que se espera alcanzar con esta investigación.

- Analizar las diversas variables que conforman el proceso de la satisfacción informativa.

- Sintetizar las diferentes variables que intervienen en el proceso de satisfacción informativa para conformar un marco teórico que lo explique y proponer un modelo.

- Identificar los diversos Sistemas de Información Geográfica que se utilizan en México.

- Identificar las diferentes comunidades que utilizan los Sistemas de Información Geográfica.

- Determinar el perfil de los usuarios que usan los diversos Sistemas de Información Geográfica. 
La investigación sobre las necesidades de información en...

\section{Hipótesis}

Partimos del supuesto donde las variables que intervienen en la satisfacción informativa de los usuarios de diversos Sistemas de Información Geográfica permitirán explicar dicho proceso en las comunidades que los utilizan.

Si lo anterior se da, entonces, las variables que intervienen en el proceso de satisfacción informativa de los profesionales de las diferentes disciplinas, como usuarios de los SIG permitirán analizar y establecer diferentes relaciones espaciales (geográficas) con los fenómenos de estudio de cada Sistema de Información Geográfica de manera pronta y oportuna, y así poder predecir diferentes fenómenos físicos lo cual les permitirá tomar decisiones.

Las variables que se pueden investigar porque intervienen e influyen en algún grado o nivel de la satisfacción informativa del usuario de los SIG son: la actitud del individuo en el uso del sistema, la habilidad para usarlo, la experiencia en el uso de tecnologías, el idioma en el cual se encuentra la información contenida en el SIG, los puntos de acceso y búsqueda de la información que contiene el sistema, y la utilización que le dará el usuario a la información que busca en el SIG. 


\section{Comportamiento en la búsqueda de información}

Son varias las causas que influyen en el individuo para lograr la recuperación de información de manera satisfactoria como el desconocimiento del manejo del sistema, el escaso uso de los SIG, la poca experiencia en el uso de los sistemas de información, el lenguaje de recuperación de la información que utilizan, entre otros.

Respecto al uso del lenguaje, Frank y $\mathrm{Mark}^{2}$ mencionan el uso de dos lenguajes, el lenguaje natural y el lenguaje formal que en un SIG puede traer varios problemas en la recuperación de la información del usuario. Si se usa lenguaje natural o coloquial, el programa puede recuperar información en forma ambigua, por otro lado, si el usuario usa lenguaje formal o técnico tiene que forzar la lectura al lenguaje que usa. Este potencial limita las habilidades de los usuarios para interactuar dentro del Sistema de Información Geográfica.

La recuperación de la información depende de los conocimientos previos que se tengan sobre el asunto y del comportamiento informativo que el individuo presente al utilizar un SIG.

2 A.U. Frank and Mark D.M. Language Issues for Geographical Information Systems. Ref.7. p.147 
La investigación sobre las necesidades de información en...

\section{Recuperación de la información (o satisfac- ción informativa)}

Partiendo de que la información registrada en algún tipo de soporte es la que el individuo consulta durante el proceso de investigación, esta se encuentra previamente organizada en sistemas de información para su difusión y conservación. Entonces, el ser humano hace uso de estos servicios y sistemas de información cuando presenta una necesidad informativa, la cual requiere satisfacer.

La satisfacción informativa se encuentra en la tercera etapa del fenómeno de las necesidades de información y para fines de esta investigación nos enfocaremos solo en la recuperación de la información que brindan a los usuarios los sistemas de información, en concreto a los Sistemas de Información Geográfica.

A continuación se mencionarán algunas definiciones de lo que se entiende por satisfacción informativa y por recuperación en sistemas de información.

Verdugo ${ }^{3}$ señala que: "[...] satisfacción es el hecho de dar solución a una duda, o una dificultad,

3 Juan José Calva González. Las necesidades de información: fundamentos teóricos y métodos. México, UNAM. Centro Universitario de Investigaciones Bibliotecológicas. 2004. p. 136 
aquietar y convencerse con una razón eficaz, la duda o queja que se había formulado".

Por otro lado Calva dice: "Nuestra sensación de estar satisfecho la reducimos, por tanto, a lo que nos es grato, próspero, o bien a sentirnos complacidos o simplemente contentos".

Zmud y Boynton definen satisfacción como "[...] la suma de emociones o sentimientos relativos a la recuperación de la información en los sistemas de información". ${ }^{5}$

Entonces, la satisfacción informativa es un estado en donde se han cumplido las expectativas del individuo lo que le provoca un estado de emoción ante los logros alcanzados en la resolución de sus necesidades de información, sin embargo para llegar a esta fase es notoria la influencia de varios factores como: el conocimiento que se tiene del tema o el asunto, la habilidad ante el uso de fuentes y recursos de información, la habilidad en el manejo del sistema de información, además del tiempo, dinero y esfuerzo invertidos.

Gluck menciona que "[...] es posible que un sistema proporcione perfecta precisión y recopilación,

4 Op. Cit.p. 136

5 Myke Gluck. "Exploring the relationship between user satisfaction and relevance in information systems". En: Information Processing E Management. v. 32, No. 1. 1996. p. 90 
La investigación sobre las necesidades de información en...

pero que este no permita la satisfacción de la necesidad de información del usuario o recuperación de la información y que para entender el sistema hay que usarlo varias veces. Esto puede ocurrir por varias razones:"6

- El usuario no es claro con la necesidad de información que tiene

- El usuario es incapaz de evaluar los documentos recuperados

- El usuario desconoce la recuperación

- El sistema no tiene toda la información que necesita

- La información buscada no existe

- Los datos del sistema son organizados arbitrariamente y relativamente satisfacen las necesidades de los usuarios.

Otros factores que influyen en la satisfacción informativa en los sistemas de información son estudiados por autores como Nilan et al. (1989), donde indica "que la satisfacción de los usuarios frecuentemente depende de su habilidad para plantear preguntas al sistema que satisfagan su necesidad, usando un sistema orientado con un lenguaje apropiado o jerga". ' Sobre este mismo asunto Sheneiderman "indica que, los usuarios que emplean la jerga del

6 Op Cit. p. 92

7 Op Cit. p. 91 
sistema pueden ayudarse más a planear su pregunta a diferencia de los usuarios que no emplean la jerga del sistema. ${ }^{8}$

Por lo anterior, se puede considerar que es importante que el lenguaje usado por la disciplina sea conocido por las personas que alimentan el sistema de información, ya que el usuario al buscar información lo hace con la terminología usada cotidianamente por el especialista, sin embargo se debe considerar normalizarla en el sistema para evitar dispersión de conceptos y la obtención de la información sea lo más precisa posible.

Tessier indica que la satisfacción de los usuarios puede ser descrita con tres diferentes perspectivas: evaluación global del sistema (el cual se debe investigar), satisfacción del usuario con la información requerida y si la información obtenida cubre las expectativas de los usuarios. ${ }^{9}$

Por lo tanto, en esta investigación se profundizará sobre el análisis de las variables que intervienen en la recuperación de la información que presenta el usuario para cubrir su necesidad informativa. El investigar sobre dichas variables aportará fundamentos teóricos que pueden explicar el proceso de

8 Op.Cit. p.91

9 Myke Gluck, p. 91 
La investigación sobre las necesidades de información en...

recuperación de la información de los usuarios en concreto con los SIG.

Es importante considerar que los resultados de esta investigación aportarán los factores para que cualquier sistema de información, incluyendo los geográficos, cumpla con las funciones que tiene encomendadas en beneficio de sus usuarios.

Por lo anterior, el marco teórico para esta investigación es fundamental para encontrar las variables que intervienen en el proceso de recuperación de la información, así como relacionarlas con los Sistemas de Información Geográfica utilizados por las diversas comunidades. La intención de la investigación es explicar cómo se lleva a cabo este proceso y además proponer un modelo que soporte tal explicación.

\section{Sistemas de Información Geográfica}

La investigación tratará de los Sistemas de Información Geográfica (SIG) partiendo primeramente de que son un conjunto de herramientas computacionales que facilitan el análisis espacial de fenómenos geográficos. Un SIG tiene, entre otras ventajas, la capacidad de almacenar, manejar y analizar información espacial en tiempos reducidos.

Pero un SIG "[...] no es un simple programa de cómputo para crear mapas a diferentes proyecciones, su importancia radica en que es una herramienta, para el análisis de información geográfica con la 
capacidad de establecer relaciones espaciales entre diferentes objetos o fenómenos, al ligar datos espaciales con información geográfica". ${ }^{10}$

En cuanto al contenido: "El tipo de datos que pueden ser capturados y transformados para manejarse dentro de un SIG es muy amplio, comprende mapas y cartas impresas, información digital existente, información de campo e información obtenida a partir de teledetección, sensores remotos tales como fotografías aéreas, imágenes de satélite, imágenes de radar, registro de coordenadas a partir de sistemas de posicionamiento". ${ }^{11}$

Entonces, un SIG es un programa de cómputo que permite la captura y almacenamiento de datos para el análisis espacial de un objeto o fenómeno del mundo real, que permite también conocer las características y las interrelaciones espaciales de objetos o fenómenos en el espacio geográfico que se encuentran.

Chuvieco define a los SIG como "[...] bases informatizadas de datos en algún tipo de componente espacial. Esto significa que la información que almacenan está referenciada geográficamente, ya se trate de mapas, estadísticas o datos climáticos, sobre un

10 ESRI. Understanding GIS. The ARC/INFO method. Redlands. 1990.

11 Laura Luna González. Op. Cit., ref. 1, p.34 
La investigación sobre las necesidades de información en...

territorio concreto por lo que todas estas variables pueden relacionarse mutuamente de formas muy diversas". ${ }^{12}$

De acuerdo con diferentes autores como Aronoff, ${ }^{13}$ Burrough, ${ }^{14}$ Maguire ${ }^{15}$ un SIG debe ser capaz de responder a ciertas preguntas referente al fenómeno estudiado, tales como:

- Localización. ¿Qué hay en...?

- Condición. ¿Dónde está...?

- Tendencia. ¿Cuánto ha cambiado desde...?

- Definición de ruta. ¿Cuál es el mejor camino a...?

- Patrones. ¿Qué patrones espaciales existen...?

- Escenarios. ¿Qué sucede si...?

\section{Marco de referencia}

Los SIG se desarrollaron en los años sesenta como respuesta a las crecientes necesidades de información sobre el territorio. Canadá resultó pionero en el nacimiento de estos programas, si bien se exten-

12 Emilio Chuvieco. Fundamentos de teledetección espacial. Madrid. Ediciones Rialp, 1990. p. 397.

13 S. Aronoff. Geographic information systems. A management perspective. Otawa, WDL Publications, 1991. 294 p.

14 P. Burrough. Principles of geographical information systems form land resources assessment. Oxford University Press, 1990.194 p.

15 D.L.Maguire. An overview and definition of GIS. Geographical information systems. Principles and application. v. 1. New York, John Willey \& Son, 1991, pp. 9-20. 
dieron rápidamente hacia el sur y a otros países anglosajones. A finales de ese década ya existían varios SIG operativos, como el DIME (U. S. Bureau of Census) o el GRDSR (Statistics Canadá). El creciente interés por la planificación del medio ambiente permite que los SIG se consoliden en la década de los setenta. En estos años aparecen los primeros planes de estudio universitarios sobre esta tecnología, así como algunas empresas dedicadas a su desarrollo y explotación, mientras crece el interés de agencias oficiales en sus distintas aplicaciones.

En la actualidad el uso de los SIG se sigue incrementando en varias áreas, tales como salud, urbanismo, administración, agricultura, medio ambiente, climatología, minería, geología, arqueología, manejo de redes de energía eléctrica, etcétera.

Aunque esta tecnología en México se está aplicando en instituciones públicas y privadas como es el caso del Instituto Nacional de Estadística, Geografía e Informática. INEGI; Instituto Nacional Indigenista. INE; Secretaría de Comunicaciones y Transportes. SCT; Instituto Mexicano del Transporte. IMT; Comisión Nacional de Áreas Naturales Protegidas. CONANP; entre otros. No se tiene el dato de todos los SIG que existen ya que existen

16 Emilio Chuvieco. Op. Cit., ref. 7, p. 399 
La investigación sobre las necesidades de información en...

dependencias principalmente de instituciones privadas que no permiten el acceso al público, por considerar esta información de carácter privado.

A continuación se mencionan algunos ejemplos de SIG que se han desarrollado en México:

- UNIGEO. Unidad de Información Geoespacial desarrollado en el Instituto de Geografía dentro de la UNAM. Este sistema se implemento para dar acceso al acervo cartográfico de colecciones nacionales e internacionales, que albergan las diferentes dependencias de la UNAM. ${ }^{17}$

- GEOINFORMACIÓN. Es una sección de consulta y disposición de cartografía temática e imágenes de satélite, de uso interno de la Comisión $\mathrm{Na}$ ción Nacional de la Biodiversidad (CONABIO) ${ }^{18}$

- CONANP. Comisión Nacional de Áreas Naturales Protegidas. Contiene cartografía de las diferentes áreas protegidas de México. ${ }^{19}$

- OEGT. Insumos para el Ordenamiento Ecológico General. Este sistema reúne las bases de datos del Instituto Nacional de Ecología (INE), y se pone a disposición de los responsables e interesados en la planeación territorial para apoyar su tarea. La información está organizada en cinco te-

17 http://www.unigeo.igeograf.unam.mx.

18 http://www.conabio.gob.mx/información/geo_español/

19 http://www.conanp.gob.mx/sig 
mas: medio físico, medio biótico, medio social, medio económico y estudios regionales. ${ }^{20}$

Estos son sólo algunos ejemplos de SIG, ya que existe una gran variedad de estos sistemas enfocados a diferentes temas de estudio.

\section{Metodología}

Para llevar a cabo la investigación que se plantea en este protocolo es preciso determinar los siguientes aspectos:

1.- Unidad de análisis:

- Variables que intervienen en el proceso de la recuperación de la información

- Sistemas de Información Geográfica en México

- Usuarios de los Sistemas de Información Geográfica en México

La investigación es de carácter teórico en la parte concerniente a la discusión de las variables que intervienen en el proceso de la recuperación de la información y es una investigación de tipo exploratoria-descriptiva, en lo concerniente a verificar si dichas variables corresponden a explicar la recuperación de la información que tienen los diversos usuarios de los Sistemas de Información Geográfica.

$20 \mathrm{http} / / / \mathrm{www} \cdot$ ine.gob.mx/index.html 
La investigación sobre las necesidades de información en...

\section{Método}

Para llevar a cabo esta investigación se elaborará una investigación documental, el análisis crítico del proceso de recuperación de la información y una investigación de campo en diversas comunidades de usuarios que utilizan los SIG para comprobar las variables propuestas que intervienen en dicho proceso.

\section{Técnica}

Se realizará un análisis y la contratación de las variables teóricas que intervienen en el proceso de recuperación de la información a partir de la literatura encontrada sobre este tópico.

Debido a que se investigará a las comunidades de usuarios que utilizan diversos SIG se pretende llevar a cabo una encuesta (se analizará la conveniencia de utilizar una muestra de la población a investigar). Se determinará a la población a estudiar a partir de los diferentes sectores que usen los SIG en México

\section{Instrumento}

Para la parte concerniente a la verificación de las variables, para explicar el proceso de la recuperación de la información de los usuarios de los SIG se pretende utilizar como instrumento un cuestiona- 
Comunidades de investigadores universitarios

rio aplicado de forma personal (entrevista estructurada).

\section{Referencias bibliográficas}

Aronoff, S. Geographic information systems. A management perspective. Ottawa, WDL Publications. 1991. 294 p.

Blyunmenau, D.I. Refining initial concepts in information need theory. "Nauchno tekhinicheskaya informatsiya”, Serie 2, no. 2, 1986, p. 7-12 (en inglés, pp. 48-57)

Burrough, P. Principles of geographical information systems form land resources assessment. Oxford, University Press. 1991. 194 p.

Calva Gonzalez, Juan José. "Una aproximación a lo que son las necesidades de información". En: Investigación Bibliotecológica: Archivonomía, Bibliotecología e Información, Vol. 5, no. 11, jul.-dic. 1991, pp. 24-32

--. "Las necesidades de información de las comunidades científicas dentro del Programa de Formación de Recursos Humanos en Servicios Bibliotecarios y de Información para la integración de la Red de Bibliotecas del Subsistema de Humanidades y Ciencias Sociales". En: Investigación Bibliotecológica: Archivonomía, Bibliotecología e Información, Vol. 10, no. 20, enero-junio 1996. pp. 33-35

Calva Gonzalez, Juan José. "Las necesidades de información de los investigadores del área de humanida- 
La investigación sobre las necesidades de información en...

des y ciencias sociales y del área científica”. En Primer Congreso Interno de la Comunidad Cientifica del CUIB: los investigadores y sus investigaciones. México: UNAM, Centro Universitario de Investigaciones Bibliotecológicas, 1997, pp. 82-85.

--. "Las necesidades de información de los usuarios en la planeación bibliotecaria”. En : Biblioteca Universitaria. Boletín Informativo de la Dirección General de Bibliotecas, Vol. 6, no. 1, enero-marzo 1991, pp. 25-30.

--. Las necesidades de información: su naturaleza, manifestación y detección. México: J.J. Calva González, 1998, 247 p. Tesis (Maestría en Bibliotecología)UNAM. Facultad de Filosofía y Letras, 1998.

Craig, William J., Harris, Trevor M. and Weiner, Daniel. Community participation and geographic information systems. London and New York, Taylor and Francis. c2002. p.383.

Crist, Margo, Daub, Peggy Ellen, Macadam, Barbara. "User studies: reality check and future perfect", En Wilson library Bulletin. Vol. 68, february 1994. pp. 38-41.

Day, J. y MacDowell, E. "Information needs of science and technology students", En Education Libraries Bulletin, Vol. 30, p. 1, spring 1987, pp. 1-16.

De Mers, Michael N. Fundamentals of geographic information systems. 3a. Ed. Estados Unidos de América, John Wiley and Sons. c2005. p. 468. 
Eisenbers, K. "Special documents as sources for maps", En: Geography-and-Map-Division-Bulletin. (128) jun. 1982, pp. 32-35. 12 ref.

Fallas, Jorge. "Normas y estándares para la comunidad de usuarios de sistemas de información geográfica". En: Revista geográfica de América Central. 1995 1996. No. 32 - 33 jul. - jun. pp. 41 - 62.

Fallas, Jorge. "Sistemas de información geográfica: una visión integral”. En: Revista geográfica de América Central". 1995 - 1996. No.32 - 33, jul. - jun. pp.17 39.

Garrods, Carlos. "Los sistemas de información geográfica en la geografía médica”. En: El Colegio Mexiquense. 1998. V.1. No. 3, ene. - jun. pp. 597 -618.

Gelfand, J. “Computer software for geographers, map librarians and cartographers" En: Western-Association-of-Map-Libraries-Information-Bulletin. 19 June 1988, pp. 132-136.

Graff, T.-O; Wellar,-Barry-S Geographic aspects of information systems: introduction and selected bibliography. 1971.

Hill, Linda L. Georeferencing. The geographic associations of information. Massachusetts, The MIT Press. c2006. p.260.

Korte, George B. The GIS book. Canadá, Onword Press. c2001. 387 p. 
La investigación sobre las necesidades de información en...

Lo, Chor Pang. Concepts and techniques of geographic information systems. New Jersey, Prentice Hall, c2007.

Geographic information systems a science. Longley, Paul A. [et. Al.]. New York, Jhohn Wiley and Sons. c2001. 454 p.

López Blanco, Jorge. "Sistemas de información geográfica (SIG): Conceptos, definiciones y contexto metodológico". En: Quivera. 1998. V. 1. Jul. pp. 27 - 38.

Maguire, D. J. An overview and definition of GIS. Geographical information systems. Principles and applications. V. 1. New York, John Wiley \& Sons. 1991.

Martínez Barajas, Juan Oscar. "Desarrollo de la Tecnología SIG en Internet”. En: Revista Cartográfica. 2000. No. 71 jul - dic. pp. 29 - 34.

Mcdonnell, Rachael. International GIS dictionary. Cambrige, [Engdland], GeoInformation International : New York, Wiley, 1995.

Mongomery, G. and Schuch, H. GIS data convertion bandbook. USA, GIS World, Inc. 1993. $291 \mathrm{p}$.

Nicholas, David. Information seeking in an information society: end user in the city and the media. Londres: Mansell, 1987.

Obokoh, N.P "Bibliometric study of research fields of Nigerian geographers, 1957-1978”. En: Bulletin (Special Libraries Association Geography and Map Division) no158 Dec 1989. pp. 18-29 
Osborne, Larry N. Systems analysis for librarians and information professionals. Englewood, Colorado, Libraries unilimited, 1994.

Rivas, Arturo. "Sistemas de información geográfica digitalizada. Control, eficiencia y servicio". En revista: Obras. 2003. V. 31 No. 363 mar. p.86 -89.

Rodríguez Bachiller, Agustín. Expert systems and geographical information systems for impact assessment. Londres: Taylor \& Francis, 2004

Santos Rosas, Antonia. El comportamiento informativo de los investigadores del área de geografía en México. Tesis Maestría en Bibliotecología y Estudios de la Información. UNAM. FFyL, ASR. 2007. 159 p.

Santos, Vilma Moreira dos. "Information needs and uses of information channels in different phases of projects: a literature review", en Revista da Escola de Biblioteconomia da UFMG, Vol. 17, no. 2 sep. 1988, pp. 214-235

Semra, H. "Documentary practices and needs of geographers specializing in the Maghreb". En: INSPEL, Vol.20 no3 1986, pp. 168-73

Solano, Manuel A. “ $¿ E l$ estudio de sistemas de información geográfica (SIG) es una disciplina? El papel importante de los SIG en la Geografía”. En: Revista geográfica de América Central. 1995 - 1996. No. 32 - 33 jul. - jun. pp.13 - 23. 
La investigación sobre las necesidades de información en...

Summers, M.; Easdown, G. "Information technology in initial teacher education: preconceptions of history and geography interns, with reflections of mentors and tutors" En: Journal-of-Information-Technology-for-Teacher-Education. 5 (1 \& 2) 1996, pp. 155-172.

Tieleman, P. Some information of online databases for geographers. Amsterdam: University of Amsterdam, Laboratory of Physical Geography and Soil Science, 1979.

Verbyla, David L. Practical GIS analysis. Londres y New York, Taylor and Francis. 2002. p. 294.

Wang, Fahui. Quantitative methods and applications in gis. Londres y New York, Taylor and Francis. 2006. p. 263. 
Comunidades de profesores y estudiantes universitarios 


\title{
Comportamiento informativo de alumnos y profesores universitarios
}

\author{
FABIOLA MARTÍNEZ LÓPEZ
}

Posgrado en Bibliotecología y Estudios de la Información

Universidad Nacional Autónoma de México

\section{Justificación del tema}

Tna de las principales razones por las que los estudiantes de una buena parte de las escuelas estudiadas han dejado de visitar con cierta frecuencia sus bibliotecas, es el aumento de las vías digitales o telemáticas de acceso a la información. Se trata de una tendencia (a mayor dependencia de los buscadores de Internet menos visitas y conocimiento de los servicios que ofrecen las bibliotecas) que, por supuesto, se presenta sobre todo entre estudiantes que poseen cierto bienestar económico y viven en entornos tecnológicos dinámicos y de fácil acceso.

En México, sobre todo en algunas de las universidades privadas (donde los alumnos en su mayoría tienen un buen nivel económico y poseen una computadora con acceso a Internet), esta situación es 
La investigación sobre las necesidades de información en...

cada vez más frecuente, pues al parecer cada vez son menos los alumnos que acuden físicamente a satisfacer sus necesidades de información en las bibliotecas universitarias.

Ese, al menos, es el caso específico de la UIA ciudad de México, donde el número de usuarios ha venido decreciendo paulatinamente en los últimos años en acudir a bibliotecas.

En función de que son considerables los recursos económicos y humanos que se invierten para mantener al día una biblioteca como la Biblioteca Francisco Xavier Clavijero BFXC, resulta necesario preguntarse en torno a las razones que han llevado paulatinamente a los usuarios a dejar de visitarla y averiguar dónde buscan información. Así como las posibles propuestas que hay que llevar acabo en un futuro cercano para revertir esta tendencia.

\section{Antecedentes}

Sin embargo, aunque no se han realizado estudios sistemáticos, lo que si es un hecho es que, como bien muestran algunas de las estadísticas sobre los usuarios de la BFXC de la UIA (publicadas en su página web: http://www.bib.uia.mx), el número de visitantes que consulta el material ha disminuido considerablemente entre 1999 y 2005. 
Comunidades de profesores y estudiantes universitarios

Si bien es cierto que son varios los estudios cuantitativos y cualitativos sobre usuarios de bibliotecas universitarias que se han hecho en México en los últimos años y aunque también es cierto que en el caso de la UIA, sus autoridades han hecho esfuerzos por levantar y dar a conocer periódicamente estadísticas destinadas a describir el comportamiento de sus usuarios, es importante decir que hasta ahora no se han realizado investigaciones cualitativas/cuantitativas sistemáticas sobre el tema.

\section{Preguntas de Investigación}

- ¿Cuál es la frecuencia con la que los profesores universitarios utilizan los servicios bibliotecarios y de información para buscar la información que requieren?

- ¿Cuántas veces los profesores han accedido en los últimos años (del 1999 a la fecha) a las Bibliotecas universitarias.

- ¿Cuáles son las principales causas por las que se ha presentado una paulatina disminución de los usuarios de información, principalmente en el uso de bibliotecas universitarias cuando buscan su información?

- ¿A qué fuentes y recursos acuden los profesores universitarios a buscar la información que necesitan? 
La investigación sobre las necesidades de información en...

\section{Principales objetivos}

- Describir y comparar estadísticamente el comportamiento de los usuarios en cuanto al uso de las bibliotecas universitarias.

- Determinar (cualitativamente) las razones por las cuales los profesores universitarios han disminuido el número de visitas y consultas a las bibliotecas.

- Identificar a qué otras fuentes y recursos de información acuden los profesores universitarios.

\section{Hipótesis o supuestos}

- El índice de usuarios de la información de la UIA que acuden a alguna biblioteca ha venido disminuyendo por cuatro razones principales:

- El Internet como herramienta prioritaria para satisfacer sus necesidades de información sobre el uso de bibliotecas "tradicionales".

- Los usuarios de la información no conocen del todo los distintos servicios e infraestructura de las bibliotecas universitarias.

- Los usuarios de la información de la UIA tienen una imagen positiva pero fría, avejentada y distante de su biblioteca universitaria.

- Los usuarios no tienen el conocimiento necesario para poder utilizar y aprovechar el catálogo y 
Comunidades de profesores y estudiantes universitarios

tampoco conocen a fondo la gama de servicios que les ofrece su biblioteca universitaria.

\section{Metodología}

Dado que lo que busco es indagar los hábitos informativos de los ususarios, para la realización de esta investigación recurriré sobre todo los métodos cualitativos (entrevistas cualitativas):

- Investigación documental para conocer los antecedentes de mi tema.

- Diseño y aplicación de observaciones etnográficas para conocer y seleccionar a mis informantes.

- Realizar entrevistas cualitativas con los informantes seleccionados que cumplan con el perfil que me interesa conocer. 


\section{Comportamiento informativo de los tesistas de licenciatura en Bibliotecología de la ENBA, el Colegio de Bibliotecología de la UNAM y de la UAEM: causas que lo originan}

ARMANDO SÁNCHEZ SOTO

Instituto de Educación Media Superior del Gobierno del Distrito Federal, México

\section{Introducción}

Gl presente documento es una continuación de la Drimera presentación que se llevó a cabo en el II Seminario de Usuarios de la Información en el mes de octubre del año 2006. En aquel entonces me encontraba en la elaboración de mi protocolo de tesis, por lo que únicamente hice una presentación de los avances del mismo, de los que rescato lo siguiente:

\section{Planteamiento del Problema}

¿Cuáles son las necesidades de información de los bibliotecólogos durante el proceso en el cual realizan sus trabajos de titulación?

¿Cuál es el comportamiento informativo de los tesistas de licenciatura en Bibliotecología de la 
La investigación sobre las necesidades de información en...

ENBA, el Colegio de Bibliotecología de la UNAM y de la UAEM?

¿Cuáles son las variables que intervienen en el comportamiento informativo de los tesistas de licenciatura en Bibliotecología de la ENBA, el Colegio de Bibliotecología de la UNAM y la UAEM?

\section{Objetivo General}

Identificar las variables que determinan el comportamiento informativo de los tesistas de licenciatura en Bibliotecología de la ENBA, el Colegio de Bibliotecología de la UNAM y la UAEM.

\section{Hipótesis}

El comportamiento informativo de los tesistas de Licenciatura en Bibliotecología de la ENBA, el Colegio de Bibliotecología de la UNAM y la UAEM está determinado por los recursos de información disponibles en cada escuela de Bibliotecología (bibliotecas, catálogos, colecciones etcétera).

Las características inherentes a las fuentes de información bibliográfica que existen (disponibilidad de acceso, tipo de información, formato de presentación, confiabilidad, etcétera) definen la consulta a determinadas fuentes de información bibliográfica por parte de los tesistas de Licenciatura en Bibliotecología de la ENBA, el Colegio de Bibliotecología de la UNAM y la UAEM. 
Las necesidades de información de los tesistas de Licenciatura, en Bibliotecología de la ENBA, el Colegio de Bibliotecología de la UNAM y la UAEM, definen el comportamiento informativo de los mismos, en relación a las fuentes de información que consultan para realizar sus trabajos de investigación.

\section{Metodología}

Tipo de investigación: Investigación documental e investigación de campo

Método de investigación: El método a aplicar en esta investigación será cuantitativo e inductivo.

Técnicas e instrumentos: Se llevará a cabo una investigación documental en combinación con otra de campo. Se utilizarán como instrumentos cuestionarios para los tesistas registrados que llevan a cabo su trabajo de tesis.

\section{Capítulo 1. Comportamiento informativo de los estudiantes de Humanidades}

Las aproximaciones al estudio de las necesidades de información varían considerablemente. Algunas se enfocan en los individuos, otros en las instituciones, a menudo en las bibliotecas; otras específicamente en las necesidades de información de varios sujetos de estudio como los científicos, los hombres de negocios, las enfermeras, los ingenieros, etcétera. Los sistemas de información no pueden diseñarse sin 
La investigación sobre las necesidades de información en...

una clara idea de lo que el usuario quiere o necesita, cómo busca la información y cómo la evalúa.

El concepto de necesidad de información puede ser muy general, cuando la incertidumbre se presenta en el individuo y éste cree que puede satisfacerla con información. Sin embargo el concepto puede separarse también al distinguir lo que se desea de lo que se necesita. Una información que se quiere es el deseo de satisfacer una incertidumbre, una necesidad de información es la condición, reconocida o no por el individuo, de que la información es requerida para resolver un problema.

\section{Comentarios}

Como puede observarse, las definiciones en torno al concepto de necesidades de información son muy variadas, por lo que ahondar en ello podría resultar repetitivo, sobre todo si se toma en cuenta que en la mayoría de las exposiciones anteriores ya se ha abordado el tema.

Por otra parte, son múltiples las investigaciones que se han realizado en torno a las necesidades de información de diferentes comunidades; sin embargo muy pocas de ellas se han aplicado a los bibliotecólogos como profesionales de la información.

De hecho, haciendo un rastreo de investigaciones que se han realizado en otras partes del mundo, y que podrían ser similares a las que planteo en esta 
exposición; encontré que únicamente en el Reino Unido y en Rusia se ha hecho algo parecido.

Lo anterior, de alguna manera, justifica la importancia de realizar una investigación de esta naturaleza dentro de nuestro entorno; en este caso en aquellos que habiendo concluido sus estudios de licenciatura en Bibliotecología tienen la necesidad de buscar y recopilar información útil para la realización de su trabajo de titulación.

\section{Necesidades de información en las Humanidades}

Algunas de las diferencias en el comportamiento informativo de los humanistas con respecto a los científicos se encuentran en la capacidad que éstos tienen de trabajar en equipo, la tipología de documentos que solicitan y los métodos que utilizan para llevar a cabo sus investigaciones.

Asimismo, una característica de los humanistas en el proceso de búsqueda de información es la necesidad de hojear libros. El objetivo de hojear los libros es el de encontrar información útil a partir de la presencia física de la fuente original, página por página, de una forma sosegada y capítulo a capítulo.

Por otra parte, en cuanto a los recursos bibliográficos utilizados por los humanistas, el primer lugar lo ocupan las monografías seguidas por las publicaciones periódicas. En humanidades, las monografías 
La investigación sobre las necesidades de información en...

a menudo se utilizan como vehículos transmisores de información primaria, es decir, de resultados originales de investigación.

En cuanto a la actualidad de la investigación se ha demostrado en algunas investigaciones que los humanistas utilizan un material de mayor antigüedad que los investigadores de Ciencias Sociales y por supuesto que "los experimentales" y los tecnólogos.

Finalmente, la capacidad idiomática en el manejo de la información es otro factor que distingue a los humanistas con respecto a los investigadores de otras áreas. Estos hacen un mayor uso de documentos escritos en lenguas distintas que los de otras comunidades científicas, quizá debido a que estos hacen una consulta constante a diferentes fuentes bibliográficas en comparación a las comunidades de otras disciplinas.

\section{Comentarios}

Como pudo observarse son muchas y muy precisas las características que presentan los humanistas en cuanto a su comportamiento informativo y las necesidades de información cuando realizan una investigación. En ese sentido dentro de la conformación de este primer capítulo; el segundo paso consistió en realizar un análisis de dos investigaciones previas realizadas en dos comunidades diferentes que pertenecen al área de humanidades; esto con 
Comunidades de profesores y estudiantes universitarios

el fin de corroborar que todo lo planteado se cumpla efectivamente.

Los resultados obtenidos de dicho análisis son los siguientes:

Necesidades de información en usuarios del área de Humanidades: estudios de caso. Investigadores del CIALC (antes CCY DEL) y docentes del CELE M

El CIALC es un centro especializado en estudios sobre Latinoamérica con un enfoque humanístico, cuenta con tres líneas de investigación que son: Filosofía e historia de las ideas latinoamericanas, Historia de América Latina y Literatura latinoamericana.

El CELE Mascarones tiene como objetivo general, impartir cursos especiales a la comunidad universitaria y al público en general en las siguientes lenguas extranjeras: inglés, alemán y francés.

Respecto a las fuentes de información consultadas por los investigadores del CIALC y los docentes del CELE Mascarones, se expresó lo siguiente:

- Necesidad de hojear libros para satisfacer sus necesidades de información.

- Necesidad de consultar documentos originales.

- Necesidad de utilizar también fuentes secundarias Por su parte los docentes del CELE Mascarones manifestaron su preferencia por consultar determinadas fuentes de información, de acuerdo con la siguiente tabla: 
La investigación sobre las necesidades de información en...

\begin{tabular}{||l|c|}
\hline Fuentes de Información & Preferencia \\
\hline Libros & $1^{0}$ \\
\hline Revistas & $2^{\circ}$ \\
\hline Videos & $3^{\circ}$ \\
\hline Casetes & $4^{\circ}$ \\
\hline
\end{tabular}

De acuerdo a lo anterior se observa que existen coincidencias entre una y otra comunidad, en cuanto a la preferencia en la consulta de determinadas fuentes de información, que en este caso son los libros y las publicaciones periódicas. Así como también se cumple con una de las condiciones que caracterizan a los humanistas en el uso de la información mencionados anteriormente: el de la preferencia a consultar monografías como vehículo transmisor de información primaria.

Sobre la antigüedad de las fuentes de información consultadas por los investigadores del CIALC y los docentes del CELE M, los investigadores del CIALC expresaron que utilizan material con mayor con antigüedad. Los docentes del CELE M expresaron lo siguiente:

\begin{tabular}{||l|c|}
\hline \multicolumn{1}{|c|}{ Antigüedad } & Número de respuestas (docentes) \\
\hline Meses & 20 \\
\hline Años & 11 \\
\hline Días & 9 \\
\hline No Contestó & 8 \\
\hline
\end{tabular}


Comunidades de profesores y estudiantes universitarios

En este aspecto, se puede apreciar que existen coincidencias entre uno y otro caso, es decir que en ambos los documentos primarios y de primera mano, así como los documentos de mayor antigüedad; resultan fundamentales para satisfacer necesidades de información.

\section{Comentarios}

$\mathrm{Al}$ realizar la tesis se considerarán los datos obtenidos de los dos estudios de caso, ya que en ambos se encuentran una serie de coincidencias en lo que respecta a las necesidades y al comportamiento informativo de los humanistas. Lo anterior tendrá que verse reflejado en los resultados de la misma.

\section{Capítulo 2. Los estudios de Bibliotecología en México}

El fin y la función de las Escuelas de Bibliotecología en México particularmente en la ENBA, el Colegio de Bibliotecología de la UNAM y la UAEM es el de formar profesionales cuyos conocimientos, técnicas y habilidades puedan cubrir las necesidades de información que exige la sociedad contemporánea.

Para lograr tales objetivos es necesario que quienes ingresan a dicha carrera cubran un plan de estudios que incluye materias organizadas en un determinado número de semestres. Durante este tiempo 
La investigación sobre las necesidades de información en...

el estudiante realiza habitualmente trabajos de investigación documental, por lo que al concluir sus estudios tentativamente posee las técnicas para realizar un trabajo escrito de titulación como parte de los requisitos necesarios para obtener el título o grado correspondiente.

Dicho trabajo representa el conjunto de conocimientos y habilidades adquiridos por los estudiantes de bibliotecología en cada una de estas escuelas durante el curso de sus carreras. El reglamento de cada escuela menciona las características generales que debe de cubrir la presentación de dicho trabajo; sin embargo en todos los casos, tomando en cuenta la estructura y la trascendencia del mismo, es necesario que el estudiante muestre un manejo crítico y adecuado de las fuentes bibliográficas pertinentes, dado que la información que se obtenga de ellas, proporcionará datos necesarios para sustentar o fundamentar teóricamente la investigación que todo trabajo de esta naturaleza implica.

\section{Comentarios}

Uno de los objetivos principales de mi tesis es la utilidad que las fuentes de información bibliográfica representan para la realización de un trabajo escrito de titulación. En ese sentido el propósito del mismo es observar los motivos que conducen a los estudiantes de bibliotecología de la ENBA, el CB de 
Comunidades de profesores y estudiantes universitarios

la UNAM y la UAEM a realizar sus trabajos, así como consultar determinadas fuentes de información con respecto a otras.

Finalmente, uno de los propósitos de realizar una tesis de maestría es el de aportar nuevos y originales conocimientos que coadyuven al crecimiento y consolidación de la disciplina sobre la cual versa dicha investigación. Una de mis aportaciones dentro de este segundo capítulo consiste en recopilar los títulos, autores, asesores; así como los temas que están implicados en todos los trabajos de titulación presentados hasta el año 2007 en la ENBA, el Colegio de Bibliotecología de la UNAM y la UAEM.

Hasta el momento únicamente he obtenido los datos relacionados con el CB de la UNAM y la UAEM; lo que corresponde a la ENBA está en proceso de investigación, dada la dificultad de obtener la información correspondiente. Es muy probable que en la siguiente emisión de este Seminario los resultados ya estén completos.

Para efectos de este trabajo y tomando en cuenta que sería muy difícil presentar en una sola exposición todos los datos mencionados, únicamente se presentan algunos datos relevantes en torno a esta investigación: 
La investigación sobre las necesidades de información en...

\begin{tabular}{||c|c||}
\hline \multicolumn{2}{|c|}{$\begin{array}{c}\text { Trabajos de titulación de Licenciatura en } \\
\text { Bibliotecología presentados en la UNAM } \\
\text { entre 1959-2007 }\end{array}$} \\
\hline Total de trabajos presentados & 534 \\
\hline Tesis presentadas & 320 \\
\hline Tesinas presentadas & 127 \\
\hline Informes académicos presentados & 87 \\
\hline Tesis colectivas presentadas & 47 \\
\hline Mujeres tituladas & 397 \\
\hline Hombres titulados & 189 \\
\hline Años de mayor titulación \\
\hline 2001 & 48 \\
\hline 2003 & 44 \\
\hline 2000 & 37 \\
\hline 2004 & 37 \\
\hline 2005 & 35 \\
\hline
\end{tabular}

\begin{tabular}{||l|c|}
\hline \multicolumn{2}{|c|}{$\begin{array}{c}\text { Trabajos de titulación de Licenciatura en } \\
\text { Bibliotecología presentados en la UAEM } \\
\text { entre 1998-2007 }\end{array}$} \\
\hline Total de trabajos presentados & 37 \\
\hline Tesis presentadas & 32 \\
\hline Tesinas presentadas & 3 \\
\hline Informes académicos presentados & 2 \\
\hline Tesis colectivas presentadas & 1 \\
\hline Mujeres tituladas & 25 \\
\hline Hombres titulados & 15 \\
\hline
\end{tabular}


Comunidades de profesores y estudiantes universitarios

\begin{tabular}{|c|c|}
\hline \multicolumn{2}{|c|}{ Años de mayor titulación } \\
\hline 2002 & 9 \\
\hline 2006 & 7 \\
\hline 2004 & 6 \\
\hline 2007 & 6 \\
\hline
\end{tabular}

\section{Referencias bibliográficas}

Artellano Jiménez, Julissa. Estudio de las necesidades de información de la comunidad del Centro Mascarones pertenecientes al CELE-UNAM. México: Julissa Artellano Jiménez, 1999. 94 p.

Calva González, Juan José. Las necesidades de Información: fundamentos teóricos y Métodos. México: UNAM, CUIB, 2004. 284 p.

Calva González, Juan José. "Las necesidades de información de los Investigadores del área de humanidades y Ciencias Sociales". En Revista General de Información y Documentación. Vol. 13, no 2 (2003) pp. 155-180.

López, Ana María del Pilar. Necesidades y Comportamiento Informativo en los investigadores del CCyDEL. México: Ana María López Jaramillo, 2000. 127 p.

Sanz Casado, Elías. "La realización de estudios de usuarios: una necesidad urgente". En: Revista General de Información y Documentación. Vol. 3, no 1 (1993). 


\title{
Nuevas alternativas de servicios de información con base en las necesidades de información de los estudiantes de preparatoria del ITESM
}

\author{
LAURA Miranda Munguía \\ Instituto Tecnológico de Estudios Superiores \\ de Monterrey, México
}

\section{Justificación}

$\mathbf{Z}$ una biblioteca se requiere el constante diseño - de servicios de información, los cuales deben de girar con base en las necesidades de información que manifiestan nuestros usuarios, con la finalidad de responder con efectividad a sus demandas.

Actualmente, las nuevas tendencias de la sociedad como la globalización, la tecnología, la competitividad, han enriquecido la línea de investigación del usuario valorando sus características y necesidades de información, así como para repercutir en su beneficio a través del diseño de servicios de calidad que satisfagan sus perspectivas.

Los servicios de biblioteca se ofrecen bajo un estándar de acuerdo al tipo de biblioteca, sea infantil, escolar, pública, universitaria o especializada, dejando a un lado los estudios de necesidades de información que requieren nuestros propios usuarios; 
La investigación sobre las necesidades de información en...

dichos estudios pueden ser diferentes aún cuando se trate del mismo tipo de biblioteca o pertenezcan a una misma institución, sin olvidar que hay variables que pueden influir en sus diferentes requerimientos de información.

El diseño de servicios orientado a los estudiantes de preparatoria es una oportunidad para captarlos como usuarios y colaboradores de la biblioteca de por vida. Debido a que este sector de la población en pocos años ingresará a estudios profesionales y su trayectoria académica puede trascender y pertenecer a grupos especialistas de investigación.

\section{Planteamiento del problema}

En virtud de lo anterior, el presente trabajo se orienta a responder a las siguientes interrogantes:

- ¿Qué necesidades de información tienen los estudiantes de preparatoria entre 15 a 18 años?

- ¿Con qué finalidad necesitan la información?

- ¿Qué variables intervienen para manifestar sus necesidades de información?

- ¿Cuáles son las características generales de los estudiantes de nivel preparatoria como sujetos de 15 a 18 años?

- ¿Qué servicios de información se derivan de la detección de necesidades de información de los estudiantes de preparatoria? 
Comunidades de profesores y estudiantes universitarios

\section{Objetivo}

El objetivo por alcanzar en la presente investigación es identificar las necesidades de información y a partir de ellas proponer nuevas alternativas de servicios informativos para los estudiantes de preparatoria de la RZC del ITESM.

\section{Objetivos especificos}

- Proponer nuevas alternativas de servicios para cubrir las necesidades de información de los alumnos de preparatoria del ITESM.

- Detectar las necesidades de información de los estudiantes de preparatoria RZC del ITESM.

- Analizar las necesidades de información de los estudiantes de preparatoria RZC del ITESM.

- Identificar las características generales de los alumnos de nivel preparatoria.

- Determinar las variables que intervienen en los tipos de necesidades de información que presentan los alumnos de preparatoria. 
La investigación sobre las necesidades de información en...

\section{Hipótesis}

- Los servicios que ofrece actualmente la biblioteca no refleja las inquietudes propias de la edad de los sujetos.

- La clase co-currícular ${ }^{1}$ que cursan los sujetos influye en sus necesidades de información.

- Las inquietudes propias de la edad ${ }^{2}$ de los sujetos influyen en sus necesidades de información.

- La detección de necesidades de información hace posible el diseño de nuevos servicios de información.

\section{Variables externas}

- El lugar geográfico donde se ubican los estudiantes de preparatoria determina sus necesidades de información.

- El grado académico de sus familiares influye en las necesidades de información de los estudiantes de preparatoria.

1 La clase co-curricular puede ser deportes, teatro, ensamble, clases de música, pintura, fotografía, etcétera.

2 La moda, salud, estrenos cinematográficos, sucesos de espectáculos, últimas publicaciones de libros de literatura, deportes, últimos modelos de autor, novedades de equipo electrónico, programas de cómputo, etc. 
Comunidades de profesores y estudiantes universitarios

En el estudio me abocaré a la Rectoría Zona Centro, específicamente, lo que comprende la educación media superior. Dicha Rectoría está integrada por 3 Campus, algunos tiene sedes, donde se imparte esté nivel educativo.

- Campus Estado de México.

Localizado al norte de la zona metropolitana de la ciudad de México. Cuenta con una biblioteca exclusiva para ofrecer los servicios a los alumnos de preparatoria.

- Campus Querétaro.

Ubicado en el centro del Bajío de la República Mexicana. Al igual que el anterior Campus cuenta con una biblioteca donde se ofrecen servicios separados del resto de los alumnos de otros grados académicos. Cuenta con una sede en Celaya, Guanajuato que ofrece el servicio de biblioteca.

- Campus Toluca.

Localizado al sur de la capital del Estado de México. La biblioteca ofrece servicios a todos los alumnos de preparatoria, licenciatura, y doctorado. Cuenta con dos sedes: Atlacomulco y Metepec, las cuales tienen su respectiva biblioteca.

El ITESM, imparte el nivel bachillerato en 3 programas, todas serán incluidas en el presente estudio. 
La investigación sobre las necesidades de información en...

a) Preparatoria Bilingüe. El Programa Bilingüe busca aumentar el nivel de inglés en los alumnos, de manera que puedan tomar cursos en este idioma.

b) Preparatoria Bi-cultural. El Programa Bi-cultural está diseñado para alumnos que ya manejen adecuadamente el idioma inglés.

c) Preparatoria Internacional. Este programa busca aumentar el perfil de cada estudiante, permitiendo su inserción en un ambiente global, con la oportunidad de vivir una experiencia académica en el extranjero. Se ofrece en algunos campus, los cuales cuenta con la certificación de la Organización del Bachillerato Internacional (OBI).

De los avances obtenidos en el primer capítulo se cuenta con el anexo de la siguiente página, donde se incluyen los primeros 8 temas que los usuarios han manifestado como de su interés, conjuntado los resultados de 10 estudios. 







\title{
El comportamiento informativo de los usuarios basado en las TIC de las bibliotecas del Tecnológico de Monterrey
}

\author{
JuAn C. Alba LeOnel \\ Posgrado en Bibliotecología \\ Universidad Nacional Autónoma de México
}

\section{Introducción}

Genéricamente podemos entender por TIC el quisición, producción, almacenamiento, procesado, comunicación y recuperación de información en forma digital. Esto incluye todos los sistemas informáticos y no solamente las computadoras, ya que éstas son sólo un medio más, el más versátil, pero no el único; también se incluyen redes de telecomunicaciones, telemática, los teléfonos celulares, la televisión, la radio, los periódicos digitales, faxes, dispositivos portátiles, etcétera. Todas estas herramientas electrónicas de primera mano son de carácter determinante en la vida de todo profesional.

El impacto de las TIC sobre las apreciaciones de los usuarios de las bibliotecas no afecta solamente al conjunto de habilidades y destrezas que éstos ya 
La investigación sobre las necesidades de información en...

poseían para buscar y localizar su información, sino a la capacidad para desarrollar habilidades y un pensamiento creativo y analítico para discriminar y seleccionar la información de su utilidad.

En otras palabras, hay tecnologías de información que sirven para comunicarnos pero, para el propósito de esta investigación, tan solo nos interesan las que utilizamos para compartir recursos como son:

a) La Internet a través del servicio de World Wide Web (WWW).

b) La Biblioteca Digital del Sistema Bibliotecario del Tecnológico de Monterrey.

\section{Comportamiento informativo}

Es importante estudiar y evaluar las TIC en las bibliotecas, pero esas investigaciones no se deben limitar a estudiar y evaluar únicamente las aplicaciones de estas tecnologías. Además es de sumo interés conocer los efectos que los servicios de información, basados en tecnología, producen en nuestros usuarios.

Es tan sencillo quedarse absorto en el servicio basado en tecnología y olvidarse de todo lo referente al usuario, ¿piensa el usuario que es una buena idea? Ningún servicio es bueno si no tiene usuarios, de aquí la trascendencia de los estudios del comportamiento informativo; la retroalimenta- 
ción por parte de los usuarios es de un valor incalculable que facilita a los bibliotecarios la toma de decisiones sobre el papel adecuado y el impacto de la tecnología sobre una población estudiantil cada vez más diversa.

De estos planteamientos reales surgen varios interrogantes respecto a los usuarios: ¿En qué época los bibliotecarios han cumplido mejor con su misión informativa? ¿Ahora que los usuarios están sobre-informados con tantos recursos y fuentes de información o antes, cuando los usuarios manifestaban que les hacía falta información porque los acervos de las bibliotecas no estaban actualizados?

\section{Planteamiento del problema}

Es fundamental que se estudie el comportamiento informativo de los usuarios de las Bibliotecas en el nuevo contexto basado en las TIC. Se deben considerar aquellos factores que de alguna manera llegan a influir en que el usuario tenga éxito o fracaso en la búsqueda de su información. De este modo, frente a la pregunta, ¿cuál es el patrón de búsqueda que siguen los alumnos del Tecnológico de Monterrey para la localización de la información al usar recursos basados en las TIC y tener éxito en su localización y satisfacción de su necesidad en su campo de estudio?, surgen otras cuestiones que hay que indagar: 
La investigación sobre las necesidades de información en...

- ¿El usuario de las bibliotecas del Tecnológico de Monterrey sabe cómo localizar los sitios Web que le proporcionen información relevante y fiable sobre su campo de estudio?

- ¿Cuáles son las exigencias organizativas y los obstáculos que se les presentan antes de lograr tener éxito en la localización de su información?

- ¿Cuál es el comportamiento informativo de los alumnos del Tecnológico de Monterrey al buscar información en algún recurso basado en TIC? (Internet, Biblioteca digital)

- ¿Cuáles son las fuentes principales de información que utilizan los alumnos del Tecnológico de Monterrey al usar las TIC?

\section{Objetivos}

- Analizar el comportamiento informativo de los alumnos del Tecnológico de Monterrey en el contexto de un proceso de uso de TIC.

- Desarrollar el planteamiento de un modelo tutorial asistido por bibliotecarios profesionales para los alumnos durante la elaboración de sus proyectos escolares en diversas áreas de estudio.

- Determinar el comportamiento informativo que siguen los usuarios de las bibliotecas del Tecnológico de Monterrey para la satisfacción de sus necesidades de información al utilizar recursos basados en TIC. 
Comunidades de profesores y estudiantes universitarios

- Identificar las diferentes manifestaciones de búsqueda de información que presentan los alumnos del Tecnológico de Monterrey RZC al utilizar TIC en la localización de su información.

\section{Hipótesis}

Las hipótesis de investigación buscan probar el impacto que tienen las TIC (la Internet y Biblioteca Digital) entre sí, y las causas y efecto que éstas pudieran tener en el comportamiento informativo de los usuarios de las Bibliotecas:

- Las TIC determinan el comportamiento informativo de los alumnos del Tecnológico de Monterrey de la RZC al hacer sus búsquedas de información.

- Los alumnos piensan que las Tecnologías de Información traen enormes beneficios para la satisfacción de sus necesidades de información durante su trayectoria escolar.

- Los alumnos del Tecnológico de Monterrey de la RZC prefieren utilizar más los buscadores Web que la Biblioteca Digital por el formato de búsqueda sencillo que presentan.

- La manifestación de éxito que presentan los alumnos del Tecnológico de Monterrey RZC al realizar sus búsquedas de información, es menor en los que utilizan buscadores Web en comparación con los que prefieren usar la Biblioteca digital. 
La investigación sobre las necesidades de información en...

\section{Marco teórico}

En otros países se han realizado estudios sobre el comportamiento informativo en diversos grupos o sectores de la sociedad, como lo muestran las búsquedas realizadas en LISA, Emeral, pero pocos son referidos al comportamiento informativo basados en el uso de las TIC.

\section{Marco de referencia}

- La Rectoría Zona Centro del Tecnológico de Monterrey, comprende 3 Campus: Estado de México, Toluca y Querétaro,

- La Rectoría Zona Centro (RZC) es la segunda en tamaño con el 19\% del total de alumnos a nivel sistema, equivalentes a una población estudiantil de esta rectoría de 17,646 alumnos inscritos en algún programa académico de nivel preparatoria, profesional y de posgrado.

\section{Muestra}

El tamaño de muestra es $n=376$ fue distribuido de manera estratificada por nivel académico (atributo) para cada Campus de la Rectoría Zona Centro diseñando una muestra probabilística estratificada. 
Comunidades de profesores y estudiantes universitarios

\begin{tabular}{|c|c|c|c|c|c|c|c|c|}
\hline \multirow{3}{*}{ Campus } & \multicolumn{7}{|c|}{$\begin{array}{l}\text { Tecnológico de Monterrey Rectoría Zona Centro } \\
\text { Número de alumnos inscritos en los programas académicos } \\
\text { de preparatoria, profesional y posgrado }\end{array}$} & \\
\hline & \multicolumn{4}{|c|}{ Enero de 2006} & \multicolumn{4}{|c|}{ Agosto de 2006} \\
\hline & Preparatoria & Profesional & Posgrado & Total & Preparatoria & Profesional & Posgrado & Total \\
\hline $\begin{array}{l}\text { Estado de } \\
\text { México }\end{array}$ & 2146 & 5444 & 822 & 8412 & 2134 & 5487 & 765 & 8386 \\
\hline Querétaro & 1298 & 3080 & 285 & 4663 & 1277 & 3337 & 294 & 4908 \\
\hline Toluca & 1627 & 2099 & 625 & 4351 & 1541 & 2245 & 783 & 4569 \\
\hline Total & 5071 & 10623 & 1732 & 17426 & 4952 & 11069 & 1842 & 17863 \\
\hline
\end{tabular}

\begin{tabular}{||c|c|c||}
\hline \multicolumn{3}{|c||}{ Muestra probabilística estratificada } \\
\hline \multicolumn{1}{||c||}{ Estrato del Tec de } & $\begin{array}{c}\text { Número de Estudiantes } \\
\text { Mnero Agosto 2006 }\end{array}$ & $\begin{array}{c}\text { Determinacion de tamaños de } \\
\text { muestra para cada nivel de } \\
\text { estudios y campus }\end{array}$ \\
\hline A. Estado de México & 8399 & 46 \\
- Preparatoria & 2140 & 117 \\
- Profesional & 5465 & 17 \\
- Posgrado & 794 & 27 \\
\hline B. Querétaro & 4784 & 68 \\
- Preparatoria & 1287 & 6 \\
- Profesional & 3208 & 289 \\
- Posgrado & 289 & \\
\hline
\end{tabular}

\section{Instrumento}

Se utilizará un cuestionario aplicado a la muestra estratificada y se utilizará también una cédula de observación aplicada al $10 \%$ de los sujetos seleccionados. 


\title{
El comportamiento informativo de los docentes en las áreas de Educación y Humanidades en la Universidad Autónoma del Estado de México
}

\author{
José ARTURo MejÍA LÓPEZ \\ Universidad Autónoma del \\ Estado de México
}

\section{Justificación}

Z1 motivo de la presente investigación es elaboLrar una serie de perfiles para determinar cuál es el comportamiento informativo que existe dentro de las universidades, con la finalidad de detectar los cambios de hábitos y necesidades que tienen los docentes en Educación y Humanidades.

Se hace imprescindible llevar a cabo los estudios que permitan determinar lo que necesitan y utilizan los docentes en su trabajo, ya que son los transmisores de información hacia los alumnos. Cabe resaltar que no se han realizado estudios sobre el comportamiento informativo en ningún área de conocimiento dentro de la Universidad Autónoma del Estado de México (UAEMéx). 
La investigación sobre las necesidades de información en...

\section{Planteamiento del problema}

Debido a lo anterior, y con el interés de conocer a esta comunidad de usuarios (los docentes en las áreas de Educación y Humanidades), se parte de los siguientes cuestionamientos:

- ¿Cuáles son los factores a los que se enfrentan los docentes para tener acceso a las fuentes de información?

- ¿Con qué frecuencia utilizan determinados recursos informativos en Educación y Humanidades?

- ¿Cuál es el comportamiento informativo que presentan los docentes en las áreas de Educación y Humanidades cuando buscan información en la UAEM?

- ¿Cuáles son los recursos informativos que utilizan los docentes en las áreas de Educación y Humanidades?

\section{Objetivos}

Como objetivos de este proyecto de investigación tenemos:

- Determinar el comportamiento informativo que existe entre los docentes en las áreas de Educación y Humanidades en la UAEM. 
Comunidades de profesores y estudiantes universitarios

- Establecer los factores a los que se enfrentan los docentes para acceder a las fuentes de información.

- Identificar los recursos informativos que utilizan los docentes con base en sus intereses, opiniones y actitudes para preparar sus clases.

- Identificar qué recurso informativo utilizan los docentes con mayor frecuencia.

\section{Hipótesis}

A partir del planteamiento del problema y de los objetivos tenemos las siguientes hipótesis:

- Los docentes en Educación y Humanidades recurren más a sus colegas que a la biblioteca.

- Los docentes en Educación y Humanidades utilizan materiales primarios para llevar a cabo sus actividades docentes.

- El acceso físico hacia los materiales es un problema al que se enfrentan los docentes para utilizar las fuentes de información.

- Los docentes en Educación y Humanidades no utilizan fuentes de información electrónicas debido a que consideran no fiable la información que encuentran a través de los motores de búsqueda, por lo tanto es escaso el uso de ellas. 
La investigación sobre las necesidades de información en...

\section{Marco teórico}

Los estudios de usuarios de documentación surgen en la década de los veinte del siglo pasado; si bien, como apunta Elías Sanz (1994), es a partir de los años cincuenta cuando comienzan a ser investigaciones menos inusitadas. La causa de la proliferación de estas investigaciones fue el elevado número de documentos con información tecnológica sobre avances científicos generados durante la II Guerra Mundial. Para Martha Valencia:

Los estudios de usuarios son considerados como un método sistemático de recolectar información concerniente con la biblioteca, sus actividades, operaciones, personal, uso y usuarios, en un tiempo dado. Sirven para dar una visión más que un plan detallado y pueden ser motivados por la necesidad de incrementar y proveer información o satisfacer una curiosidad. 1

Un estudio de usuarios se define como el medio eficaz para conocer las necesidades de los usuarios y establecer los mecanismos para satisfacerlos apropiadamente, permitiendo una evaluación continua del sistema. ${ }^{2}$

1 Martha Valencia de Veizaga. Estudios de Usuarios en las bibliotecas universitarias. OEA, 1982, p. 2

2 Sandra Alpizar Moya. El usuario y los servicios de información; ILANUD,1993. 
Comunidades de profesores y estudiantes universitarios

Se utilizará como soporte teórico, el modelo de las necesidades de información (NEIN) ${ }^{3}$, para poder explicar el tema de esta investigación. Este modelo tiene como objetivo aportar conocimientos teóricos en torno a las necesidades de información y por ende al comportamiento informativo. Esté ultimo, con sus tipos y patrones está conformado por las distintas manifestaciones de las necesidades de información de los sujetos. En esta etapa es donde el usuario es motivado a buscar la satisfacción de dichas necesidades.

Cabe resaltar que el comportamiento informativo está bajo el predominio de factores internos (características particulares del usuario) y externos (ambiente).

La satisfacción de las necesidades de información permite observar cómo el usuario da uso de la información, dependiendo de esto, el usuario estará satisfecho o insatisfecho.

Por lo citado, el estudio de usuarios no es un concepto nuevo pero sí es un concepto que auxilia a ampliar la importancia y la razón de ser de las bibliotecas. Sus resultados facilitan el proceso de decisión y son útiles en la identificación de las necesidades.

3 Juan José Calva González. Las necesidades de información: Fundamentos teóricos y métodos. México: UNAM, Centro Universitario de Investigaciones Bibliotecológicas. 2004. p. 284 
La investigación sobre las necesidades de información en...

Del estudio de usuarios sobresale en gran medida el estudio del comportamiento en la búsqueda de información, área importante ya que es la que nos indicará si efectivamente se satisfacen las necesidades, precisa las condiciones que deben cumplir los servicios, define el tipo de preparación y/o formación de los usuarios. ${ }^{4}$

\section{Marco referencial}

El 8 de marzo de 1965 el H. Consejo Universitario autoriza las carreras de Licenciado en Historia, Filosofía y Letras. Por esta razón, en sus inicios se cursaba un tronco común para las tres licenciaturas y después, se cursaban las materias correspondientes a la carrera elegida.

En 1985 se reestructuró el plan de estudios de la licenciatura en Letras, aumentando un año más la duración de los estudios.

El plan de estudios de la Licenciatura en Historia se reformó y se aprobó en 1984.

4 Mónica Izquierdo Alonso, Joaquín Ruíz Abellan y Tomás Piñero, José "Los estudios de usuarios en los programas de gestión de calidad. Propuesta de un marco teórico integrador para el estudio del usuario de información”. En: VI Jornadas Españolas de Documentación FESABID 98. Disponible en:

http://fesabid98.florida-uni.es/Comunicaciones/m_izquierdo /m_izquierdo.htm 
Comunidades de profesores y estudiantes universitarios

En lo referente a la Licenciatura en Arte Dramático, el 29 de agosto de 1985 fue aprobada esta Licenciatura por el H. Consejo Universitario con el propósito de responder a las necesidades de la juventud del Estado de México para adquirir preparación Universitaria en esta rama.

Por último, y no por eso menos importante, buscando la manera de formar los profesionales que se requieren en la organización, conservación, catalogación, clasificación, análisis y difusión de material documental y bibliográfico mediante la aplicación y el dominio de nuevas tecnologías; se creó la Licenciatura en Ciencias de la Información Documental.

En lo que respecta al área de Educación se encuentran las Facultades de Ciencias de la Conducta y Lenguas.

La Facultad de Ciencias de la Conducta brinda la licenciatura en Psicología, Trabajo Social y Educación. La carrera de Licenciado en Psicología se funda el 3 de octubre de 1973. Esta carrera comenzó a funcionar en las instalaciones de la Facultad de $\mathrm{Hu}-$ manidades en el Cerro de Coatepec, Ciudad Universitaria; posteriormente se trasladó al Edificio de Rectoría de la UAEM, y finalmente, en 1976, ocupa las instalaciones ubicadas en el Km. 1.5 de la carretera Toluca-Naucalpan. 
La investigación sobre las necesidades de información en...

También la Facultad de Ciencias de la Conducta, ofrece dos nuevas opciones de estudios superiores, con la creación de la carrera de Trabajo Social y Educación. Dichas carrera fueron aprobadas por el H. Consejo Universitario en el año 2006.

En lo que respecta a la Facultad de Lenguas es uno de los organismos académicos de más reciente creación en la UAEM. Su ámbito de desarrollo es el estudio, enseñanza e investigación de las lenguas. La Facultad ha tenido un crecimiento y desarrollo acelerado a partir de la fecha de su creación en julio de 1992, como un programa de Licenciatura dependiente de la Secretaría Académica de la UAEM. La Facultad ofrece las licenciaturas en Enseñanza del Inglés, Lengua Inglesa, Lengua y Cultura francesa y Lenguas.

\section{Metodología}

El estudio, siguiendo la anterior exposición, aborda a los docentes de tiempo completo y medio tiempo de la Facultad de Humanidades, Ciencias de la Conducta y Lenguas; se omite a los Docentes por Asignatura debido a que no se encuentran el tiempo suficiente en las dependencias para obtener de ella los servicios al $100 \%$ para impartir sus clases, es decir su vida académica es parcial. 
Comunidades de profesores y estudiantes universitarios

La población está repartida de la siguiente manera:

\section{Facultad de Humanidades}

La población consta de 130 docentes repartidos en:

> 53 de Tiempo completo

> 6 de Medio tiempo

- 71 de Asignatura (Docentes a omitir)

\section{Facultas de Ciencias de la Conducta}

La población consta de 109 docentes repartidos en:

> 45 de Tiempo completo

, 3 de Medio tiempo

- 61 de Asignatura (Docentes a omitir)

\section{Facultad de Lenguas}

La población consta de 54 docentes repartidos en:

> 16 de Tiempo completo

- 0 de Medio tiempo

- 38 de Asignatura (Docentes a omitir)

Por ende, la población que se estudiará será de 114 docentes de tiempo completo y 9 docentes de medio tiempo dando un total de 123 docentes de las áreas de Educación y Humanidades. Los anteriores están repartidos por licenciatura de la siguiente manera: 
La investigación sobre las necesidades de información en...

\section{Facultad de Humanidades}

- Licenciatura en Filosofía: 12 docentes de tiempo completo y 1 docente de medio tiempo

- Licenciatura en Historia: 15 docentes de tiempo completo y 2 docente de medio tiempo

- Licenciatura en Letras: 20 docentes de tiempo completo 1 docente de medio tiempo

- Licenciatura en Arte Dramático: 1 docente de tiempo completo y 1 docente de medio tiempo

- Licenciatura en Ciencias de la Información Documental: 5 docentes de tiempo completo y 1 docente de medio tiempo

Facultas de Ciencias de la Conducta

- Licenciatura en Psicología: 39 docentes de tiempo completo y 3 de medio tiempo.

- Trabajo Social: 3 docentes de tiempo completo

- Educación: 3 docentes de tiempo completo

\section{Facultad de Lenguas}

- Licenciatura en Enseñanza del Inglés: 3, (también dan clases en la licenciatura en lenguas).

- Licenciatura en Lenguas: 16 docentes de tiempo completo

Una vez seleccionado el universo objeto de estudio es necesario elegir un método para recolectar datos. Con otras palabras, hay que establecer los instrumentos que se van a usar para el estudio. 
Comunidades de profesores y estudiantes universitarios

Los estudios de mercado utilizan la observación (encuestas, entrevistas...) como método más común de acopio de datos. No obstante, existe una extensa tipología, que va desde el uso de fuentes estadísticas hasta el de documentos bibliográficos; estos últimos comparten el no ser métodos concebidos para tal uso sino que, generados por otros individuos u organismos, pueden reutilizarse para investigaciones de estas características.

Por otro lado, los diversos métodos de acopio de datos están íntimamente ligados a la actitud del usuario que puede ser directa, cuando se les interroga sobre los aspectos que se desean conocer, o indirecta, cuando se les observa o se interpretan sus acciones. Sin lugar a dudas, de un estudio que conjugue ambas opciones se puede extraer información más completa. Por lo anterior será una investigación exploratoria-descriptiva y se acudirá a los 123 docentes. Se utilizará como instrumento una "cédula de entrevista".

\section{Referencias bibliográficas:}

Alpizar Moya, Sandra. El usuario y los servicios de información; ILANUD, 1993. Disponible en: http://eprints.rclis.org/archive/00001103/

Busha, Charles. Métodos de investigación en bibliotecología: técnicas e interpretación. México: UNAM, CUIB, 1990. 
La investigación sobre las necesidades de información en...

Calva González, Juan José. Análisis de las necesidades de información documental: teoría y métodos. Madrid: El autor, 2001 (tesis de doctor), Universidad Complutense.

Calva González, Juan José. "El comportamiento en la búsqueda de información de los investigadores del área de humanidades y ciencias sociales". En: Investigación Bibliotecológica: Archivonomía, Bibliotecología e Información. Vol. 13, no. 27, 1999.

Calva González, Juan José. Las necesidades de información: Fundamentos teóricos y métodos. México: UNAM, Centro Universitario de Investigaciones Bibliotecológicas. 2004.

Calva González, Juan José. “Las necesidades y comportamiento de los investigadores como usuarios de las bibliotecas de las instituciones de educación superior en América Latina". En: Documentación de las ciencias de la información (DIALNET), número 27, 2004, pp. 97-116. Disponible en:

http://dialnet.unirioja.es/servlet/oaiart?codigo = 1089847

Calva González, Juan José. "Surgimiento y manifestación de las necesidades de información en los investigadores”. En: Investigación Bibliotecológica: Archivonomía, Bibliotecología e Información. Vol. 09, no. 19, 1995. 
Comunidades de profesores y estudiantes universitarios

Case Donald Owen. "The collection and use of information by some American historians: a study of motives and methods". En: Library Quarterly, No. 1, Vol. 61, 1991.

Directrices para los estudios relativos a los usuarios de la información. Versión experimental. 1981 Disponible en:

http://unesdoc.unesco.org/images/0004/000437/

043721eb.pdf

Domínguez Aroca, M. Isabel. "La biblioteca universitaria ante el nuevo modelo de aprendizaje: docentes y bibliotecarios, aprendamos juntos porque trabajamos juntos”. En: RED Revista de Educación a Distancia, número IV, 2005, Disponible en: http://redalyc.uaemex.mx/redalyc/src/inicio/ ArtPdfRed.jsp? $\mathrm{iCve}=54709706$

French Beverly A. User needs and library services. Library Trends. 1990, vol. 38, number 3 winter.

Fulton, C. "Humanist as information user". En: Australian academia and research libraries. Vol. 22, No. 3, 1991.

Gonzalez Teruel, Aurora. Los estudios de necesidades y usos de la información: fundamentos y perspectivas actuales. Somonte-Cenero, Gijón: Trea, 2005. 
La investigación sobre las necesidades de información en...

James Kalbach. Designing for Information Foragers: $A$ Behavioral Model for Information Seeking on the World Wide Web. Disponible en:

http://www.internettg.org/newsletter/dec00/article_information_foragers.html

Legislación de la UAEM 2006. Toluca, México, Universidad Autónoma del Estadio de México. 2006.

Orera Orera, Luisa. La biblioteca universitaria: análisis en su entorno híbrido. Madrid: Síntesis, 2005.

Peñaloza García, Inocente. La UAEM y sus fuentes: Fragmentos de la historia universitaria a través de documentos 1827-1956. Toluca, México: UAEM, 2005.

Peñaloza García, Inocente. Orígenes de la autonomía ICLA-UAEM. Toluca, México: UAEM, 2004.

Santaella Ruiz, Rita Dolores. Metodología de estudios de usuarios de información. Estudio de casos en la Administración Pública. 2005. Revista TEXTOS de la CiberSociedad, 5. Temática Variada. Disponible en: http://www.cibersociedad.net

Santos Rosas, Antonia. El comportamiento informativo de los investigadores del Instituto de Geografía de la UNAM. México. El autor, 2005 (Tesis licenciatura). UNAM.

Santos Rosas, Antonia y Juan José Calva González. "Identificación de las necesidades de información: un estudio" En Documentación de ciencias de la información. vol. 20, 1997. 
Comunidades de profesores y estudiantes universitarios

Sanz Casado, Elías. Manual de estudios de usuarios. Madrid: Fundación Germán Sánchez Ruipérez, 1994.

Valencia de Veizaga, Martha. Estudios de Usuarios en las bibliotecas universitarias. OEA, 1982. Disponible en: http://eprints.rclis.org/archive/00001103/

Wilson T.D., Ellis David y Nigel Ford. Uncertainty in information seeking. Disponible en:

http://informationr.net/tdw/publ/unis/

Wan Gary. Remote user needs of library services. 2005. Disponible en: http://gwan3.blogspot.com/2005/05/remote-userneeds-of-library-services.html 
Comunidades vitivinícolas 


\title{
Desarrollo de la industria vitivinícola en Mexico. Información para la producción de Vitis vinífera. Proyecto PAPIIT IN404408-3
}

\author{
JUAN JOSÉ CALVA GONZÁlEZ
}

Centro Universitario de Investigaciones Bibliotecológicas Universidad Nacional Autónoma de México

\section{Introducción}

\section{L}

as personas presentan necesidades de diferentes tipos: fisiológicas, primarias o básicas como son el hambre, la sed, el sueño, etcétera, así como necesidades de salud, de protección o seguridad, de empleo y de niveles más altos donde se pueden encontrar las de información.

Debido a que las personas presentan necesidades de información y que por lo tanto este es un fenómeno recurrente en el hombre en sus múltiples facetas de actividad, puede ser investigado.

Por otro lado cada unidad de información (biblioteca, centro de documentación, centro de información, etcétera) atiende a un sector de la sociedad (investigadores, niños, estudiantes, agricultores, vitivinicultores, ganaderos, productores de leche, tequila, etcétera) y para satisfacer sus necesidades de información requiere, primeramente, cono- 
La investigación sobre las necesidades de información en...

cer cuáles son, por lo cual debe detectarlas, identificarlas, analizarlas y desarrollar los mecanismos necesarios para satisfacerlas y esto lleva a afirmar que el usuario está concatenado recíprocamente con la unidad de información y el documento que tiene registrada información.

La información que necesita el usuario para satisfacer su necesidad puede no estar incluida en el acervo documental de la unidad de información, por lo que tocaría a ésta vincular al usuario con dicha información, aunque éste se ubique fuera de ella en algún otro documento no bibliográfico o en otro tipo de unidad de información como un museo o un archivo.

La investigación sobre la información que necesitan los usuarios y donde se localiza tanto en bibliotecas como en otros recursos informativos pueden dar pautas para descubrir las bases o principios para conformar una "teoría sobre las necesidades de información" 1 y de esta forma, crear y enriqueces diversos modelos siendo uno de ellos el modelo NEIN (Modelo sobre las Necesidades de Informa-

1 D.I. Blyumenau. "Refining initial concepts in information need theory" Nauchno Tekbinicheskaya informatsiya. 1986, serie 2, no. 2, p. 49. Texto en inglés. "Teoría de las necesidades de información" es un término empleado por este autor para decir que sí es posible la existencia de una teoría acerca de las necesidades de información. 
ción), donde se relacionen las variables que intervienen y que pueda ser aplicado en la práctica con una metodología rigurosa.

$\mathrm{El}$ análisis de investigaciones llevadas a cabo permitirá adentrarse en la existencia de relaciones entre varios elementos (variables) para seguir o continuar con la conformación de bases para de una "teoría acerca de las necesidades de información".

Por todo lo anterior, el presente trabajo es una introducción a la presentación del proyecto PAPIIT IN404408-3 "Desarrollo de la industria vitivinícola en México: información para la producción de Vitis vinífera" en el cual participan varias investigaciones que culminarán en la obtención de grados de doctorado y maestría, pero a la vez se cuenta con la participación de alumnos de licenciatura que desde su perspectiva y conocimiento profesional podrán en dos de los casos obtener el título y en otro de ellos adquirir la experiencia de participar en proyectos de investigación y obtener el conocimiento sobre aspectos bibliográficos.

Este proyecto se encuentra dentro del Programa de Apoyos a Proyectos de Investigación e Innovación Tecnológica (PAPIIT) IN404408-3 y cuenta con profesores e investigadores participan-

2 D.I. Blyumenau, Op Cit., p. 49. 
La investigación sobre las necesidades de información en...

tes, con la elaboración de tesis de doctorado, maestría y licenciatura.

La investigación sobre aspectos de información (necesidades, comportamiento y satisfacción) de los vitivinicultores en México no se ha llevado a cabo. Asimismo, tampoco se tienen antecedentes con respecto a las fuentes y recursos de información que utilizan o pueden brindarles apoyo para aumentar la producción y calidad de los viñedos y los productos derivados de ellos.

Los materiales publicados radican sobre los siguientes aspectos principales:

a) Historia del desarrollo de la industria vitivinícola mexicana a partir de la llegada de los europeos a Mesoamérica.

b) El desarrollo histórico de las diferentes marcas o bodegas que producen vino a partir de la Vitis vinifera como por ejemplo: La Cetto y Domecq.

c) La llegada de vitivinicultores europeos a las diferentes regiones donde se cultiva la Vitis vinifera, describiendo sus bodegas y los productos que ofrecen a la sociedad mexicana.

d) Problemas económicos para el desarrollo de la industria vitivinícola mexicana en algunas regiones como el estado de Sonora.

e) Descripción de los procesos de producción de la Vitis vinifera y de la elaboración de los diferentes tipos de vinos en México (tintos, blancos y 
espumosos) presentados como textos elaborados principalmente por la Universidad Autónoma Metropolitana para apoyar la materia de enología (no licenciatura).

Por otro lado existe mucha literatura sobre otras regiones del mundo principalmente la francesa y la española, no así para la mexicana.

Asimismo, existe bastante literatura sobre el producto final que es el vino y la forma de servirlo en y con los alimentos sobre todo enfocado a la industria restaurantera y turística (elementos que no son parte, por lo menos de esta investigación).

Los antecedentes generales de la producción de Vitis vinifera para producir vino adquirieron visibilidad a finales de los años ochenta, esto incluyó no solo a los mexicanos sino también a los argentinos y a los habitantes de otras regiones como Nueva Zelanda y Australia principalmente.

En el caso mexicano, la introducción en nuestro país se logró al trabajo de varios actores entre ellos a los productores establecidos en diferentes regiones, así como a los enólogos y vitivinicultores expertos que en algún momento dado decidieron ir hacia una nueva aventura y producir vinos de alta calidad capaces de competir con los extranjeros.

Hoy día, el vino mexicano está siendo considerado, y cada vez con más frecuencia, entre los mejores del mundo. Por el reconocimiento, tanto nacio- 
La investigación sobre las necesidades de información en...

nal como internacional, que en la actualidad estimula los esfuerzos de sus protagonistas

Hoy en día, la industria vitivinícola en México goza de muy buena salud es decir, sigue en desarrollo por lo cual se hace importante su estudio a profundidad desde una perspectiva bibliotecológica y de la información, así como de la geográfica.

Debido a las actividades propias de los vitivinicultores y del producto que generan, que es el vino en sus tres tipos, es preciso cuestionarse sobre los siguientes problemas de investigación:

Los vitivinicultores en México cuentan con la información necesaria y el acceso a la misma para desarrollar su industria y su producto final que es el vino en sus diferentes tipos. Y averiguar si existe alguna relación entre el acceso a la información que necesitan y la producción de la vid y del vino que producen. Asimismo es preciso indagar cuáles son las necesidades de información que tienen los vitivinicultores para poder producir una alta calidad de vid y por tanto de vino.

A la vez tomar en cuenta que si la industria vitivinícola en México ha iniciado su ascenso es preciso profundizar sobre qué fuentes y qué tipo de recursos de información son accesibles en cada región de vitivinicultores en México.

Debido a los escasos acercamientos desde la bibliotecología hacia esta comunidad de usuarios de 
la información, nos basaremos en los siguientes modelos teóricos donde se contemplan los aspectos de necesidades de información, comportamiento en la búsqueda de información y la satisfacción de las necesidades informativas:

- Modelo NEIN (UNAM)

- Modelo de Krikelas (University of Wisconsin)

- Modelo de Applegate (The College of St. Scholastica Library)

Los cuales brindarán algunas de las variables que se manejarán, como son:

a) Entorno físico donde se ubican los usuarios y el producto que elaboran.

b) Características del usuario de la información (vitivinicultores)

- Experiencia

- Conocimiento previo

- Forma de buscar la información (uso de fuentes de información)

c) Información que necesitan para desarrollar su industria.

d) Recursos de información disponibles en México para esta comunidad de usuarios.

El objetivo principal de la investigación es la identificación de las necesidades de información y el comportamiento informativo de los vitivinicultores en México, distribuidos en las cinco grandes regiones donde existe o desarrolla esta industria. Tomando en 
La investigación sobre las necesidades de información en...

consideración la descripción de las regulaciones o normas aplicables en México para la producción de Vitis vinifera y sus derivados. Asimismo, en la medida de las posibilidades, describir la situación geográfica de las regiones productores de Vitis vinífera para la posibilidad del diseño de un sistema de información para el desarrollo de bibliotecas, centros de información y documentación que apoyen la producción vitivinícola mexicana.

Partiendo del supuesto que los vitivinicultores presentan necesidades de información para poder desarrollar su industria, así como de los planteamientos presentados en los apartados anteriores se tienen las siguientes hipótesis:

a) El acceso a los recursos informativos existentes en México intervienen como una variable más en la producción, proceso y elaboración de los productos obtenidos de las regiones vitivinícolas mexicanas a parte de las ya conocidas y propias de esta industria como el suelo, el clima, la variedad de uva, la forma de cultivo y las regulaciones propias del producto.

b) La información es un factor determinante para el trabajo de los productores vitivinícolas en México, para mantenerse en el mercado competitivo con los demás productores mexicanos y con los extranjeros. 
c) Si la información que necesitan los productores vitivinícolas mexicanos es una variable que determina su producción, proceso y elaboración de productos entonces la existencia de sistemas de información como bibliotecas u otros, aumentarán las posibilidades para que los vitivinicultores puedan estar en posibilidades de competir con otros mexicanos y extranjeros.

d) La identificación de la situación geográfica de cada una de las regiones vitivinícolas mexicanas puede ser incluida en una biblioteca o sistema de información que puede favorecer el acceso a la información y por tanto el aumento de la producción, proceso y elaboración de los productos obtenidos por cada productor vitivinícola.

\section{Metodología}

La presente investigación tiene como unidades de análisis:

a) Las necesidades de información de los productores vitivinícolas (de la vid y de sus productos) mexicanos ubicados en las regiones donde se cultiva la Vitis vinifera en México.

b) Los recursos y fuentes informativas sobre la producción de Vitis vinifera y sus derivados utilizados por los vitivinicultores.

c) Las regulaciones o normas para la producción de Vitis vinifera en México. 
La investigación sobre las necesidades de información en...

Para llevar a cabo la investigación sobre sus tres objetos se llevará a cabo lo siguiente:

a) Una investigación documental.

b) Se realizará un análisis crítico de los recursos informativos identificados.

c) Investigación de campo con los productores de Vitis vinifera en las regiones donde se cultiva en el país y donde se utiliza para la producción de vino.

La investigación de campo se llevará a cabo a través de una entrevista simiestructurada.

Con base en los objetos de investigación que se persiguen y de cómo serán abordados, los instrumentos que se utilizarán para la recolección de los datos que permitan su análisis e interpretación serán:

a) Cédula para la descripción y análisis de los recursos informativos mexicanos tanto impresos como de otro tipo (electrónicos, audiovisuales, reales).

b) Cédula de entrevista.

Las diferentes regiones serán investigadas por los participantes en este proyecto es decir, cada uno de los tesistas adscritos a este proyecto se distribuirán en las diferentes regiones que cultivan la Vitis vinifera y de la cual se produce el vino, que por lo regular la casa productora se encuentra ubicada en los propios viñedos o en sus cercanías. 
La distribución de las regiones vitivinícolas será con el siguiente esquema aproximadamente:

- Mtro. Fermín López Franco (tesis de doctorado) - Baja California.

- Lic. José Mejía Ruiz (tesis de maestría)

- Querétaro

- Lic. Ana Laura Peña Aguilar (tesis de maestría)

- Guanajuato

- Lic. Enedina Salazar Méndez (tesis de maestría)

- Coahuila

- Lic. José Tomas Palacios Medellín (tesis de maestría)

- Zacatecas, Aguascalientes y Durango.

- Pas. Miguel Ángel de la Rosa Hernández (tesis de licenciatura)

- Regulaciones nacionales - posible becario.

- Pas. Dora Luz Otero Sánchez (tesis de licenciatura)

- Bibliografía sobre fuentes y recursos de información vitivinícola en México.

- Dr. Juan José Calva González

- Baja California.

Asimismo todo parece indicar que México sigue siendo el que lleva la vanguardia en esta temática e inicia un acercamiento hacia otro tipo de comunidades de usuarios como lo son los sectores productivos que en este caso son los vitivinicultores. 
La investigación sobre las necesidades de información en...

\section{Referencias bibliográficas}

Atherton, Pauline. Manual para sistemas y servicios de información, el cual está editado por la UNESCO y bajo la responsabilidad de Pauline Atherton. París: UNESCO, 1978.

Hill, Helen K. Methods of analysis of information need. Denton, Texas: H. K. Hill, 1987. Tesis (Master of Arts)-School of Library and Information Studies. p.1.

Blyumenau, D.I. "Refining initial concepts in information need theory" Nauchno Tekbinicheskaya informatsiya. 1986, serie 2, no. 2, p. 49. Texto en inglés. "Teoría de las necesidades de información" es un término empleado por este autor para decir que sí es posible la existencia de una teoría acerca de las necesidades de información.

Negrete Gutiérrez, María del Carmen. La selección de materiales documentales en el desarrollo de colecciones. México: UNAM, Centro Universitario de Investigaciones bibliotecológicas, 1988, p. 23.

Shera, J. Fundamentos de la educación bibliotecológica. México: UNAM, Centro Universitario de Investigaciones Bibliotecológicas, 1990. p.32.

Norman, D.A. El procesamiento de la información en el hombre. Buenos Aires: Paidós, 1972, p. 16. 
Comunidades vitivinícolas

Morales Campos, Estela. "Sociedad e información" OMNIA: revista de la coordinación General de Estudios de posgrado. Septiembre 1990, año 6, no. 20, p. 83.

López Yepes, José. "Reflexiones sobre el concepto de documento ante la revolución de la información: cun nuevo profesional del documento?” Scire, enero junio 1997, vol. 3, no. 1, pp. 11-30. 


\title{
Los vitivinicultores de la región de Baja California: necesidades de información y comportamiento informativo
}

\author{
FERMÍN LÓPEZ FRANCO \\ Colegio de Bibliotecología \\ Universidad Nacional Autónoma de México
}

C1 presente trabajo se encuentra auspiciado den-
tro del proyecto PAPIIT IN404408-3, donde se
abarcan diversas regiones vitinícolas en el país. En
él se aborda la región de Baja California.

Se estudia a la comunidad de vitivinicultores porque nos interesa conocer el lugar de donde obtiene la información para llevar a cabo las diferentes actividades que realiza como la siembra, la cosecha, la producción y la comercialización de la vid, además del embotellamiento de sus productos y demás insumos que se relacionan con esta industria.

Esta situación parte del principio de estudiar a comunidades no académicas ya que se considera que éstas se encuentran atendidas por bibliotecas y centros de información, principalmente en las ciudades, pero se cuestiona acerca de qué sucede con sectores productivos, es decir, comunidades no académicas. 
La investigación sobre las necesidades de información en...

Al momento de realizar el presente trabajo reflexionamos acerca de qué se tiene que investigar sobre términos relacionados con la vitivinicultura, la enología, la historia y el desarrollo de la industria no sólo en México sino en países europeos y americanos, es decir, los términos relacionados con este sector. Se observa también que no se cuenta con información sobre necesidades de información y comportamiento informativo de los vitivinicultores. Al no encontrarse información se procede a buscarla en temas relacionados, es decir, la agricultura.

A continuación se proporciona una definición de necesidad de información definida por Sanz Casado como "la sensación de la carencia de algo". ${ }^{1}$ Esta definición es muy breve pero el ser humano, al identificar esa carencia, busca satisfacerla de diversas formas, buscando en libros, y acudiendo a bibliotecas o unidades de información.

Una definición más completa es la siguiente:

Las necesidades de información surgen de una motivación para buscar, recuperar y usar la información la cual tiene un carácter eminentemente utilitario y de producción. Aún para los investigadores que aparentemente utilizan información sin fines prácticos

1 Elías Sanz Casado. Manual de estudios de usuarios. Madrid: Fundación Germán Sánchez Ruipérez, 1994. p. 24. 
e inmediatos, ésta utilización está fundamentada en la necesidad de producir conocimiento o simplemente para apoyar la toma de decisiones. ${ }^{2}$

Se puede reafirmar que el concepto de "necesidades de información" es un término abstracto construido expresamente para identificar lo que un individuo a manera personal, profesional, etcétera, requiere para satisfacer su carencia de información y así obtener el o los documentos que demanda para satisfacer dicha necesidad.

El comportamiento informativo de los individuos está motivado por las necesidades de información de la persona, está influido por aspectos relacionados al individuo en sí mismo, así como por situaciones del entorno laboral, social, académico, etcétera, que rodean al individuo.

Calva González menciona que el comportamiento "está delimitado por factores individuales (fisiológicos, emocionales, cognitivos) y sociales, únicamente separables con fines descriptivos, ya que los factores se combinan y condicionan. El

2 “Terminología relacionada con los estudios de usuarios”. En: Seminario Latinoamericano sobre Formación de Usuarios de la Información y Estudios de Usuarios. México: CUIB, 1997. p 3. 
La investigación sobre las necesidades de información en...

comportamiento puede ser comprendido en función de las necesidades que presentan las personas dentro del contexto en el cual ocurre". ${ }^{3}$

El comportamiento en la búsqueda de información se define como "todo el proceso que realiza una persona para encontrar información, entre las actividades que se realizan durante este proceso encontramos las siguientes: ${ }^{4}$

- Determinar su necesidad de información.

- Transformar esta necesidad en palabras o puntos de acceso que estén incluidas dentro del sistema (autor, título, palabras clave, etcétera).

- Plantearle esta necesidad a algún sistema de información.

- Solicitar a los especialistas de ese sistema que busquen y encuentren la información que requieren (tipo de búsqueda delegada).

- Realizar las búsquedas en forma personal (tipo de búsqueda directa).

3 Juan José Calva González. "Las necesidades de información de la comunidad académica como base en el desarrollo de las colecciones”. En: 1er. Seminario Internacional de Desarrollo de Colecciones. México: UNAM, CUIB, 1998. p. 52

4 Patricia Hernández Salazar. "La producción del conocimiento científico como base para determinar perfiles de usuarios". En: Investigación Bibliotecológica: Archivonomía, Bibliotecología e Información. Vol. 15, No. 30, 2001. p. 39 
- Utilizar herramientas secundarias: catálogos índices, resúmenes, bibliografías, etcétera.

- Ir directamente al acervo y tratar de encontrar el material.

- Buscar dentro de las colecciones personales.

- Hacer contacto con colegas (colegios invisibles, medios informales de comunicación).

- Asistir a eventos académicos (medios informales de comunicación).

- Obtener información de referencias y citas.

Como se observa en los puntos anteriores el proceso del comportamiento informativo se manifiesta de diversas formas dependiendo de las características personales del individuo como nivel de estudios, nivel socioeconómico, lugar de trabajo, etcétera.

Una definición más del comportamiento en la búsqueda de información es la que proporciona Ucak al decir: "cualquier actividad de un individuo dirigida a identificar un mensaje que satisfaga una necesidad percibida como tal. En otras palabras la búsqueda de información comienza cuando alguien 
La investigación sobre las necesidades de información en...

se da cuenta de que el nivel actual de conocimientos que posee es menor del que necesita para afrontar una cuestión (o un problema)".

Con lo anterior se ratifica que el ser humano busca satisfacer las necesidades de información que surgen a partir de la actividad que desarrolla.

Existe un modelo presentado por Kuhlthau, quien identifica seis etapas en el proceso de búsqueda de información hacia donde los buscadores de información se mueven de la senda de la incertidumbre hacia la construcción del entendimiento.

Comienza con los siguientes pasos:

留 Iniciación. Va de los sentimientos a la incertidumbre.

Selección. Aquí se identifican las posibles fuentes de información.

Exploración. La persona explora la información general y escoge un tópico, sentimientos de incertidumbre y confusión incrementan está etapa y al mismo tiempo la incapacidad de expresar concretamente que información se requiere.

槕 Formulación. Esta es la parte más crítica del proceso donde el buscador de la información se enfoca a la solicitud.

5 Nazan Ozenc Ucak. Necesidades de información y comportamiento para la búsqueda de información entre los estudiosos de una Universidad Turca. En:

http://www.ifla.org/IV/ifla64/041-112s.htm 21-10-2002 
糨 Recolección. Este es posterior a la formulación, aquí se clarifica la incertidumbre en la cual se encontraba el solicitante de información, aquí se encuentra en una etapa de confianza y claridad respecto a lo que solicita y es aquí donde se obtiene la información.

: Presentación. En esta etapa de alivio en que la búsqueda está completa y se expone el trabajo realizado con la información obtenida a lo largo del proceso. 6

Como se mencionó anteriormente no se han encontrado estudios sobre las necesidades y el comportamiento informativo de la comunidad de vitivinicultores en un país en especial. Se han encontrado trabajos que tratan sobre las necesidades y el comportamiento informativo en el área de la agricultura, por lo que se procedió a buscar información de esta área por ser cercana a la vitivinicultura.

Las ciencias biológicas y agrícolas son áreas muy cercanas y examinan los aspectos fundamentales de los sistemas vivos y su relación con el medio ambiente, mientras que las ciencias agrícolas se enfocan

6 Simon Attfield. "Information seeking in the context of writing: a design psychology interpretation of the problematic situation”. En: Journal of Documentation. Vol. 59, No. 4, 2003. p. 432 
La investigación sobre las necesidades de información en...

a aspectos nacionales y globales de la producción, así como el consumo de alimentos.?

Es decir, existe una relación entre la vitivinicultura y los estudios agrícolas porque poseen las mismas características para su estudio, así como se han realizado estudios desde la Física y la Geología aunque desafortunadamente no en el área vitivinícola, por esta razón se estudia a los usuarios del área agrícola para entender sus actividades y su filosofía, entre otras cosas.

El estudio de Kuruppu tiene por objetivo examinar las necesidades de información de los científicos relacionados con la enseñanza, investigación y actividades de extensión del área de biología y agricultura en la Universidad Estatal de Iowa,

Los cuestionamientos de los que parte Kuruppu, para llevar a cabo su trabajo son los siguientes:

噒 ¿Cuál es el tipo de información que utilizan los científicos de las áreas biológica y agrícola?

¿Qué fuentes utilizan ambas comunidades?

¿Q ¿Qué herramientas y procedimientos utilizan para localizar su información?

7 U. Kuruppu Pali. "Understanding the information needs of academic scholars in agricultural and biological sciences". En: The Journal of Academic Librarianship. Vol. 32, No. 6, 2006. p. 609. 
¿QQ ¿Qué fuentes y servicios adicionales les gustaría tener disponibles para encontrar su información?8

Además de la producción y consumo de alimentos, Lisa Nason menciona la contribución de los agricultores en la economía de los Estados Unidos. Señala que:

[...]los agricultores en el desarrollo de las naciones tienen necesidades similares a las de sus colegas norteamericanos como son el tipo de suelo de los campos de cultivo, el clima y la necesidad de acceder a la tecnología agrícola, así como la obtención de créditos y el mercado de precios. ${ }^{9}$

Los aspectos que menciona Lason y que requieren los granjeros son los siguientes:

- Información sobre métodos de agricultura

- Legislación y políticas operaciones agrícolas

- Políticas de mercado.

Las fuentes a las que alude Lason y en las que la comunidad citada busca información son las siguientes:

8 Pali U. Kuruppu, "Understanding the information needs of ... Op. Cit. p. 611.

9 Lisa Nason. "The farmers in the library: information needs of farmers and how the rural public library can fulfill them”. 19-45 pp. En: Rural Library. Vol. 27, No. 2, 2007. p. 20. 
La investigación sobre las necesidades de información en...

Fuentes electrónicas. Entre las que se encuentra la base de datos PLANTS, AGRICOLA.

Radio y televisión.

品 Publicaciones para granjeros y agricultores.

Bibliotecas.

覀 Servicios Cooperativos.

Estaciones experimentales. ${ }^{10}$

Cabe mencionar que los objetivos del presente trabajo son los siguientes:

- Identificar Unidades de Información a las que acuden los productores de la vid para satisfacer sus necesidades de información y donde manifiestan su comportamiento informativo.

- Identificar las necesidades de información de los vitivinicultores en la región de Baja California.

- Establecer las variables que motivan la aparición de necesidades de información de los vitivinicultores para su producción y comercialización.

- Identificar el comportamiento informativo de esta comunidad.

10 Lisa Nason. "The farmers in the library: information needs of farmers ... Op. Cit. p. 24. 
Por lo que respecta a las hipótesis que se formularon para el desarrollo de este trabajo son las siguientes:

- La información sobre normas, regulaciones, situación geográfica, son un factor externo que determina el trabajo de los productores vitivinícolas en México con respecto a la siembra, cosecha, producción y comercialización para mantenerse en el mercado competitivo con los demás productores mexicanos y extranjeros.

- La falta de accesibilidad a los recursos y fuentes de información y la carencia de sistemas de información para la atención a necesidades informativas de este tipo de productores de la vid afecta los procesos que intervienen en la producción de los derivados de la planta.

La metodología se detalla a continuación:

- Investigación documental

- Investigación de campo

- Encuesta directa a los productores de Vitis vinífera

- Cédula para el análisis de cada documento

Para comprender mejor a la industria vinícola se han buscado información acerca de las definiciones de términos relacionados con esta área y son los siguientes: 
La investigación sobre las necesidades de información en...

- La uva. Fruto de la vid que es una baya más o menos redonda y jugosa la cual nace apiñada con otras, adheridas todas a un vástago común por un pezón formando racimos. ${ }^{11}$

- La uva es el fruto de las plantas del género Vitis, perteneciente a la familia de las vitáceas. Sus especies originarias de las zonas templadas del hemisferio norte incluyen variedades utilizadas como frutos de mesa, pasas, vinos, y zumos de uva o mostos. ${ }^{12}$

- La vid es una planta vivaz y trepadora de la familia de ampélidas, en botánica es nombre castellano de la vitis de la familia de las vitáceas. ${ }^{13}$

El buen desarrollo de la vid requiere de veranos largos, secos y calurosos e inviernos frescos. Ciertas condiciones invernales destruyen las plantas si no se adoptan precauciones; son especialmente peligrosas las heladas y la escarcha cuando se encuentran en pleno crecimiento. Las viñas se adaptan a una gran variedad de suelos:

11 Enciclopedia Universal Ilustrada: Europea Americana. - Madrid: Espasa-Calpe, 1996. Tomo 66. p. 198.

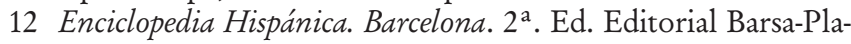
neta, 2003. T. 14. p. 214.

13 Enciclopedia Universal Ilustrada: Europea... Op. Cit. Tomo 68. p. 664. 
- Arenosos.

- Arcillosos.

- Calcáreos.

- E incluso de baja fertilidad.

La mayor parte de la uva cultivada proviene de la especie Vitis vinifera, natural de la Europa mediterránea y de Asia central. En menor cantidad se producen en América y Asia:

- Vitis labrusca, natural de Estados Unidos y Canadá.

- Vitis riparia, natural del este de Estados Unidos y norte de Quebec.

- Vitis rotundifolia, natural del suroeste de Estados Unidos desde Delaware al Golfo de México.

- Vitis vulpina. Que es de madera dura y corteza sin estrías y se encuentra en la costa este de los Estados Unidos, se le conoce por uva de invierno.

- Vitis amurensis la más importante de las especies de Asia. ${ }^{14}$

Al cultivo de la uva se le denomina viticultura, es una práctica antigua que se remonta a la época del neolítico. Jeroglíficos egipcios del tercer milenio anterior a la era cristiana, citas bíblicas y referen-

14 http://es.wikipedia.org/wiki/Uva 19-mar-2008. 
La investigación sobre las necesidades de información en...

cias de las obras homéricas confirman la realidad del consumo del vino como hecho habitual. ${ }^{15}$ Mientras que la vinicultura refiere al proceso de elaboración de vinos. ${ }^{16}$

La vid es uno de los arbustos cultivados con más esmero desde hace muchos siglos, La Biblia refiere que Noé gustó del zumo de la uva y los antiguos libros religiosos indios hablan de una bebida sagrada llamada "soma", según algunos, extraída del jugo de las uvas que dedicaban a la divinidad de Brahma.

Según Plinio, el primero que enseñó a los galos la existencia de la vid y les reveló las grandes ventajas de su cultivo y de la obtención del mosto fue un helvecio llamado Helicón. Plutarco y Tito Livio dicen, por el contrario, que fue un emigrado toscano el que introdujo en Las Galias el mejor vino de Italia.

Existen variedades de uvas denominadas cepas entre las que se dividen las blancas y las tintas clásicas; así como las blancas y las tintas importantes, entre las primeras se encuentran las siguientes:

15 Enciclopedia Hispánica... Op. Cit. t. 14. p. 214.

16 Enciclopedia Universal Ilustrada: Europea... Op. Cit. t. 14. p. 4661. 
Blancas clásicas:

- Chardonnay. Es la variedad de uva blanca más famosa en el mundo y su vino el más popular. A los viticultores les gusta porque es fácil de cultivar, vigorosa, resistente y generosamente productiva en la mayoría de los suelos y climas. A los vinicultores les gusta por lo maleable ya que se puede presentar en una variedad de estilos, en Borgoña y Champagne se ha mostrado capaz de producir algunos de los mejores vinos del mundo.

- Sauvignon Blanc. Es la variedad de uva a la que recurren los consumidores cuando quieren un cambio con respecto a los vinos blancos con mucho cuerpo y con frecuencia con sabor a roble, este tipo de uva es más fresca y firme con una acidez refrescante.

- Sémillon. Esta variedad de uva es el pilar principal del vino blanco tipo Burdeos. En Burdeos se aprecia por su calidad redonda y su carácter de lanolina y sus sabores herbáceos similares a los del Sauvignon blanc. En el valle de Hunter en Australia es renombrada por dar un tipo de vino blanco seco y longevo.

- Riesling. La auténtica uva Riesling es originaria de Alemania es una de las mejores cepas del mundo. Tiene al igual que la Sauvignon blanc una fuerte personalidad y una alta acidez. Crece en los climas fríos de Europa, así como los climas 
La investigación sobre las necesidades de información en...

cálidos de Australia. Este tipo de uva tiene el potencial de envejecer durante muchos años, tiene carácter afrutado y una acidez equilibrada.

- Chenin Blanc. Se trata de una cepa de una acidez muy elevada y potencialmente de una gran longevidad, pero también de una cepa de un vino más desagradable que el promedio, cuando no hay suficiente sol: la Chenin poco madura adquiere sabor a queso.

Mientras que entre las tintas clásicas se describen a continuación algunas de ellas:

- Cabernet Sauvignon. En términos de categoría y popularidad, esta cepa puede considerarse como el equivalente en vino tinto a la Chardonnay, la Cabernet Sauvignon es una uva de color intenso y piel gruesa que produce un vino oscuro y sabroso, particularmente por su sabor grosella, los vinos de la Cabernet Sauvignon poseen el potencial de envejecer durante mucho tiempo y ganan en categoría si envejecen en roble. Desde el punto de vista del viticultor, esta variedad se ha aclimatado como la Chardonnay. La Cabernet es natal de Burdeos.

- Merlot. Es parecida a la Cabernet Sauvignon, pero es menos tánica, con menos sabor incisivo a grosella, los vinos de esta variedad tienen un sabor más suave, más rollizo y aparentemente más dulce. Se encuentra muy extendida en el mundo. 
- Pinot Noir. Esta cepa es muy remilgada con su propio clima y un producto menos generoso que la Chardonnay. En Burdeos, el factor crítico es alcanzar suficiente madurez, es una variedad con un tanino y una acidez relativamente bajos, un color medio y una vida cuya duración resulta más que larga. En los climas más cálidos del Nuevo Mundo, los productores padecen el problema opuesto: uvas sobremaduradas que dan sabores cocidos, bastos y confitados.

- Syrab o Shiraz. Es la variedad más nueva del siglo XXI. El Syrah clásico del valle del Ródano en Francia, así como el Shiraz clásico de Australia son vinos oscuros con mucho cuerpo potentes y con un potencial de envejecimiento, este tipo de uva crece en climas más cálidos que la Pinoit Noir, en general es más adaptable. En climas más fríos produce vinos más ligeros y con más pimienta, con fruta de baya menos madura y con una riqueza menos carnosa o de chocolate. ${ }^{17}$

Para comprender la vitivinicultura se ha buscado también información que concierne a Francia Italia, España, a continuación una breve descripción:

17 Joanna Simon. Conocer el vino. Barcelona: Blume, 2004. p. 50. 
La investigación sobre las necesidades de información en...

- Francia. Es el principal productor de vinos del mundo (58 millones de hectolitros en el año 2000). También es el principal país exportador de vinos y su consumo por habitante es el más alto del planeta (60.2 litros por habitante en 1997). ${ }^{18}$

Entre sus regiones vinícolas se encuentran: Alsacia, Burdeos, Champaña, Loira.

- Italia. En la década de 1990, Italia se convirtió en uno de los productores de vino más dinámicos de Europa. Una nueva generación de viticultores aportó nuevas habilidades y dedicación. Combinando el respeto por la tradición con una apreciación de las técnicas modernas se centraron en las uvas autóctonas, pero sin miedo a introducir a la Chardonnay, la Merlot, etc.

Entre las regiones vinícolas italianas se encuentran: Aglianico del Vulture, Alto Adigio, Barbaresco y Barolo, Chianti.

- España. No existe una clara unanimidad sobre el lugar en el que comenzaron a realizarse los primeros cultivos de vid en España y quienes fueron los que introdujeron las técnicas de elaboración del vino. Diversas fuentes apuntan que los primeros viñedos se habrían asentado en el lito-

18 Geografía del vino. http://www.verema.com/mundo/geografia/francia/default.asp 17-may-2008. 
ral sudoccidental andaluz constituyendo el punto de entrada y el lugar de las viñas más antiguas de España. La llegada de los musulmanes en el siglo VIII también se tradujo en algunas dificultades para el desarrollo de la vid y la elaboración del vino debido a la prohibición coránica de consumir bebidas fermentadas y alcohólicas. Pese a ello, el cultivo de la vid continuó e, incluso, se mejoró durante el periodo de dominación musulmana. Entre las regiones vinícolas españolas se encuentran: Andalucía, Aragón, Cataluña, La Rioja.

Además se describen aspectos de la vitivinicultura en algunos países del continente americano entre ellos Estados Unidos de América y Chile. A continuación se mencionan algunos aspectos del tema que nos ocupa.

- Estados Unidos. Las primeras referencias a una industria vinícola hablan de Pensilvania, los estados de Nueva Inglaterra, Kentucky y las Carolinas donde se elaboraba vino a partir de cepas locales. Muchos productores trataron de encontrar una uva que produjera vinos estilo europeo porque las especies nativas en especial la Vitis labrusca producían un vino con olores desagradables a pelaje húmedo. Por esta razón se trajeron cepas europeas de la especie Vitis vinifera, pero estos esfuerzos fueron en vano: no resistían 
La investigación sobre las necesidades de información en...

los ataques de las enfermedades y parásitos que fueron identificados posteriormente, entre las regiones vinícolas se encuentran las siguientes: Napa Valley, Sonoma Valley, Shenandoah Valley, Fiddletown, entre otras.

- Chile. Al igual que en el caso de México, las vides llegaron a Chile, Argentina y Perú gracias a los conquistadores españoles en el siglo XVI y prácticamente en la actualidad todos los países sudamericanos producen vino, entre las regiones chilenas que producen vino se encuentran las siguientes: Casablanca, Maipo, Curicó, Rapel.

Como se ha observado, se investigaron algunos países europeos y americanos para tener una idea más clara de vitivinicultura y apreciar el desarrollo que ésta ha tenido en México, en particular la región de Baja California, este estado se encuentra situado en la región noroeste en la semidesierta península del mismo nombre en la que solo brota la vegetación gracias a la humedad de las nieblas matutinas y las brisas marinas. El clima es mediterráneo con inviernos húmedos y veranos secos y templados. ${ }^{19}$

19 Luis Tomás Melgar Gil. La enciclopedia del vino. Madrid: Ramón Llaca, 2008. p. 70. 
Los jesuitas plantaron las primeras vides en las misiones de Baja California desde 1697 y fueron reemplazados por los franciscanos cuando en 1767 se les expulsó de América. Finalmente los dominicos continuaron con esa actividad abriendo nuevas misiones y cultivos en los valles de Guadalupe y Santo Tomás.

Se ha elaborado vino en Baja California desde el siglo XVIII, al traer los misioneros jesuitas a la península sarmientos de lo que después se conocería como uva misión y que hasta la fecha sigue cultivándose. Sin embargo, fue hasta el año de 1834 que los misioneros dominicos establecieron la Misión de Nuestra Señora de Guadalupe del Norte, la cual le dio su nombre al valle. Esta fue la última misión establecida en las Californias y la que menos tiempo funcionó, pues fue abandonada en 1840 después de un ataque indígena. ${ }^{20}$

La historia del vino en el Valle de Guadalupe comienza de nuevo en 1904, cuando un grupo de cien familias rusas, pertenecientes a una secta religiosa llamada "molocanes" compraron las tierras de la antigua misión y ahí se establecieron. Siendo pacifistas, habían abandonado Rusia para evitar ser conscriptos en el ejército zarista. En un principio

20 Monte Xanic http://www.montexanic.com.mx/inicio.html 2-ago-2008. 
La investigación sobre las necesidades de información en...

se dedicaron a cultivos diversos, incluyendo viñedos, de manera que al comenzar a poblarse el valle, muchos de los nuevos propietarios tomaron su ejemplo. ${ }^{21}$

Los viñedos de Ensenada, Baja California, se encuentran en el área sur de la línea fronteriza que se extiende desde Mexicali hasta Ensenada, en una posición perpendicular al océano Pacífico, por lo que tienen un buen grado de influencia marina debido a un permanente ir y venir de los vientos tierra-martierra.

Esta es la zona templada conocida como la franja del vino, situada entre los 30 y 50 grados de latitud norte y cuyas propiedades climáticas se conocen como las de clima mediterráneo: hay inviernos húmedos y veranos secos y templados, eso permite obtener cosechas de máxima calidad.

- Valle de San Antonio de las Minas al noroeste de Ensenada.

- Valle de Guadalupe al noroeste de Ensenada.

- Valle de Santo Tomás, a 45 km., al sur de Ensenada.

- Valle de San Vicente, a unos 90 km., al sur de Ensenada.

21 Monte Xanic http://www.montexanic.com.mx/inicio.html 2-Ago-2008. 
De estas cuatro zonas vinícolas se seleccionaron el Valle de San Antonio de las Minas y Valle de Guadalupe.

A continuación se mencionan las vinícolas que se encuentran en San Antonio de las Minas:

- Viñas de Liceága.

- La Casa Vieja.

- Casa de Piedra.

- Vinisterra.

- Bibayoff.

- Viñas de Pijoan.

- Mogor Badán.

- Vitivinícola Tres Valles.

- LaFarga

Por lo que respecta a Valle de Guadalupe las vinícolas que se asientan allí son:

> L. A. Cetto.

- Monte Xanic.

- La Casa de Doña Lupe.

- Pedro Domecq.

- Adobe Guadalupe.

- Chateau Camou.

- Barón Balché.

De estas vinícolas se buscarán aspectos relacionados con su historia y en un primer acercamiento, en estudio de campo, se visitaron del 6 al 10 de julio de 2008 las casas vinícolas que se mencionaron anteriormente a excepción de Viñas Pijoan, Mogor 
La investigación sobre las necesidades de información en...

Badán, Vinícola tres Valles y LaFarga, teniendo una respuesta positiva de parte de las personas representantes de dichas casas vinícolas.

\section{Referencias bibliográficas}

Attfield, Simon. "Information seeking in the context of writing: a design psychology interpretation of the problematic situation". 430-453 pp. En: Journal of Documentation. Vol. 59, no. 4, (2003).

Calva González, Juan José. "Las necesidades de información de la comunidad académica como base en el desarrollo de las colecciones". En: 1er. Seminario Internacional de Desarrollo de Colecciones. México: UNAM, CUIB, 1998. p. 52.

Enciclopedia Hispánica. Barcelona. $2^{\mathrm{a}}$. Ed. Editorial Barsa-Planeta, 2003. 14 t.

Enciclopedia Universal Ilustrada: Europea Americana. Madrid: Espasa-Calpe, 1996. 70 t.

Geografía del vino. http://www.verema.com/mundo/geografia/francia/default.asp 17-may-2008.

Kuruppu, Pali U. "Understanding the information needs of academic scholars in Agricultural and biological sciences". En: The Journal of Academic Librarianship. Vol. 32, No. 6, 2006. p. 609.

Melgar Gil, Luis Tomás. La enciclopedia del vino. Madrid: Ramón Llaca, 2008. p. 70. 
Monte Xanic http://www.montexanic.com.mx/inicio.html 2-ago-2008.

Nason, Lisa. "The farmers in the library: information needs of farmers and how the rural public library can fulfill them". 19-45 pp. En: Rural Library. Vol. 27, No. 2, 2007. p. 20.

Ozenc Ucak, Nazan. "Necesidades de información y comportamiento para la búsqueda de información entre los estudiosos de una Universidad Turca”. En: http://www.ifla.org/IV/ifla64/041-112s.htm 21-102002.

Sanz Casado, Elías. Manual de estudios de usuarios. Madrid: Fundación Germán Sánchez Ruipérez, 1994.

Simon, Joanna. Conocer el vino. Barcelona: Blume, 2004. p. 50. 


\title{
Información y vitivinicultores en Aguascalientes, Zacatecas y Durango: el acercamiento inicial
}

\author{
José TOMÁs PALACIOS MEDELLÍN \\ Colegio de Bibliotecología \\ Universidad Nacional Autónoma de México
}

$A$ bordar una comunidad poco conocida en el implica una cuidadosa preparación que permita acercarse a ella con conocimiento sobre sus actividades, saber acerca de las variedades de uva, su cultivo, tipo de suelos, climas, la vendimia, el proceso de elaboración, sus productos, su forma de comercializarlos, su lenguaje profesional, la ubicación de los viñedos y de la planta para el proceso de vinificación, cuántos y quiénes son, etcétera. Se trata de un trabajo de investigación que nos da la oportunidad de conocer a los vitivinicultores y de que conozcan a los bibliotecarios.

La información bibliográfica sobre el cultivo, tipo de suelos, climas, variedades de uva, vendimia, proceso de elaboración y lenguaje, es adecuada y suficiente ya que las fuentes de información que han sido publicadas, prácticamente en cada región que produce vinos en el mundo, son abundantes. Sin embargo, no se puede decir lo mismo de otros 
La investigación sobre las necesidades de información en...

aspectos también muy importantes acerca de esta comunidad en México y que guardan una estrecha relación temática.

Al hacerme algunas preguntas con el fin de profundizar en el tema y buscar documentos para encontrar respuestas, resultó que son muy pocos por lo que hay que implementar una estrategia que permita obtener información sobre los vitivinicultores. Algunas dudas al respecto son:

- ¿Actualmente cuántos vitivinicultores están activos en los estados de Auascalientes, Zacatecas y Durango?

- ¿Qué variedades de uva utilizan para producir sus vinos?

- ¿Cuántas toneladas de uva ocupan para producir vinos?

- ¿Únicamente producen vinos o también otros productos?

- ¿Cuál es la ubicación de sus viñedos y de sus instalaciones vinícolas?

- ¿Su trabajo es artesanal o está modernizado?

- ¿Cómo y en dónde venden el vino que producen?

- ¿Cuántos empleados de la industria vitivinícola hay en cada estado?

- ¿Existen asociaciones u organismos relacionados con la vitivinicultura? 
Tratando de conseguir información para resolver las dudas mencionadas, busqué en bibliotecas (Chapingo, UNAM, Iberoamericana, Colmex y otras), puestos de revistas, librerías, profesionales del vino, tiendas de vinos, una Asociación, la Secretaría de Agricultura, el INEGI, hasta busqué en las tiendas Sanborn's y en sitios de Internet y una cosa quedó clara: hay que visitar los estados y las comunidades de vitivinicultores con el fin de obtener información in situ, pues la información conseguida no es suficiente ya que es obsoleta y variada.

El acercamiento a los vitivinicultores de los estados fue planeado de la siguiente forma:

Tomar en cuenta no visitarlos en época de vendimia, pues prácticamente trabajan las 24 horas del día, esto es en los meses de agosto, septiembre $y$ a veces hasta en el mes de octubre no se los puede visitar.

Llevar los nombres y ubicaciones de los vitivinicultores mencionados en la literatura consultada y, una vez en el estado, acercarse a instituciones públicas y privadas, taxistas, comerciantes, prestadores de servicios, guías de turistas, policías y habitantes en general a fin de comparar la información obtenida y buscar en cada estado a los vitivinicultores; comprobar personalmente la existencia o no de esta comunidad, sus actividades, cultivos, instalaciones y productos así como reunir datos de los res- 
La investigación sobre las necesidades de información en...

ponsables de cada una de las vinícolas localizadas y visitadas.

Iniciar el acercamiento a principios del mes de julio 2008 (lunes 13) comenzando por el estado de Aguascalientes, continuar viaje hacia Zacatecas y finalizar en Durango, visitando la capital y los municipios en donde se supone están los vitivinicultores, de acuerdo a la información bibliográfica obtenida de cada lugar, $y$, si es necesario, visitar más regiones, municipios, comunidades o colonias de acuerdo a la información local y acercarse a ellos.

Un punto muy importante a considerar es visitar todos los lugares productores de vino que se mencionan en la literatura consultada, es decir, no porque se mencione que en algún lugar ya no hay vitivinicultores tomarlo al pie de la letra y no revisar si en realidad es así, porque además se puede dar el caso contrario, se puede tener información que indique que si hay vitivinicultores en alguna región o municipio y éstos ya no existan, por razones tales como que se haya realizado un cambio o venta de alguno de ellos.

Poncelis Brambila menciona que hay más de 50 vinícolas en México:

[...] entre bodegas grandes, medianas y pequeñas que producen más de 250 vinos de precio bajo, medio y alto (vinos premium), muchos exquisitos y de buena 
calidad; cada uno se distingue por su estilo y personalidad propios. ${ }^{1}$

\section{Aguascalientes}

De acuerdo con el plan de acercamiento, asigné los días 13, 14 y 15 de julio de 2008 al estado de Aguascalientes a fin de visitar los municipios de Aguascalientes, San Francisco de los Romo, Pabellón de Artega y Calvillo, esperando localizar las vitivinícolas La Bordaleza y Hacienda de Letras, únicas mencionadas en la bibliografía obtenida. Para el acercamiento a las vinícolas llegué a la ciudad capital Aguascalientes y ahí solicitar información.

\section{Municipio de Aguascalientes, Región Jesús María}

Aquí se ubica la Casa Vitivinícola Leal, propietaria de Viñedos La Bordaleza y Viñedos Ríos.

Fundada en 1969, tiene más de tres décadas de cultivar uva en sus viñedos que tienen una extensión de 180 hectáreas ubicadas a 1820 metros sobre el nivel del mar. Las variedades de uva que cultiva son: Málaga Champagne, French Colombag, Chennin Blanc, Cariñan, Victoria, Ruby Cabernet

1 Poncelis Brambila, Pedro. Navidad con vinos mexicanos. En: Revista del Consumidor. México : Procuraduría Federal del Consumidor, número 370, diciembre 2007, p. 54 
La investigación sobre las necesidades de información en...

y Salvador, con ellas elabora vinos de mesa y brandy de la marca Leal, además con la variedad Victoria produce el concentrado de uva denominado Mega Uva; la mayor parte de su producción es exportada pero también cuentan con tiendas propias en la capital del estado y en los viñedos de La Bordaleza. Realizan la vendimia cada año en el mes de agosto.

Los responsables son Jorge Ríos Leal y Víctor M. Vargas. Su dirección es: Antigua Carretera Aguascalientes-Zacatecas, $\mathrm{km} \mathrm{8}$. Sus teléfonos son: 973-0063 y (449) 911-0864. Sitio web: www.labordalesa.com

\section{Municipio Pabellón de Arteaga}

Aquí se encuentra Viñedos y Bodegas Hacienda de Letras, S. A. de C. V. de la Vitivinícola Dinastía en el poblado de San Luis de Letras que es parte del Valle de Monte Grande, es una empresa establecida en 1978 y efectúan una distribución regional de sus productos.

Sus instalaciones son parte de una antigua hacienda que data de 1854, donde está una pequeña bodega que produce vinos de autor con viñedos cultivados en una extensión de casi 100 hectáreas, donde tienen las siguientes variedades de uva: Ruby cabernet, Hacienda de Letras, Carigñan, Sangiovese, Syrah, 425 Aniversario (Cabernet Sauvignon), 
Pinot Noir, Tempo (Cabernet Sauvignon, Malbec y Merlot), Cabernet Franc y Nebbiolo para vinos tintos y las Riesling, Chardonnay, Sylvaner, Sauvignon Blanc, Semillón, Capilla de Fátima (Muscat Blanc, seco), Karol (Muscat Blanc, dulce natural) y Christine (Muscat Blanc, cream) para vinos blancos; cuentan con vinos de las llamadas líneas superiores: Montgrand, Cabernet Sauvignon, Malbec y Tempranillo.

Cuentan con 120 hectáreas cultivadas y cuando realizan la vendimia, seleccionan 50 toneladas de uva para la producción de vinos de su bodega, principalmente vinos de autor. La Hacienda produce 2 mil cajas anuales con 12 botellas cada una, reposados en barricas de roble americano y francés. Sus vinos son $100 \%$ monovarietales y fechados, cinco productos son de vino tinto y tres de vino blanco; se puede visitar la "Casa Grande" con su sala de vino, su vinícola y también comprar vino.

Responsable es el Ing. Luis Carlos Hernández Chacón. Su dirección es: Viña y Vino \# 1, Municipio Pabellón de Arteaga, Aguascalientes (por la antigua carretera Aguascalientes-Zacatecas, km 35 aprox.), su teléfono es: (449) 973 6721; Correo electrónico: luca_0712@hotmail.com. 
La investigación sobre las necesidades de información en...

\section{Municipio de Calvillo}

Otra gran empresa que continúa en activo en Aguascalientes es la Bodega y Vinícola Valle Redondo, anteriormente conocida como Productos de uva de Aguascalientes. Lo curioso es que siendo una empresa grande, las instituciones gubernamentales y los habitantes de Aguascalientes no la ubican como productora de vinos sino de jugos. Esta empresa tiene sus viñedos con un poco más de 300 hectáreas en el Rancho Aurora, km. 60 de la carretera \# 45 Aguascalientes- Zacatecas (al norte de Tepezalá) y produce sus vinos en la Vinícola Augurio, ubicada en el km. 6.5 de la carretera \# 71 Aguascalientes -Calvillo; produce 3,700.000 litros de vino al año, del cual el $70 \%$ es vino tinto elaborados con uvas Cabernet Sauvignon; Barbera y Petite Sirah; el $30 \%$ restante es vino blanco de uvas Riesling, Sauvignon Blanc y Blanc de Blancs.

Las marcas de vino que produce Valle Redondo son California, con uva seleccionada y traída desde Baja California (a la venta en botella y garrafa y tetra pack); Don Angel, con uva de Aguascalientes (a la venta en botella y garrafa) y una marca reciente: Fratello. Anualmente celebran su fiesta de la vendimia entre los meses de julio y/o agosto.

Los encargados son Jorge Pimentel, Rafael Garza y el enólogo Francisco J. M. de Oro y puede ha- 
ber comunicación con ellos en los teléfonos (449) 976-4202 hasta el 05.

\section{Municipio de San Francisco de los Romo}

En las obras consultadas se menciona al municipio de San Francisco de los Romo como productor vinícola, sin embargo, en la visita realizada a este municipio encontré que ya no se cultiva la uva desde hace más de diez años y ahora el municipio se conoce popularmente como San Pancho de las Carnitas, donde cualquier persona puede elegir directamente del cazo las carnitas de cerdo que prefiera.

Información adicional sobre la vitivinicultura en Aguascalientes

Ahora se comprende por qué en la literatura sobre la vitivinicultura en el estado de Aguascalientes ya no se menciona a la empresa Pedro Domecq, puesto que esta empresa que llegó a Aguascalientes en 1963 y sus viñedos se extendían desde la ciudad de Aguascalientes hasta los límites con el estado de $\mathrm{Za}$ catecas y producía el vino tinto, blanco y rosado Los Reyes, fue vendida a la empresa británica Allied Lyons en 1994 y en adelante fue llamada Allied Domecq. Las instalaciones que tenía Pedro Domecq en Aguascalientes fueron abandonadas y se trasladó su infraestructura a Baja California (vinos varietales y cavas), Ensenada (cavas), Los Reyes La Paz, Estado 
La investigación sobre las necesidades de información en...

de México (añejamiento y embotellado), Sonora (Destilación de Uva), Zacatecas (licor de café Kahlúa) y Arandas, Jalisco (elaboración, añejamiento y embotellado de tequila). Actualmente continúa con una extraordinaria producción de vinos y licores. Los terrenos donde estaban los viñedos de la empresa Pedro Domecq actualmente están ocupados por centros comerciales, bodegas y almacenes de todo tipo, oficinas de gobierno y todavía hay una gran extensión de terrenos llanos.

Asociaciones y fiestas en Aguascalientes relacionadas con la Vitis vinifera

- Fiesta de la Vendimia Valle Redondo: 26 de julio de 2008, Rancho Aurora, km. 60 Carretera \# 45 Aguascalientes-Zacatecas. Cata de vinos Don Ángel, California y Fratello.

- Fiesta de la uva en Aguascalientes: 26 de agosto de 2008, con la participación de vinícolas y vitivinicultores del estado.

\section{Zacatecas}

El plan para acercarme a los vitivinicultores de $\mathrm{Za}$ catecas fue asignar los días 16, 17 y 18 de julio 2008, para visitar los municipios de Fresnillo, Ojocaliente y Luis Moya y buscar a los vitivinicultores de Cantera y Plata, Carrera y Cacholá. El acercamiento a los vitivinicultores fue desde la ciudad capital 
Zacatecas, en donde busqué información sobre los vitivinicultores para después trasladarme a los municipios y acercarme a ellos.

En la Secretaría de Turismo de Zacatecas no supieron darme información acerca de viñedos, vinícolas o vitivinicultores del estado, policías, taxistas y guías de turistas tampoco, quienes si sabían algo fueron los conductores de camiones que tienen la ruta Zacatecas - Fresnillo y los conductores de combis de la ruta Zacatecas - Ojocaliente - Luis Moya.

\section{Municipio de Fresnillo}

La primer vitivinícola localizada en este municipio fue Vinícola El Saucito, que tiene sus viñedos en las comunidades de Santa Claudia, Tapias, Buenaventura, Ex Hacienda de Baños y en Santa Cruz en donde produce el vino blanco de la marca Carrera con uva de la variedad Traminer.

La responsable de atender al público es la Srita. Micaela. Su dirección de atención al público es: $\mathrm{Ca}$ rretera Panamericana $\mathrm{km}$ 680. Teléfonos 92-23398, 92-20645, (914) 93-20110 y (914) 93-20295

Tratando de saber si había más vitivinícolas en este municipio y preguntando en vinaterías, el mercado, taxistas, conductores y a personas que viven aquí, una persona me informó de una empresa de uvas ubicada hacia la salida a Valparaíso. Llegué al 
La investigación sobre las necesidades de información en...

lugar indicado (después de preguntar más), dicha empresa se llama Multiuva, ubicada en la avenida Prolongación Enrique Estrada s/n. Esquina con calle Costa Rica, colonia Las Américas, teléfono 932-8885. Compra uva, la deshidrata, la procesa como mosto y la exporta a Estados Unidos. En esta empresa se encuentra la oficina del presidente de la Unión Agrícola Local de Vitivinicultores de Fresnillo, S. P. R. de R. L., el sr. Manuel Perales Gutiérrez, quién informa que cultivan viñedos en 500 hectáreas (aprox.) en las comunidades de El Salto, Colonia Hidalgo, Carrillo, Cabrales, Misericordia, San Juan del Río, Matías Ramos, El Epazote, San Jerónimo, Milpillas de la Sierra y San José de Lourdes y venden su uva a esta empresa. Acerca de las preguntas: ¿qué variedades de uva cultivan? No estaba seguro de cuales variedades; ¿conoce alguna vitivinícola? La respuesta fue no.

\section{Municipio de Guadalupe}

Aquí se encuentra la Compañía Vinícola del Valle de las Arcinas (Grupo Mier), fundada en 1984 por Jesús López López. Produce el vino de la marca Cacholá, el cual en su mayor parte exporta a otros países pero que también vende en el mercado Jesús González Ortega de la ciudad de Zacatecas. Para fabricar su vino (un tinto y dos blancos) cuenta con 
las variedades de uva French Colombard, Ruby Cabernet y Chenin Blanc.

La responsable de atención al público es Claudia Vacio. Su dirección está en la Carretera Panamericana km 634 (Las Arcinas, Guadalupe, Zacatecas), C. P. 98600 y en San Luís Potosí, Carretera Panamericana km 161. Teléfonos 0149241555 y 9246422.

\section{Municipio de Ojocaliente}

Pasando la ciudad de Ojocaliente y viajando hacia Aguascalientes, por toda la orilla de la carretera se observan viñedos. Preguntando a todo tipo de personas acerca de alguna vitivinícola, comentaron que sólo conocían una empresa que procesa la uva y que está a la orilla del camino hacia Aguascalientes. Al llegar a dicha empresa (sin nombre alguno en el exterior y a unos $5 \mathrm{~km}$. de la ciudad) comentaron que no dan informes; un acercamiento a personas en los viñedos a la orilla de la carretera me informaron que ellos son comuneros y cada uno posee una hectárea de viñedos (los viñedos abarcan hasta el horizonte lejano hacia el oriente, norte y sur) en los poblados de Sacramento, Rancho La Providencia, Colonia 20 de Noviembre, Colonia Flores Magón, Ejido La Esperanza y Viñedos Jarillos. Venden su uva a una empresa que se encuentra a la orilla del camino (la misma que no quiso dar da- 
La investigación sobre las necesidades de información en...

tos) pero que se las paga muy barato; ellos mismos venden la uva a la sombra del camino, en camionetas o en locales a la orilla del camino y en el mercado de Ojocaliente.

\section{Municipio de Luis Moya}

También en este municipio hay una gran extensión de viñedos a la orilla del camino, son comuneros propietarios de viñedos en Noria de Molinos, El Coecillo, Julián Adame o Esteban S. Castoreña y venden la uva a empresas que vienen de Fresnillo, como Cantera y Plata, pero de forma principal a Industrias Vinícolas Pedro Domecq, S. A. de C. V. Que se ubica en la carretera Aguascalientes - Zacatecas km. 75, Pueblo Luis Moya, C. P. 98770 y tiene los teléfonos (498) 9870058 / 987.

Información adicional sobre la vitivinicultura en $\mathrm{Za}$ catecas

Cantera y Plata: una vinícola especial

Manuel Ignacio Díaz es el fundador de la empresa Cantera y Plata. En el año de 1990 registró esta marca. Se trata de una empresa que no cuenta con viñedos propios, que compra las variedades de uva que necesita, como la Chenin Blanc, Clarete, Grenznche, Petite Sirah, Ruby Cabernet y con 
ellas produce quince vinos de tipo semi-artesanal: blancos, tintos, rosados, varietales y mezclas, Díaz menciona: "Compramos uva de regiones como Fresnillo, de Ojo caliente, Luis Moya, Villa de Cos -cuando producía- y de Calera. La planta está ubicada en Morelos, Zacatecas, a 15 kilómetros del centro de la ciudad y sólo producimos los fines de semana". ${ }^{2}$

Cuatro marcas de vinos produce la empresa: Cantera y Plata, Igneus, Fray Margil y Vinos Personalizados que se pueden comprar en el Mercado González Ortega, local A-14 (Av. Hidalgo sin número), teléfono (01492) 9221-406 y en Av. Rayón 301, teléfono (01492) 9229-259.

García René menciona a la casa vitivinícola Tavera Díaz. Aclara que aún está en plantación, por lo que podemos suponer que tendrá producción de vinos propios en 3 o 4 años. Se encuentra ubicada esta bodega entre los pueblos de Bermejo y Zoquite, por la carretera federal 175, viniendo de Zacatecas se pasa el poblado de Guadalupe (carretera federal 46) y un poco adelante desviarse hacia la 175.

2 Rocío Fonseca. "Secretos sabor uva (buena mesa)", [entrevista a Manuel Ignacio Díaz]. En: MURAL. México, D. F., 7 de junio 2002. [en línea]

http://vinomex.homestead.com/zacatecas01.html consultado el 30 julio 2008 
La investigación sobre las necesidades de información en...

Actualmente producen artesanalmente de 500 a 800 botellas con uva comprada de las variedades Cabernet Sauvignon, Malbec, Merlot y Ruby Cabernet para elaborar vinos tintos, para vinos blancos dulces de las variedades Beirut Blanca y Moscatel de Alejandría, para vino blanco seco de la Chenin Blanc. Producen las marcas Tavera Díaz y Don Lupe, mismas que distribuyen entre amigos, familiares y venden en Zacatecas, en el Pasaje Lancaster número 121.

Responsable: enóloga Yolanda Adoración Díaz Cervantes. Correo electrónico: sansimon.zac@servicios.itesm.mx. Teléfonos: (492) 922-0852. Sitio web: http://servisitios.com/tavera/glosario.htm (solo incluye diccionario). Informes: Guillermo Tavera. Correo electrónico: taveradiaz@hotmail. com.

Asociaciones y fiestas relacionadas con la Vitis vinifera en Zacatecas

- Viñedos El Alpino Productores de Uva y Hortalizas SPR de RL.

Representante: Francisco Méndez Garcini. Dirección: Plaza Principal no. 5, Ojocaliente, Zacatecas; teléfono 449 94-07929; Correo electrónico: vinedoselalpino@yahoo.com.mx y vinedoselalpino@hotmail.com 
- Pastoría SPR de RL.

Representante: J. Magdaleno Ruiz Pérez.

Dirección: Calle Porvenir no. 3, Pastoría.

Teléfono 01458 944-3092.

Centro de Acopio Regional de Uva. Municipio Villa Hidalgo, Zacatecas. Inaugurado en agosto de 2006, esta a cargo de la Asociación de Productores de Vid de Villa Hidalgo.

- Feria de la Tuna y la Uva. Ojocaliente, Zacatecas. Cada año se lleva a cabo en la primera semana de septiembre.

- Fiesta religiosa en honor del patrono del Municipio de Luis Moya, San Francisco de Asís. Dicha fiesta incluye vendimias y se celebra del 4 al 12 de octubre cada año.

\section{Durango}

Para finalizar el plan de acercamiento a los vitivinicultores de México continué el viaje el 18 de julio por la noche para llegar el 19 por la mañana a la ciudad de Gómez Palacio, Durango y ubicar a la planta vinícola Vergel.

\section{Municipio de Gómez Palacio}

Fue fácil localizarla, pues todo taxista conoce las instalaciones de la Compañía Vinícola el Vergel. Esta empresa fue fundada en el año de 1943 por el Sr. Luis J. Garza y conocida en todo México por su 
La investigación sobre las necesidades de información en...

brandy Viejo Vergel, actualmente ya no existe, veamos el motivo.

La Compañía Vinícola del Vergel, ubicada en las cercanías de Gómez Palacio, Durango, en el kilómetro 11 de la carretera Gómez Palacio Durango-Chihuahua (también conocida como carretera Torreón-Ciudad Juárez), contaba con extensos viñedos en lo que entonces eran las afueras de la ciudad. Produjo vinos jóvenes, de postre y brandys. Entre sus productos estaba el vino tinto Viña Santiago, el vino blanco verdizo y su producto más conocido fue el brandy Viejo Vergel. Tuvo cavas subterráneas de mármol sin pulir.

De acuerdo con la reseña histórica de los municipios elaborada por el gobierno de Durango, tenemos que: "1995. En los primeros meses de este año concluyó sus actividades la Cía. Vinícola 'El Vergel', por más de 40 años representó una importante fuente de trabajo y un centro de procesamiento de la producción vinícola de la Región". ${ }^{3}$

$\mathrm{Su}$ desaparición comenzó a gestarse en el año 1985. Se cuenta con el testimonio de Luis Garza Suárez, director de Casa Arias, distribuidores de

3 Gobierno del Estado. Municipios del Estado de Durango, Gomez Palacio., historia. [en línea] www.durango.gob.mx/plantillas/info_municipios.php?op= tipo\&id $=98$ it $=$ Historia Consultado el 14 de agosto 2008 
bebidas alcohólicas en Gómez Palacio: "Desde que nací me he dedicado a éste negocio. Mi padre era uno de los propietarios de la Vinícola El Vergel. En 1985 se realiza la venta de la compañía a Bacardí”. Sí, se trata de la empresa Grupo Bacardí de México, quien poco a poco trasladó la producción de vinos de Gómez Palacio hacia Baja California, proceso que finalizó en 1995.

Esta es la causa por la que hoy las instalaciones de la Compañía Vinícola el Vergel se encuentran abandonadas y sus puertas de acceso sólo están custodiadas por dos vigilantes, además, la casa donde vivieron los dueños de la compañía (Familia Garza Suárez) actualmente es alquilada (incluyendo cavas subterráneas) para todo tipo de eventos sociales con la razón social "La Casa Grande del Vergel".

Fiestas relacionadas con la Vitis vinífera en Gómez Palacio, Durango.

- 20 de agosto al 5 de septiembre, 2008, Feria del Algodón y la Uva

4 Virginia Hernández. Entrevista/Distribuir vino, un negocio complicado. En: El Siglo de Torreón [Sección] Reportajes, 30 de marzo 2005. [en línea].

http://www.elsiglodetorreon.com.mx/noticia/140947.entrevista-distrubuir-vino-un-negocio-complic.html Consultado el 30 de julio 2008 
La investigación sobre las necesidades de información en...

\section{Referencias bibliográficas}

Aguilar, María Luisa. Radiografía del vino mexicano. En: Día Siete, suplemento de El Despertador y distribuido en El Universal. México, D. F. Año 7, número 419, 2008, pp. 51-57.

Este artículo incluye como zonas vinícolas registradas por la Asociación Nacional de Vitivinicultores los estados y municipios de Durango: Región de La Laguna; Zacatecas: Región de Fresnillo-Calera, Región de Luis Moya y Valle de las Arcinas.

Calderwood, Michael. El vino mexicano, raíz sarmiento y frutos. México: Revimundo, 2003.

Fuentes, Enrique. ¿Copas vacías?: el cambio climático enemigo del vino que nadie vio... En: Día Siete, suplemento de El Despertador y distribuido en El Universal. México, D. F. Año 7, número 420, 2008, pp. 48-55.

García René. Pisando fuerte. En: Día Siete, suplemento de El Despertador y distribuido en El Universal. México, D. F. Año 7, número 420, 2008, pp. 56-63. Incluye información de las vitivinícolas en Aguascalientes Bodega Hacienda de Letras, S. A. de C.V.; La Bordaleza. De Zacatecas incluye a Vinos Cacholá, quién compra la uva para producir sus vinos y a Tavera Díaz, aunque aclara que aún está en plantación, por lo que podemos suponer que tendrá producción de vinos propios en 3 o 4 años. 
Gómez Durán, Thelma. Mapa de aromas y sabores. En: Día Siete, suplemento de El Despertador y distribuido en El Universal. México, D. F. Año 7, número 418, 2008, pp. 37-45.

Guía México desconocido. Rutas turísticas Aguascalientes, cómo y dónde. Edición 129. México, D. F.: México Desconocido : INAH, 2006.

Guía México desconocido. Rutas turísticas Durango, cómo y dónde. Edición 118. México, D. F. : México Desconocido : INAH, 2000.

Guía México desconocido. Rutas turísticas Zacatecas, cómo y dónde. Edición 112. México, D. F. : México Desconocido : INAH, 2000.

Melgar Gil, Luis Tomás. La enciclopedia del vino. Alcobendas, Madrid; Libsa: R. Llaca, 2008, p. 68.73.

Haciendo la aclaración de que la información fue recibida por parte de una Asociación, ésta obra menciona Aguascalientes y los municipios de Calvillo, Paredón. Rincón de Romos y Pabellón de Arteaga con 7 mil hectáreas de uva y a las vinícolas Álamo, Compañía Vinícola de Aguascalientes, L. A. Cetto, Los Romeros, San Marcos y productos de Uva de Aguascalientes. De Durango menciona 5 mil hectáreas cultivadas en los municipios Gómez Palacio, Lerdo y Tlahualillo. Como productor de vinos da el nombre de Vinícola el Vergel. Zacatecas está incluido con los municipios de Ojocaliente y [sic] Valle de la Macarena. Los nombres asociados con la uva son: 
La investigación sobre las necesidades de información en...

Bodegas del Altiplano, Unión Vinícola zacatecana, Bodegas Puerta de Hierro, Bodegas Antonio Fernández, Casa Hermanos Pisón y Cacholá.

Poncelis Brambila, Pedro. Navidad con vinos mexicanos. En: Revista del Consumidor. México: Procuraduría Federal del Consumidor, diciembre 2007, número 370, pp. 52-63. 


\title{
Recursos de información para el uso de los productores de la vid en el estado de Guanajuato
}

\author{
ANA LAURA PEÑa Aguilar \\ Posgrado en Bibliotecología y Estudios de la Información \\ Universidad Nacional Autónoma de México
}

$\mathrm{E}$ sta investigación se propone aportar a la Bibliotecología un estudio sobre el comportamiento informativo de un grupo muy específico de la población, y al mismo tiempo contribuir a que la sociedad conozca cuáles son los obstáculos y necesidades a los que se enfrentan los productores de vid del estado de Guanajuato.

En el caso de estos productores de vid, específicamente en los municipios de Dolores Hidalgo y San Luis de la Paz, se ha detectado que las empresas son familiares y se han transmitido a través de generaciones, esto hace que la producción artesanal de vino sea un elemento importante a considerar en la detección de necesidades específicas de información.

El objetivo general de la presente investigación es detectar las necesidades específicas de información e identificar las fuentes y/o recursos de información que utilizan los productores de vid del estado de Guanajuato para determinar su influencia en las etapas de producción. 
La investigación sobre las necesidades de información en...

El desarrollo del cultivo de la vid en el estado de Guanajuato se inicia desde los albores de la Nueva España, ya que el cuidado de los viñedos comenzó a extenderse a partir del trabajo de los misioneros, quienes requerían de las uvas para elaborar el vino para oficiar las misas; así los viñedos crecieron en torno a los conventos aledaños a la ciudad de México hacia las regiones septentrionales de Querétaro, Guanajuato y San Luis Potosí.

Para el año de 1810 Miguel Hidalgo hizo crecer uvas, y enseñó a algunos indígenas el proceso del vino dentro de la Villa de Dolores. ${ }^{2}$ De hecho fue promotor de la vitivinicultura en la Intendencia de Guanajuato. Durante su gestión como párroco del poblado de Dolores, de 1803 a 1810, fomentó el cultivo de la vid y la consecuente producción de vino.

Por otro lado, hace 15 o 20 años se tenía un inventario registrado de 2500 hectáreas de cultivo de vid, especialmente de las variedades Ugni-Blanc y Carignane $^{3}$ que fue roturada por el fin de su ciclo productivo.

1 Vinomex. http://www.vinomex.homestead.com/historia. html (Consultada 22/02/08).

2 Juan Meneses Quezada. Recopilación documental sobre vitivinicultura. Estado de México, FES Cuautitlán, 2001. p.71.

3 Distrito de Desarrollo Rural en San Luis de la Paz. 


\section{San Luis de la Paz}

\section{Bodega y Cavas San Luis Rey}

Las bodegas y cavas de la Fábrica de Vinos San Luis Rey datan de finales del siglo XIX, fueron fundadas en 1870 por dos italianos, Galbari y Gamba, que llegaron a México y comenzaron a producir vino para las familias francesas, españolas, italianas y alemanas que habitaban en la zona de Guanajuato y que estaban habituadas al consumo regular del vino.

A partir del año de 1916 la fábrica de vino comienza a producir oporto, en el período de mayor producción, durante los años 50 , suministraba vino de consagrar a toda Latinoamérica y su producción variaba entre 35 mil y 40 mil litros al año. Entre sus principales productos vinícolas se encuentra el Angelorum Vinum, vino de consagrar de mayor orgullo para sus productores con el cual se obtuvo la primera certificación en México por parte de la Santa Mitra Católica para su elaboración y distribución en México, además de llegar a ganar reconocimientos internacionales en Roma y Milán entre otros. ${ }^{4}$ Funciona como fábrica de vinos Rafael Gamba e Hijos desde 1907. Actualmente es dirigida por Hugo Gamba y distribuye en mínima escala.

4 Cavas (Vinícola Gamba) En:http://sanluisdelapaz.guanajuato. gob.mx/atractivos.php? id = 5 
La investigación sobre las necesidades de información en...

Las cavas fueron hechas utilizando los subterráneos elaborados por los jesuitas durante la Colonia, ${ }^{5}$ estos túneles se encuentran a 8 metros por debajo del nivel de la calle, actualmente contiene vinos que datan desde 1890 hasta el más "nuevo" elaborado en 1955 y llevado a cava en 1957.

Fabricaba además del de consagrar los vinos tipo Moscatel, Málaga, Vermouth, Jerez, así como aguardiente, vino de mesa, tónico de nogal, quina y vinagre.

Actualmente la fábrica sólo se utiliza como bodega de vinos y como museo del vino en la región; a través de la Secretaría de Turismo del Estado de Guanajuato se organizan visitas guiadas a las instalaciones. En entrevista con el Sr. Hugo Gamba, el propietario de la fábrica manifiesta el interés por retomar la producción de vino, por lo que resalta la identificación de sus necesidades de información lo que le permitiría reactivar la producción de la empresa.

5 Página del Municipio de San Luis de la Paz: http://www.sanluisdelapaz.com/mexico/turismo 


\section{Dolores Hidalgo}

Cavas Manchón S. A. de C. V.

Es una empresa vinícola enfocada a la producción de vinos de mesa y generosos de baja graduación alcohólica, aunadas a producciones mínimas de destilados como el brandy y el aguardiente. Nace como una empresa que transformaba los excesos de la producción de vid de la zona y va creciendo al grado de tener que comprar este producto primario en otros estados.

La empresa comienza a producir vino aproximadamente en 1981, debido a los excesos de producción de uva y previendo que no se desperdiciara. El Sr. Don Juan Manchón llega a Dolores cuando todavía existían viñedos en San José Segundo, El Chaparral, San Andrés, que por su extensión representaban gran parte de la producción nacional de vid.

Debido a lo anterior surge la necesidad de aprovechar la sobreproducción, ya que en Dolores Hidalgo se desperdiciaban todos los excedentes de uva de segunda que no podían ser vendidas. Es por ello que se comienza a producir vino, el que se almacenará en barricas viejas traídas de Europa. Al principio todo el vino se regalaba. Posteriormente cuando la gente de la región adquirió el gusto por el vino de la producción, ésta llegó al grado de no darse abasto y transformarse en un nuevo negocio. 
La investigación sobre las necesidades de información en...

En el año 2000 se empezó a vender el vino a granel, más adelante Don Juan Manchón se registra como productor de vinos y con la autorización comienza a embotellarlo en botellas de plástico. El nombre del vino que producen es Mistela, nombre meramente español pero con la particularidad de que se fabrica con uva de la región de Dolores Hidalgo.

En el 2006 se conforma como sociedad anónima y se empieza a prever la necesidad de expansión de la capacidad productiva y mejora tecnológica de la planta.

La empresa se localiza en el Rancho el Rosillo ubicado en el kilómetro 14.5 de la carretera de San Luis de la Paz a Dolores Hidalgo en el municipio de Dolores Hidalgo, Guanajuato.

Cavas Manchón cuenta con una capacidad productiva de $10000 \mathrm{~L}$ de vino al año, entre los que destaca con una mayor producción el vino generoso. Actualmente se cuenta con 10 hectáreas de uva sembradas en viñedos ubicados en la parte posterior de la empresa, y se tienen listos injertos para 10 hectáreas más.

Actualmente desarrolla un proyecto con los productores de la región para que dediquen de 1 hectárea de sus tierras para la siembra de vid teniendo a las Cavas Manchón como cliente cautivo de su pro- 
ducción para fomentar nuevamente la producción de vid en el Estado de Guanajuato.

A partir de enero de 2008 de Cavas Manchón pretende abarcar no sólo la zona bajío del estado en ventas sino todo el estado, y además estados aledaños como Querétaro, San Luis Potosí, Michoacán, Jalisco, Estado de México, Nuevo León, etcétera.

En sus cavas tienen actualmente 12500 litros de mistela, moscatel y brandy que se están reservando para el festejo del Bicentenario de la Independencia.

En entrevista con Juan José Manchón, gerente de la empresa, se detectaron importantes necesidades de información que deben ser retomadas por el proyecto PAPIIT para buscar su satisfacción y así sea un producto de utilidad para la comunidad de productores de vid del estado de Guanajuato.

\section{Necesidades de información}

Durante un primer contacto con los productores de vid del estado de Guanajuato se detectaron las primeras necesidades de información, durante el desarrollo de la investigación se diseñará un instrumento que permita conocer, de manera más precisa y detallada, las necesidades de información.

Las primeras necesidades de información identificadas fueron:

- Costos de producción en México y otros países.

- Normatividad existente y trámites. 
La investigación sobre las necesidades de información en...

- Información referenciada sobre: clima, temperatura, lluvia y humedad.

- Procedimientos experimentales (por ejemplo criomaceración).

- Procesos de producción.

- Injertos.

- Plagas y enfermedades de la vid. 


\title{
El perfil de información de los vitivinicultores de Vitis vinífera en la región de Coahuila
}

\author{
ENEDINA SALAZAR MÉNDEZ \\ Posgrado en Bibliotecología \\ Universidad Nacional Autónoma de México
}

a maravilla del vino principia con una pequeña
mos que en grano peso aproximado es de 0.78 a 3 graentre suelo, clima y variedad de uva le darán el sabor, aroma y color, pero lo que determinará la nobleza y originalidad de un buen vino es, sin duda, las técnicas y estilos propios por parte de sus creadores, para ello necesariamente se necesitan consultar fuentes y/o recursos de información para la realización de sus actividades.

En la actualidad se cuenta con muchos libros que tratan sobre el cultivo de la uva y el vino en general, desafortunadamente son textos poco orientados a México; ninguno de hecho está dirigido a investigaciones sobre necesidades de información, comportamiento informativo y satisfacción de los requerimientos informativos de los vitivinicultores, lo cual justifica la elaboración de este estudio, con el fin de otorgar un enfoque dirigido al conocimiento y precisión sobre las herramientas de infor- 
La investigación sobre las necesidades de información en...

mación y servicios que puedan apoyar a elevar la calidad de sus productos.

\section{Planteamiento del problema}

- Los vinos de México han comenzado a tener reconocimientos internacionales a través de los concursos en los que participan, por ende la búsqueda hacía el mejoramiento y calidad de aquellos ha sido una constante.

- En este contexto las investigaciones que indiquen y guíen respecto a las necesidades de información, el comportamiento informativo y la satisfacción de sus necesidades resulta interesante para el ambiente bibliotecológico y el vitivinícola.

\section{Objetivos}

- Identificar los requerimientos de información que presentan los vitivinicultores para la producción de sus vinos.

- Conocer las diversas manifestaciones que se presentan en el comportamiento informativo de esta comunidad.

- Delimitar el grado de satisfacción que este gremio obtiene de las fuentes de información y/o de los recursos informativos que consultan. 


\section{Hipótesis}

- La información que necesitan los productores depende de las condiciones geográficas y sociales en las que se encuentren.

- Las variables (clima, suelo, situación geográfica y social) determinan cierto tipo de demandas de información y diversos patrones de conducta informativa.

- La satisfacción de las necesidades de información es determinada por el tipo de fuentes de información y/o recursos informativos que utilizan los vitivinicultores para la producción de vino.

\section{Primer acercamiento}

Para obtener la información teórica que se enlazará a la parte práctica de este estudio se procedió, como primer paso a la identificación, al acopio y análisis de información pertinente al tema; así, con ese conocimiento previo se realizó en el mes de julio la primer visita al estado con el propósito de verificar los datos arrojados de la investigación documental, además para tener un panorama real de cada una de las bodegas y establecer los contactos pertinentes para futuras visitas; cabe mencionar que la trayectoria que se recorre de Torreón a Parras es de 150 kilómetros de desierto, con un calor impresionante, árido y monótono, pero conforme se avanza y, 
La investigación sobre las necesidades de información en...

en forma casi imperceptible, se empiezan a vislumbrar los tonos verdes de los viñedos y nogales y como una gran mancha blanca, emerge la Hacienda y Bodegas de Casa Madero que dan la bienvenida a Parras y desde ese momento hasta el aire se torna fresco, razón por la cual los lugareños consideran a Parras como un oasis dentro del desierto.

Es indispensable comentar que lo expuesto aquí es resultado de lecturas previas, la observación directa y breves conversaciones con los trabajadores y lugareños de la región, ya que, aunque en los documentos revisados indican que la vendimia se realiza en el mes de agosto, ésta se estaba realizando en julio por las fuertes lluvias que se originaban por la tarde y en ocasiones perduraban hasta el anochecer, por lo que no se pudo obtener información con las personas encargadas y en Vinos Vitali no había personal que pudiera informar.

El estado de Coahuila está situado en el extremo norte de la República Mexicana, conformado por 38 municipios de los cuales, después de la investigación documental, se detectaron sólo tres municipios productores de vino:

- Parras (Casa Madero)

- Cuatro Ciénegas (Bodegas Ferriño)

- Ramos Arizpe (Casa Domecq) 
Después de la visita se logró delimitar los lugares en los que existen realmente viñedos, bodegas y producción de vino, reduciéndose únicamente a Parras y Cuatro Ciénegas, ya que "Casa Domecq" se trasladó a Baja California; por otro lado, se localizaron dos productores: "Viñedos Buena Fe" en Parras y "Vinos Vitali" en Cuatro Ciénegas de quienes no se tenían noticias.

\section{Parras}

Se ubica al sur del estado de Coahuila, fue fundada oficialmente como pueblo de indios en 1598 por el capitán Antón Martín de Zapata, acompañado del padre jesuita Juan Agustín de Espinoza a quien se le debe la catequización y ocupación del territorio, sin embargo, ya existían haciendas españolas, la primera de la que se tiene noticia fue establecida por el capitán Francisco de Urdiñola, la que posteriormente pasaría a ser la hacienda del Rosario propiedad del marquesado de San Miguel de Aguayo.

\section{Casa Madero}

Está situada en el Km. 8.5 de la carretera Parras-Paila y aproximadamente a 15 minutos de Parras, Casa Madero es la vinícola más antigua de América, se creó en 1597. Su establecimiento se relaciona con la llegada de sacerdotes y conquistadores procedentes 
La investigación sobre las necesidades de información en...

de Zacatecas en busca de oro que no encontraron, pero se entusiasmaron con los manantiales y la gran cantidad de uvas silvestres que ahí existían por lo que deciden establecerse y fundar la Misión de Santa María de Parras. Sin embargo por los frecuentes enfrentamientos con los naturales de la región resuelven marcharse, menos Don Lorenzo García, quien solicitó a Felipe II, Rey de España una "Merced" (título de propiedad de tierras), la que recibió en 1597 con la condición de plantar viñas a la que puso por nombre "Hacienda San Lorenzo".

Más tarde, dicha hacienda es adquirida por Evaristo Madero Elisondo, por quien se le atribuye el nombre de Casa Madero; pasando de una generación a otra, Casa Madero está hoy en día bajo la dirección del ingeniero José Milmo Garza, biznieto de Don Evaristo Madero, quien se enfocó en mejorar la calidad de sus productos y estar al día en cuanto a tecnología se refiere; plantó diferentes variedades de uvas, para determinar y seleccionar cuáles de ellas se adaptan mejor al suelo y clima que allí impe$\mathrm{ra}$, encontrando que las mejores variedades tintas son las tipo Cabernet Sauvignon, Merlot, Shiraz, Cabernet Franc, Petit Verdot y Tempranillo, dentro de las blancas se inclinan por las tipo Chardonnay, Semillon y Chenin Blanc, aunque las pruebas y experimentos continúan realizándose. 
$\mathrm{Al}$ adentrarse a la hacienda se puede apreciar la plaza central con un kiosco al centro de ésta, una iglesia en donde se oficia la misa de gallo como parte de la tradicional fiesta de la vendimia que se celebra el 9 y 10 de agosto, al anochecer del día 9 bajan de un cerro los danzantes, acompañados de flautas, violines y la tambora e iluminados con antorchas llegan hasta la plaza de la hacienda e inician la Danza de los Matachines, que se alarga durante toda la noche con baile y juegos pirotécnicos, al día siguiente se pisa la uva para reventarla y sacarle el jugo como se realizaba años atrás, se corona a la reina quien desfila en una carreta adornada hasta el centro de Parras, todo termina con una cena de gala en la "Casa Grande". Parte de la "Casa Grande" también se puede rentar para los visitantes.

Dentro de la hacienda también se encuentran las oficinas administrativas, la tienda, el laboratorio, espacio para tratamiento de agua, el área para la molienda y fermentación, el museo (formado con la maquinaria que se ha utilizado a través del tiempo), bodegas y la embotelladora.

\section{Proceso en Casa Madero}

Al momento de la visita se pudo observar parte del proceso de elaboración de vino el que se describe a continuación: 
La investigación sobre las necesidades de información en...

- Vendimia. Se realiza cuando la uva ha alcanzado la concentración de azúcar apropiada, la que se mide en el laboratorio, la recolección de uva se realiza en cajas que son vaciadas en cuatro tolvas de aproximadamente $800 \mathrm{~kg}$., que jaladas por un tractor son transportadas hasta la despalilladora encargada de retirar el racimo, de ahí pasa al estrujado, en donde se presiona la uva pero se tiene gran cuidado de no afectar el mosto. Todo esto se realiza desde la madrugada hasta el mediodía pues más tarde se alcanzan temperaturas altas que pueden provocar daño a la uva.

- Fermentación. Es el proceso por el cual los azúcares que contiene el mosto se transforman en alcohol por la acción de las levaduras, en este momento se debe controlar la temperatura a través de grandes tanques de acero inoxidable.

- Crianza. El vino se lleva a las barricas con la finalidad de mejorar su calidad en cuanto a sabor y aromas hasta lograr su plenitud, Casa Madero ocupa barricas de roble francés y americano y cada año el $25 \%$ son nuevas. Al llegar a su añejamiento adecuado, los vinos son estabilizados en frío, filtrados y embotellados bajo condiciones estériles para después continuar su añejamiento 
en botella al resguardo de la luz y bajo temperatura controlada, hasta llegar a su punto óptimo de consumo, que dependerá de la uva utilizada. ${ }^{1}$

- Embotellado. Se realiza de manera automática en cuatro líneas que incluyen lavado de botellas, llenado, taponadora y etiquetadora, en esta área se cuida mucho la higiene para que no se desarrollen microorganismos, tanto al inicio como al término del trabajo que se realiza, las líneas se esterilizan.

- Comercialización. Se realiza a nivel nacional e internacional, la mayor parte de su producción se exporta a diferentes países y toda proviene de sus propios viñedos, por la gran calidad de sus vinos Casa Madero tiene en su cuenta más de 30 medallas de prestigiados concursos en los que ha participado.

\section{Marcas}

Para vinos blancos Casa Madero cuenta con:

- Monteviña Blanco. Destacan los aromas cítricos como lima.

1 “Casa Madero: cinco siglos de experiencia”. En Guía de viñedos de México. Edición 2007-2008. [2008] p. 65 
La investigación sobre las necesidades de información en...

- San Lorenzo Blanco. De color dorado con matices verdes brillantes, aroma a durazno y miel.

- Casa Madero Chenin Blanc. Dorado intenso y muy brillante, aroma a chabacano.

- Casa Madero Semillón. Dorado pálido, aroma a cera de abeja con toque a toronja.

- Casa Madero Chardonnay. Oro brillante, aroma a durazno, mantequilla y flores.

- Casa Grande Chardonnay. Dorado intenso, aroma madera, vainilla y flores blancas.

Para los vinos tintos Casa Madero cuenta con:

- Monteviña Tinto. Rubí claro, aroma a humedad.

- San Lorenzo Tinto. Claro con aroma a frutos.

- Casa Madero Cabernet Sauvignon. Rojo brillante, aroma frutos rojos con toque herbáceo.

- Casa Madero Merlot. Teja, aroma a frutos rojos, cereza y frambuesa con toque de vainilla.

- Casa Madero Shiraz. Rubí intenso, aroma herbáceo con toque de zarzamoras y eucalipto.

- Casa Grande Cabernet Sauvignon. Granate intenso, aroma moras, tabaco, pimienta verde.

- Casa Grande Shiraz. Morado intenso. Aroma capulín, pino, grafito. 


\section{Cuatro Ciénegas}

El gobernador de Coahuila, Antonio Cordero y Bustamante, en el año de 1800 fue el fundador de esta población, la cual ha sido llamada Nuestra Señora de los Dolores, Cuatro Ciénegas, Villa Venustiano Carranza, en honor a Venustiano Carranza oriundo de ese lugar, y finalmente Cuatro Ciénegas, como se le conoce actualmente. Fue elegida por sus primeros pobladores por los manantiales $y$ grandes extensiones de viñedos que ahí existían por ello es que su escudo hace alusión a las hojas de parra y racimos de uvas.

\section{Bodegas Ferriño}

Al igual que otros viajantes, Don Miguel Ferriño Lander, originario del Sur de Italia, atraído por las parras que había, así como la semejanza con su pueblo natal, decide establecerse y edificar la vinícola La Fronteriza en el año de 1860; se inició con la destilación de aguardiente de uva y brandy. Adquiere poco a poco propiedades; logra ampliar su negocio $\mathrm{y}$ dar un gran giro hacia la elaboración de vinos generosos, destacando la marca Sangre de Cristo, en recuerdo a un vino de su tierra natal llamado Lacrima Cristi. A su muerte, ocurrida en 1921, la empresa cambió de nombre a "Bodegas Ferriño" 
La investigación sobre las necesidades de información en...

A través del tiempo esta vinícola ha tenido varios cambios en su dirección, pero siempre ha contado con viñedos propios, cultivando diferentes variedades, entre las cuales se encuentran: Lenoir, Cabernet, Merlot, Carignane,, Palomino, Riesling y Moscatel y en menor proporción Rosa del Perú, Black Prince, Tokay y Moscatel de Alejandría.

\section{Proceso en Bodegas Ferriño}

Únicamente se pudo observar la parte de embotellado la cual está a cargo de una persona, otra para el etiquetado y dos para empacar siendo totalmente artesanal.

- Crianza: utilizan barricas de roble francés y americano.

- Comercialización: sólo en el país, principalmente en el D.F., Monterrey y Coahuila.

\section{Marcas}

- Moscatel. Dorado intenso. Aroma frutos secos y florales.

- Sangre de Cristo. Rojo liláceo. Aroma uvas y cerezas.

- Vino generoso Ferriño. Rojo rubí intenso. Aroma afrutado a cerezas y caramelo.

- Vino tinto Ferriño. Rojo ocre claro con destellos ladrillo. Aroma destaca el característico a Merlot, ciruela y frutos secos. 


\section{Observaciones}

De acuerdo a las diferencias observadas entre una casa vinícola y otra surgen los siguientes cuestionamientos:

- ¿Cuántas y cuáles son las fuentes y recursos de información que usan cada una de ellas?

- ¿La información interviene directamente en el desarrollo de los procesos?

- ¿De qué manera influye el comportamiento informativo de los productores para ser competitivos?

\section{Obras consultadas}

Bodegas Ferriño. Cuatro Ciénegas, Coah. Bodegas Ferriño, [s.a.] 1 hoja suelta

Bodegas Ferriño [en línea] http//www.vinosferrino.com.mx

Burera, Matías. Meditaciones sobre el gusto : vino, alimentación y cultura. Prólogo de Michel Rolland. Buenos Aires, México: Paidós, 2005

"Casa Madero: cinco siglos de experiencia". En Guía de viñedos de México. 2007-2008. pp. 61-66

Casa Madero [en línea] http//www.madero.com.mx 
La investigación sobre las necesidades de información en...

Corona Páez, Sergio Antonio. La viticultura en el Pueblo de Santa María de las Parras : producción de vinos, vinagres y aguardiente bajo el paradigma andaluz (Siglos XVII-XVIII). Coahuila: Ayuntamiento de Torreón/IMDT, 2004. 357 p.

Cuatro Ciénegas de Carranza. En: Rutas turísticas Coabuila, 2006. pp. 59-63

"Redescubriendo nuestras raíces Parras". En MiVino. 2008. pp. 4-7

"El vino: una generosa tradición". En: Rutas turísticas Coabuila. 2006. pp. 34-37 


\title{
El perfil informativo de los vitivinicultores en el estado de Querétaro: el cultivo de la vid
}

\author{
José MEJÍA RUIZ
}

Posgrado en Bibliotecología y Estudios de la Información Universidad Nacional Autónoma de México

\section{Introducción}

G 1 objetivo de este estudio es identificar las zo- nas vitivinícolas del estado de Querétaro, determinar las necesidades de información de los vitivinicultores del mismo estado en relación al área determinada para el plantío de la vid; especificar las necesidades de información de los vitivinicultores sobre los tipos de uva aptos para su área de plantío y finalmente determinar la información necesaria para los vitivinicultores acerca de la fauna nociva que afectó el cultivo de la vid.

A continuación un esbozo sobre la vitivinicultura y el perfil del vitivinicultor. 
La investigación sobre las necesidades de información en...

\section{Vitivinicultura}

En la vitivinicultura (técnica de cultivar la vid y elaborar el vino) el vitivinicultor es un profesional que demuestra sus cualidades de competencia en lo profesional y en lo general.

La vitivinicultura está formada con profesionales que tienen la responsabilidad de la dirección de un viñedo y de la colaboración con el personal que ahí labora, pero sobre todo de obtener productos de la vid de calidad.

El perfil del vitivinicultor, está determinado por sus cualidades de competencia, tanto en lo general y lo profesional. ${ }^{1}$

En lo general demuestra sus habilidades en lo concerniente a organizar, programar y supervisar la producción en la industria vitivinícola, controlando la producción, las operaciones de elaboración, estabilización y envasado de vinos y derivados, aplicando los planes de calidad, prevención de riesgos laborales y protección ambiental. ${ }^{2}$

En lo profesional se observan sus aptitudes cuando supervisa el aprovechamiento adecuado de

1 “Real Decreto 1688/2007". En: Ministerio de Educación y Ciencia, 16 de enero de 2008 BOE num. 14, p. 3100 Disponible en: http://www.boe.es/g/es/bases_datos/doc.php?coleccion= iberlex\&id =2008/00750 [fecha de consulta 15/04/08]

2 Ibid 
la materia prima; coordina las condiciones de seguridad; utiliza las tecnologías de información requeridas durante los procesos de producción; planifica el suministro, almacenamiento y el envió de las materias primas para la vinificación en la elaboración de diferentes productos. ${ }^{3}$

Continuando con el ámbito profesional, en lo relacionado al equipo el profesional programa y supervisa la operatividad, el mantenimiento y la instalación del mismo, asegurando su funcionamiento en óptimas condiciones.

El vitivinicultor, como todo profesional, necesita información que lo respalde, en la correcta toma de decisiones, esta información consta de los siguientes temas:

Organografía, crecimiento y desarrollo de la vid; factores ambientales; importancia económica del viñedo: material vegetal: variedades y patrones de vid; propagación de la vid; diseño y establecimiento de viñedos; conducción, poda y operaciones en verde; mantenimiento del suelo; fertilización del viñedo; riego del viñedo y protección del viñedo. ${ }^{4}$

\section{Ibid}

4 Infoagro Systems, S.L. "Curso superior de viticultura". Disponible en:

http://www.infoagro.com/formacion/curso_superior_viticultura_avanzada.htm [fecha de consulta 16/04/08] 
La investigación sobre las necesidades de información en...

\section{Necesidad de información}

La necesidad de información se puede definir como el desconocimiento del contenido de un tema dentro de una actividad o como un cuestionamiento de cultura personal.

\section{Justificación}

El ser humano, desde su existencia ha tenido necesidades de información en la búsqueda de su supervivencia y su desarrollo, para lograrlo utilizó la información de su entorno. En su evolución formó sociedades, las que aprendieron a utilizar los elementos de su entorno, como los son el agua, el fuego, el viento, la tierra, y la crianza de animales, generando con esto conocimientos empíricos.

Gradualmente se fueron incrementando las necesidades de información. Así realizarían varias actividades, ya sea en el campo, la industria, en las ciencias, etcétera, de esta forma consiguen satisfacer las necesidades de información. ${ }^{5}$ Una de estas actividades es la elaboración de vinos.

5 Juan José Calva González. Las necesidades de información: su naturaleza, manifestación y detección. Tesis (Maestría en Bibliotecología). México, UNAM. Facultad de Filosofía y Letras, División de Estudios de Posgrado, 1998, pp.47-50 
El desarrollo vitivinícola no fue fácil, debido a que en sus principios sólo contaban con el conocimiento empírico, generando con esto una gran necesidad de información.

Primeramente, observaron las condiciones climatológicas, siguieron con la observación del terreno y del tipo de tierra que lo conformaba, continuando con la selección de las uvas. Si en la región destinada por primera vez al cultivo de la vid, existían ya otros cultivos, se realizaban consultas, apoyándose en su experiencia, para transferir la información a los nuevos vitivinicultores. No obstante, no todas las dudas eran resueltas.

El cultivo de la vid tiene varios procedimientos, como lo serían: el escoger las varas, los injertos y prepararlas, está el riego ya sea por goteo, aspersión o desnivel, la poda, y el cuidado de las plantas de la vid acerca de las plagas y su control como por ejemplo: cochinillas, pulgones, araña roja, trips, o nematodos, entre otros. ${ }^{6}$

Algunos ejemplos de uvas blancas son: Airén, Albariño, Chardonnay; entre las tintas se encuentran: Barbera, Cabernet Franc, Cabernet.

6 Plagas de la vid y parra: Plaga en vides, parras, viñas, viñedos. Infojardin. Disponible en: http://articulos.infojardin.com/Frutales/plagas-vid-parra-plaga-vides-parras.htm [Fecha de consulta: 16-02-08] 
La investigación sobre las necesidades de información en...

Con la madurez de la uva, empieza la vendimia y el transporte a la bodega en donde se realiza la elaboración de los diferentes vinos.

Previamente a la elaboración del vino se habrá realizado una observación sobre las maquinarias apropiadas para el manejo de las uvas.

La vitivinicultura en América, específicamente en México, inicia en el siglo XVII con la llegada de los españoles, utilizando su información y su experiencia en Europa con la introducción de la Vitis vinífera, así esta industria se diseminó por el interior del país en varios estados, como en el estado de Querétaro.

El estado de Querétaro se encuentra ubicado en el centro geográfico de la República Mexicana. Tiene una altitud sobre el nivel del mar de entre los 1800 y 2000 metros. En el estado se encuentra la cuenca del Río San Juan, cuenta con una temperatura promedio anual de $16.7^{\circ} \mathrm{C}$. La precipitación pluvial media anual es de $287.44 \mathrm{~mm}$. Los vientos soplan de Norte a Sur y del Noreste al Este.

Con estas características geoclimáticas, Querétaro cuenta con las condiciones favorables para el desarrollo de la vitivinicultura.

7 Plan de desarrollo integral del municipio de Querétaro, 1998-2001, p. 21 
Después de la Revolución Mexicana, como toda industria, desde sus inicios la vitivinicultura en Querétaro tiene el propósito de ser competitiva y lograr sobresalir dentro del grupo selecto de productores a nivel nacional (1939). Para lograr esto, la industria aprovecha los recursos humanos que la integraban, para recabar la información, como en los primeros días el conocimiento empírico adquirido a través de los años en las prácticas tradicionales, actualmente con las aplicaciones de nuevas tecnologías como la utilización de equipos de cómputo y la Internet que son herramientas que los ayudan a cubrir sus necesidades de información.

Se tiene muy poca información concerniente a la vitivinicultura en el estado de Querétaro en libros y revistas, la mayoría de ésta, contempla aspectos generales y no particulares.

En general, podría considerarse que con la información proveniente de otros países y consecuentemente en otros idiomas, debería ser suficiente para cubrir las necesidades del responsable del cultivo de la vid, pero no es así.

Con la consideración anterior no se tiene la certeza de si los encargados de los plantíos vitivinícolas en el estado de Querétaro se retroalimentan con información que se genera día a día, actualizando y mejorando esta industria y consecuentemente cu- 
La investigación sobre las necesidades de información en...

briendo las nuevas necesidades de información que vayan surgiendo.

La vitivinicultura conlleva varias etapas para poder desarrollarse a plenitud, pero solo si cuenta con la información que cubra todas las necesidades de información de los encargados del cultivo en sus diferentes etapas.

Se desconoce si realmente se aprovecha eficazmente la poca información sobre los recursos y las técnicas en vitivinicultura existentes en el estado de Querétaro.

La vitivinicultura en el estado de Querétaro estuvo en plenitud en la década de 1970, en ese tiempo, se tenían más de 8000 hectáreas sembradas, esto con la ayuda del gobierno federal. Con el paso del tiempo fue en decremento el cultivo de la vid, llegando a menos de 300 hectáreas para 2008, actualmente el estado tiene a tres vitivinicultores que han logrado subsistir y son: Viñedos La Redonda, Freixenet de México y Compañía Vinícola San Patricio productor de Jerez Uva de Oro.

\section{Rancho La Redonda}

En él se estable el viñedo La Redonda en 1972 por Vittorio Giaginto Perencin, con conocimientos de peritaje agrario de la Escuela de Etnología y Viticultura de Conegliano en Italia. Este rancho fue la 
primero en desarrollar variedades viníferas, para la producción de vinos mexicanos.

\section{Finca de Doña Dolores}

Aquí se instaló la Cava Freixenet de México en 1982, originaria de España, y de la cual la cofundadora Doña Dolores Sala Vivé, da comienzo con esta industria.

\section{Compañia Vinícola San Patricio}

Productor de Jerez Uva de Oro, inicia sus operaciones en noviembre de 1999, sus propietarios son de origen mexicano y el encargado es el Ing. Alberto Rodríguez González, el viñedo se localiza en el ejido Santillán entre Tequisquiapan y Ezequiel Montes, esta compañía no cuenta con cava, las oficinas se encuentran en el centro de Ezequiel Montes.

Por lo anterior los cuestionamientos que guiarán esta investigación son los siguientes:

- ¿La información sobre la climatología, cantidad de agua de riego, el viento, la distancia entre cada planta de la vid, el talud y la tecnología para la vendimia en el estado de Querétaro es fundamental para el responsable del cultivo de la vid?

- ¿De acuerdo al tipo de suelo con que se cuenta en el estado de Querétaro, tiene el responsable del cultivo de la vid, la información necesaria para realizar cambios o modificaciones en sus cultivos? 
La investigación sobre las necesidades de información en...

- ¿Cuenta el responsable del cultivo de la vid con información sobre los tipos de uva adecuados para la región vitivinícola del estado de Querétaro?

- ¿Dispone el encargado de los cultivos de la vid con información acerca de los injertos de diferentes tipos de Vitis vinifera para mejorar la calidad de las uvas en los viñedos del estado de Querétaro?

- ¿El responsable del cultivo de la vid tiene información acerca del impacto negativo que provoca la fauna nociva como: cochinillas, pulgones, araña roja, trips, nematodos, o sus enfermedades como: Oidio en la Vid (Uncinula necator), Mildiu de la vid (Plasmo para vitícola), Podredumbre gris de las uvas (Botrytis cinerea), entre otros, en los plantíos de la vid?

Los objetivos que se pretenden lograr con esta investigación son los siguientes:

\section{Objetivo general}

Elaborar el perfil informativo de los vitivinicultores en el estado de Querétaro.

\section{Objetivos específicos}

- Identificar las zonas vitivinícolas del estado de Querétaro. 
- Determinar la necesidad de información de los vitivinicultores en relación a: climatológica, al riego, la plantación de la vid y del tipo de suelo, a la temperatura, las precipitaciones, el sol y el viento en el estado de Querétaro.

- Especificar las necesidades de información de los vitivinicultores, sobre de los tipos de uvas que son aptos para el estado de Querétaro y el tipo de maquinaria adecuada.

- Determinar la información necesaria para los vitivinicultores acerca de la fauna nociva que afecta el cultivo en el estado de Querétaro.

Debido a los escasos datos sobre la vitivinicultura en el estado de Querétaro se presupone que existe la carencia de información para cubrir las necesidades del encargado de los cultivos de la vid en este estado.

La vitivinicultura cuenta con el personal calificado para el desarrollo de las actividades de esta industria, de ahí que la información que pueden necesitar será la relativa al clima, los vientos y sus ráfagas; el tipo de suelo y el talud de los terrenos empleados; además de información sobre las lluvias y la cantidad de agua que absorben los plantíos. La carencia de información acerca del cultivo de la vid, será la merma en la vendimia.

Siguiendo con la actividad del cultivo de la vid, el vitivinicultor debe tener información acerca de las distancias y posiciones de los racimos en los te- 
La investigación sobre las necesidades de información en...

rrenos; así como el control de las enfermedades y de la fauna nociva. El desconocimiento de esta información ocasionará disturbios en la madurez de la uva y pérdidas en la materia prima.

La información acerca de variados tipos de uva en los cultivos y el empleo de maquinaria especializada es apropiada para el cuidado de las uvas, y la producción de diversos tipos de vinos. La carencia de esta información, repercutirá en la sobreproducción de una clase de vino y en pérdidas económicas por la falta de una diversificación en los vinos y equipos.

En la compilación de información para el proyecto se procederá a revisar la literatura pertinente sobre la vitivinicultura en el estado de Querétaro, con el fin de establecer las necesidades de información de los responsables del cultivo de la vid.

Se realizará una investigación de campo para reforzar el marco teórico sobre la temática de las necesidades de información para los responsables del cultivo de la vid en el estado de Querétaro. En la investigación de campo se realizarán preguntas directas a los vitivinicultores en el estado de Querétaro empleando una cédula de entrevista y de esta forma se detectarán sus necesidades de información. 


\section{Bibliografía}

Aguilera Pérez, Benigno. La vitivinicultura en México. México: El autor, 1990. Tesis Licenciatura (Químico Farmacéutico Biólogo) UNAM, Facultad de Química.

Álvarez Aspero, José. La viña, la vid y el vino. México: Trillas, 1991.

Appel, Marco. Invasión vinícola. En: Expansión, 2006, Vol.7, No.948, sep.

Bano, Jose de. La viticultura en los terrenos arenosos de la República Mexicana. México: Secretaría de Fomento, 1913.

Blas Díaz-Jiménez, José Juan de. Los vinos internacionales: origen-elaboración-características. México: Cecsa, 1978.

Calva González, Juan José. Las necesidades de información: su naturaleza, manifestación y detección. México: J. J. Calva González, 1998. Tesis (Maestría en Bibliotecología) UNAM. Facultad de Filosofía y Letras, División de Estudios de Posgrado. 
La investigación sobre las necesidades de información en...

Plan de desarrollo integral del municipio de Querétaro, 1998-2001.

Ministerio de educación y ciencia. Gobierno de España. El perfil del vitivinícola [en línea] Disponible en: http://www.boe.es/g/es/bases_datos/doc.php?coleccion $=$ iberlex\&id $=2008 / 007 \overline{50}$

Infoagro Systems, S.L. "Curso superior de viticultura". Disponible en:

http://www.infoagro.com/formacion/curso_superior_viticultura_avanzada.htm [Fecha de consulta 16 de abril de 2008]

Infojardin. Cádiz (España). Disponible en:

http://www.infojardin.com/ [Fecha de consulta 16 de febrero de 2008] 
Comunidades indígenas 


\section{La satisfacción de las necesidades de información como factor de cambio en la identidad indígena de la comunidad amuzga: reporte de avances}

\section{CÉSAR Augusto RAMÍreZ VELÁZQUEZ}

Centro Universitario de Investigaciones Bibliotecológicas

Universidad Nacional Autónoma de México

\section{Introducción}

a presente investigación tiene como objetivo Ldeterminar si la satisfacción de necesidades informativas de una comunidad indígena es causa y efecto para modificar su identidad.

El trabajo se encuentra dividido en cuatro partes:

- El primer capítulo versa sobre la identidad indígena, las comunidades indígenas y la comunidad a estudiar;

- En el segundo se trata la satisfacción de las necesidades de información, los modelos de satisfacción de necesidades de información y las necesidades de información en grupos indígenas; 
La investigación sobre las necesidades de información en...

- El tercero integra los factores, las causas y consecuencias del mantenimiento de la identidad indígena;

- El cuarto capítulo contendrá la metodología y los resultados de las investigaciones realizadas (En este reporte, se presenta solamente un esbozo de la metodología a utilizar).

\section{Identidad indígena}

La identidad indígena presupone, de acuerdo a Federico González (Persistencia, 1991), que un miembro de una comunidad americana tradicional no se ve a sí mismo como un indio -y ya se sabe que el término "indio" es completamente espurio- sino como el heredero de los dioses, la posibilidad de ser el hombre verdadero, es decir el Hombre Universal, el ser humano como intermediario de la creación.

Las distintas tradiciones indígenas no se identifican entre sí, y tienden a considerar a los integrantes de otras naciones, tribus, o mismos clanes, como extranjeros, cuando no enemigos, dadas las rivalidades y las guerras que han tenido a lo largo del pasado $-\mathrm{y}$ que posibilitaron en gran parte su propia Conquista-, muchas de las cuales se perpetúan en la actualidad, a nivel local y aun familiar, en forma de enconos.

Eso se debe a que cada pueblo se considera el Centro del Mundo y piensa que su cultura y su len- 
gua es la que mantiene viva la posibilidad del Ser, el que se perpetúa gracias a su hacer sagrado (sacrificio) y al conocimiento de los misterios cosmogónicos y metafísicos que les fueron revelados a sus ancestros en el Origen.

La identidad es "un proceso de construcción simbólica de identificación-diferenciación que se realiza sobre un marco de referencia: territorio, clase, etnia, cultura, sexo, edad" (Sociología, 2002, p.5); por lo tanto, se entiende como la forma en la que los individuos tienden a identificarse con otros o en su caso a diferenciarse.

De tal manera que dicha forma se conoce como categorización social, que a su vez, se conforma por la suma de identificaciones sociales que una persona utiliza para definirse a sí misma; es decir se circunscribe a una identidad social.

En este sentido, Tajfel y posteriormente Turner, menciona Aquiles Chihu (Sociología, 2002, p. 5) indican que "un grupo social está constituido por dos o más individuos que comparten una identificación común en la medida en que se perciben a sí mismos como miembros de una misma categoría social"; de tal manera que si observamos el hecho de que los sujetos tienden normalmente a categorizar las cosas y por ende a la gente, con el fin de saber algo acerca de las personas; entonces, se supone que conociendo las categorías, se cono- 
La investigación sobre las necesidades de información en...

ce mejor a los grupos de individuos que los rodean.

La identidad no es sólo circunstancia de lo que piensa uno de sí mismo, sino que también está ligada a la percepción que tienen los demás miembros del grupo y su validación; es decir, es producto de las relaciones sociales, y de éstas a su vez, se genera la identidad de grupo.

La identidad de grupo, da a entender que los individuos que lo conforman se identifican al interior como semejantes y al mismo tiempo comienzan a establecer categorizaciones sociales, al identificar a personas de otros grupos; esto quiere decir, que en términos de identidad, las organizaciones se construyen sobre la base de una distinción entre los miembros y los no miembros.

La identidad en general, por lo tanto, es el valor central en torno al cual cada individuo organiza su relación con el mundo y con los demás sujetos, en este sentido, el "sí mismo" es necesariamente egocéntrico (Sociología, 2002, p.48), de dicha identidad deriva la identidad indígena.

\section{Concepto de identidad indígena}

En este punto, es pertinente mencionar que la literatura y diversos autores que manejan el tema se refieren a la identidad indígena como identidad étnica, misma que como toda identidad, se remite a 
contextos históricos y sociales específicos, variando en cuanto a composición y significado, de acuerdo a los diferentes procesos de etnicidad que le dieron origen.

Por otra parte, Giménez (Sociología, 2002, p. 51), también comenta que la identidad étnica se caracteriza por ser bastante tradicional; es decir, confiere al pasado una autoridad trascendente y tiene la convicción de que sumado a la continuidad es capaz de incorporar incluso las innovaciones y reinterpretaciones que exige el presente.

\section{Factores de la identidad étnica}

Entre otros factores que se deben tomar en cuenta para considerarlos como parte de la identidad étni$\mathrm{ca}$, se tienen los siguientes:

- Territorialidad. El lugar de pertenencia por haber nacido, ser la tierra de los ancestros, herencia común, territorio modelado por muchas generaciones, vínculo material entre las generaciones del pasado y las del presente. También se le considera como el espacio de inscripción de la memoria colectiva, como soporte material de la vida comunitaria y como referente simbólico de la identidad colectiva.

- Lengua Nativa. No sólo como medio de comunicación, sino también como una forma de ver al 
La investigación sobre las necesidades de información en...

mundo desde la perspectiva de la comunidad. Tiene una connotación ancestral que la enlaza con el mito de los orígenes, con la vida y con la muerte; a través de la poesía y del canto, llega a actualizar en forma sensible y emotiva la comunión entre los miembros del grupo. Es considerada herencia de los antepasados y está estrechamente ligada con la tradición.

- Marcas distintivas de la identidad étnica, son el parentesco y la familia, que son signos de pertenencia, misma que se adquiere por nacimiento; es decir, a través de la inserción en una familia y por lo tanto en un sistema de parentesco, en el que la cuna materna como instancia primordial le da al individuo cuerpo, nombre e identidad primaria. En este sentido, Harold Issacs citado por Giménez (2002, p. 54) comenta que "la familia es un grupo básico de identidad en cuyo seno el individuo interioriza una tradición cultural, un lenguaje, una religión y un sistema de valores y estatus".

- La religión sigue siendo un factor primordial de la identidad étnica. Se caracteriza por ser predominantemente ritual, centrada en la figura de los santos patrones y en las celebraciones festivas destinadas a honrarlos. Esencialmente la religión tiene un carácter identificador; es decir, que el santo patrono se constituye como la base de la 
organización social y del consenso simbólico, en cuanto se lo considera no solo como el protector y el abogado local, sino sobre todo como centro de convergencia de todas las relaciones sociales, principio vital de la comunidad y elemento clave de su identidad.

\section{Comunidades indígenas}

Las comunidades indígenas pueden ser consideradas como aquellas que conservan la herencia y el origen de un país y que a la vez son objeto de discriminación, desprecio social, marginación y olvido. Es decir, "el ser indígena es señal de la negación primera” (Jiménez, 2000), y de todos sus derechos humanos y ciudadanos.

Los pueblos indígenas de América no mantienen mucha comunicación entre sí, ni la han mantenido, salvo a través de un sencillo comercio de trueque y las constantes guerras, (que por otro lado forman parte de su concepción dialéctica del cosmos) que han generado y generan siempre interrelaciones y todo tipo de secuelas. Por lo tanto no sienten que pertenecen a un tronco ancestral común, ya que cada pueblo tiene el propio, que enraíza directamente con lo vertical o divino.

Desde hace aproximadamente 20 ó 30 años han comenzado, junto con la irrupción de los medios de comunicación, y la "universalización" del globo 
La investigación sobre las necesidades de información en...

terráqueo, a conocerse entre ellos y a tratar de entablar algún contacto directo, lo que se ha dado tan sólo entre algunos grupos y tomando en común temas no estrictamente ligados con su tradición metafísica y cosmogónica propios de los chamanes y jefes autóctonos, sino secundarios, aunque muy importantes, acerca del trato social, económico y cultural que han padecido y siguen padeciendo de cara a la pretendida civilización del hombre blanco, su crueldad, su deshumanización y su injusticia.

Una comunidad indígena es aquella que concentra un legado cultural, ocupa un lugar en todo país; se identifica del resto de la población porque habla un idioma distinto al nacional; tiene usos y costumbres distintas; su organización política, social, cultural y económica se diferencia de los otros sectores sociales porque se sostiene en sus costumbres.

Las comunidades indígenas se ubican en los países y cuentan con una identidad propia, la cual defienden contra el desarrollo de la nación o país ya que sienten que pierden identidad y su presencia en la sociedad que se desarrolla a partir de ella pero a la vez al margen de la misma.

Pero todo país está compuesto a su vez por dos elementos esenciales que son las personas que los integran y el espacio geográfico en el cual tienen un pertenencia comunal que es la tierra, la cual trabajan para su subsistencia. Asimismo aunados a di- 
chos elementos se tienen que considerar las tradiciones, su historia, su cultura, sus costumbres, sus hábitos de vida, su alimentación y sus expresiones orales y monumentales todo ello dándoles un sentido de identidad.

Por otra parte, las comunidades indígenas actuales son "primitivas", en el sentido que poseen una clara y sencilla sabiduría sin complicaciones, otra mentalidad, o sea que su punto de vista es más sintético que el del hombre actual, su intuición mayor y directa sin necesidad de discursos y su conocimiento de los ciclos y ritmos naturales y cósmicos más profundos, al punto de llevarlos tan encarnados que constituyen casi parte de su ser, lo que paradójicamente dificulta la comunicación con el mundo moderno, al cual, se le suele conocer de manera incompleta.

Con respecto a la identidad indígena, Gonzalo Aguilar indica que "el pueblo indígena reconoce e identifica los miembros de su grupo a través de una serie de patrones transmitidos por medio de la lengua. A su vez, el sentimiento de pertenencia vendrá determinado principalmente por los patrones lingüísticos y todo el acervo cultural que representa hablar un idioma indígena. La lengua indígena y su sistema de conocimiento constituyen una manifestación y, al mismo tiempo, transmiten la diversidad cultural indígena" (Aguilar, 2006, p112). 
La investigación sobre las necesidades de información en...

La identidad cultural indígena se encuentra asimismo vinculada a la tierra, la cual es la base de su supervivencia. La tierra es parte integrante de la cultura indígena, de su visión del mundo, de su cosmogonía. En este sentido, los derechos indígenas a la tierra son también derechos culturales reivindicados por estos pueblos. Los derechos lingüísticos y los derechos a la tierra se unen en una categoría específica de derechos -los derechos colectivos-, que forman parte integrante de la diversidad cultural indígena.

Las comunidades indígenas se manifiestan por ser en el presente parte fundamental de la identidad que le proporciona a un país reconocimiento ante el mundo como región multicultural única y a la vez parecida a la de los demás países latinoamericanos.

\section{La comunidad amuzga}

Los amuzgos habitan en los estados de Oaxaca y Guerrero y se denominan con el mismo nombre de su idioma, el amuzgo. Cada pueblo amuzgo tiene su nombre específico, por ejemplo en San Pedro Amuzgos se autonombran como Tzjon Non que significa "pueblo de hilados, hilo suave o mecha"; en Santa María Ipalapa se autonombran Tzo'tyio que significa "Río Camarón” (Comunidad, 2008). 
Según algunos estudios, los términos amuzgos o amochcos se refieren al "lugar donde hay librerías o bibliotecas”. De acuerdo con Fernández Gatica, amuzgo significa entre cerros, nombre que se asignó a un pueblo y después se generalizó para nombrar a un grupo étnico.

Los mixtecos, vecinos de San Pedro Amuzgos, reconocen a este pueblo como ñun ñama que significa "pueblo de totomoxtle", en náhuatl se conoce como amuchitl que significa "en el estaño o donde hay estaño". Según el almanaque de Oaxaca el nombre correcto es amochco.

El territorio amuzgo se encuentra en los estados de Guerrero y de Oaxaca. En el estado de Guerrero se sitúan en la región sureste en los pueblos de Xochistlahuaca, Tlacoachistlahuaca, Cosuyoapan, Zacoalpa, Chochoapan, Huehuetono, El Pájaro, Las Minas, Cerro Bronco, Guadalupe Victoria, Guajentepec y Pueblo Nuevo. Al oeste de Oaxaca se encuentran en los municipios de San Pedro Amuzgos y Santa María Ipalapa. En todas estas comunidades los amuzgos conviven con mestizos que generalmente son la mayoría de la población.

Los municipios amuzgos están comunicados por carreteras pavimentadas, caminos de terracería y veredas, que se utilizan cuando las carreteras se vuelven intransitables por las lluvias. Esta región es atra- 
La investigación sobre las necesidades de información en...

vesada por la carretera Oaxaca-Pinotepa Nacional y por la de Huajuapan de León-Pinotepa Nacional.

Cuentan con escuelas de educación primaria y primarias bilingües, jardín de niños, centros de educación preescolar indígena, albergues escolares, secundaria federal, telesecundaria, centro de bachillerato incorporado a la Universidad Regional del Sureste (Urse), clínica IMSS-Solidaridad, Casa del Pueblo, mercado de artesanías y tiendas Conasupo.

Se captan las señales de la radiodifusora comercial de Putla de Guerrero, de la de Tlaxiaco que trasmite programas culturales y algunas transmisiones desde la ciudad de Oaxaca.

La lengua amuzga pertenece al grupo otomangue y es de la subfamilia lingǘstica mixtecana a la que pertenecen también el triqui, el cuicateco, el chochopopoloca, el mazateco, el ixcateco y el mixteco.

La base de la organización social radica en la familia nuclear y la familia extensa. En estas comunidades surgen agrupaciones espontáneas de ayuda solidaria o "mano vuelta" entre parientes y amigos para tratar de resolver problemas inmediatos como mayordomías, casamientos, bautizos, cultivos y construcción de sus viviendas.

Los amuzgos aún practican ritos de origen prehispánico, dedicados a la agricultura o a los dueños del monte, barrancas, ríos, arroyos, cuevas, etcétera, para recibir protección y abundantes cose- 
chas de los seres sobrenaturales. Estos ritos y ceremonias son realizados por especialistas que, además de curar, fungen como sacerdotes y magos.

\section{Metodología}

La investigación se realizará en dos vertientes:

- Se considera primero una investigación empírica de campo, cuyas técnicas a utilizar serán la observación y la entrevista para la captación de los datos requeridos, y se elaborará una guía de entrevista estructurada, constituida por preguntas previamente elaboradas, con el fin de tener un contacto más directo con la población estudiada.

- Se procederá a establecer una muestra de la población indígena estudiada, y utilizando la tabla de muestreo de Powell (Basic, 1991, p.75), se determinará el número de habitantes que representen a la población total.

- Para que la muestra refleje con mayor exactitud la información más aproximada a la realidad con relación a los factores informativos de la población, se dividirá la muestra en estratos.

- Los estratos contemplarán a la población escolar con edades entre los seis y dieciocho años y a la población adulta.

- Con esto se pretende obtener el perfil de la comunidad como usuaria de la información, establecer sus necesidades de información, su com- 
La investigación sobre las necesidades de información en...

portamiento y la satisfacción de sus necesidades informativas.

En segundo término:

- Se utilizará el método cuasiexperimental, asignando dos grupos: el de control y el experimental. Se generarán una serie de instrumentos para medir y/o evaluar la incidencia de la satisfacción en el cambio de la identidad en los dos grupos.

- Se aplicarán al grupo experimental algunas variables y los resultados se contrastarán con los del grupo de control.

- El análisis de los resultados nos indicará si los supuestos planteados a lo largo de la investigación carecen de fundamento o son verdaderos y deban ser considerados en otras investigaciones subsecuentes.

\section{Conclusión}

Este tipo de investigaciones y sus instrumentos auxiliarán a establecer perfiles de usuarios, necesidades de información, comportamientos informativos, evaluación de satisfacción de necesidades y con ello, desarrollar unidades y servicios de información de acuerdo a sus intereses muy particulares, entre otros productos relativos a la ciencia bibliotecológica. 
Comunidades indígenas

\section{Bibliografía}

Aguilar Cavallo, G. (2006). La aspiración indígena a la propia identidad. En: Revista Universum, 1, (21), p. 112.

Comunidad amuzgos. Gobierno del estado de Oaxaca. Disponible en: http://www.oaxaca.gob.mx/?P = Comunidad\&b= Amuzgos. (Consultada el 15 de enero de 2008).

Giménez Montiel, G. Paradigmas de identidad. En: Sociología de la identidad. (2002). Coord. Aquiles Chihu Amparán. México: Miguel Ángel Porrúa; UAM, Iztapalapa. pp. 35-62.

González, F. Persistencia de la identidad indígena. Conferencia pronunciada en el Centro de Estudios de Simbología de Barcelona, noviembre 1991. Disponible En: http://www.geocities.com/Athens/Atrium/9449/ s3fgon2.htm (Consultada el 18 de octubre de 2007).

Jiménez, A., Los términos indio e indígena oculta a los pueblos reales: Montemayor. En: La Jornada de en medio, 3 agosto 2000.

Powell, R. R. Basic research methods for librarians. New Jersey; Ablex, 1991. 188 p.

Sociología de la identidad. (2002). Coord. Aquiles Chihu Amparán. México: Miguel Angel Porrúa; UAM, Iztapalapa. $253 \mathrm{p}$. 


\section{Conclusiones}

as comunidades científicas tienen perfiles diferentes con alguna afinidad, en general se pue-
den definir particularidades. Los matemáticos tienen publicaciones ya establecidas, los geógrafos otras y así cada perfil se diseña para su comunidad. En el ámbito universitario se realizan encuestas para conocer y evaluar los recursos electrónicos como páginas Web, y así saber cuál es su uso y cuál la satisfacción de los usuarios al utilizar y recuperar información de estos servicios. En mi caso me di cuenta de las necesidades específicas como por ejemplo: las revistas que satisfacen sus necesidades de información pero que también quieren información retrospectiva.

En el ámbito docente se realizan estudios de usuarios potenciales para saber si se utilizan los servicios de la biblioteca y cuál es el grado de satisfacción del usuario. En el ámbito hospitalario se han llevado a cabo investigaciones sobre la satisfacción en el uso de las bibliotecas hospitalarias. Otros estudios son para que los doctores digan si utilizan los sistemas 
La investigación sobre las necesidades de información en...

electrónicos de las bibliotecas o qué recursos utilizan cuando buscan información.

Los estudios de usuarios aun es un área casi virgen, en España por ejemplo, aun se llevan acabo pocas investigaciones y las que se realizan utilizan distintas metodologías, materiales y técnicas.

Presentar resultados o avances de las investigaciones motivan el interés para que otras personas realicen investigaciones, por ello es importante que surjan inquietudes y se realicen más investigaciones y seminarios como éste donde se pueden mostrar resultados.

La comunidad de una biblioteca no solo la forman los investigadores sino que se compone de estudiantes, pasantes que buscan información especializada para sus tesis y profesores que buscan libros para los contenidos de sus materias, los investigadores de los institutos que dependen de sus habilidades para recuperar información, todos ellos buscan cosas específicas. La variable de lugar geográfico se debe a la percepción que se tiene de que los alumnos que ingresan a diferentes lugares como por ejemplo el TEC de Monterrey, viendo esta situación la comunidad tiene necesidades de acuerdo a su lugar de origen, eso determina la variable.

La tendencia del estudio es proponer nuevos servicios, a partir de éste buscar alternativas de nuevos servicios ya que hace falta vinculación de la biblio- 
teca hacia los intereses del usuario. La temática de interés de los alumnos de bibliotecología ha cambiado de acuerdo a la época en que se presenta, en el año 2000 los temas eran tradicionales: catalogación, clasificación, catálogos; 4 años después los temas son diferentes: portales, bibliotecas virtuales, bibliotecas digitales, con fuentes muy diferentes es un punto muy importante porque la temática repercute en las fuentes que se consultan. Antes eran materiales básicos, ahora con el cambio en el plan de estudios hay cosas que ya han pasado y nuevos materiales.

Hay pocos estudios del tema, se pierde toda la inversión en colecciones de las bibliotecas, los usuarios se van con la Internet y no aprovechan los recursos disponibles en la biblioteca. La investigación que hace el ponente debería incluir la forma de aprovechar los buscadores y optimizar las búsquedas para obtener información de mayor calidad, los usuarios están acostumbrados a copiar y pegar y en minutos terminar un trabajo, por eso los bibliotecarios debemos enseñar a los usuarios estrategias de búsqueda que pueden ayudarles en sus trabajos para que puedan utilizar la Internet de una forma óptima ya que no es un enemigo sino puede ser un apoyo para el trabajo que realiza la biblioteca. 
La investigación sobre las necesidades de información en...

Es importante identificar las necesidades de información para posteriormente ayudar a desarrollar habilidades de búsqueda. Los productores de Vitis viniiffera no utilizan fuentes de información impresas con frecuencia, se basan en la experiencia y en el trabajo del día a día. Es importante que se realicen estudios de libros, patentes, revistas y otras fuentes de información pero que sean financiados por las mismas empresas vitivinícolas. Sería interesante conocer si los productores están dispuestos a publicar alguna investigación. 
La investigación sobre las necesidades de información en diferentes comunidades. La edición consta de 150 ejemplares. Coordinación editorial, Zindy E. Rodríguez Tamayo. Formación editorial, Carlos Ceballos Sosa. Centro Universitario de Investigaciones Bibliotecológicas/ UNAM. Fue impreso en papel cultural ahuesado de 90 gr. en Producciones Editoriales Nueva Visión, ubicados en Juan A. Mateos número 20, Col. Obrera, México D. F. Se terminó de imprimir en el mes de septiembre de 2009. 